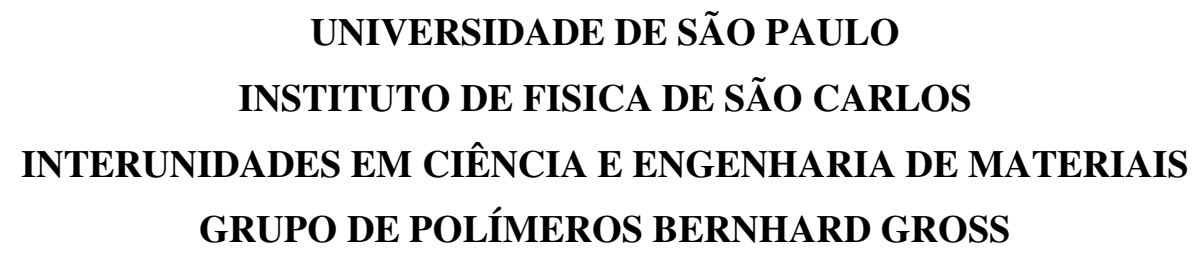

\title{
EFEITO DA FOTOCONDUÇÃO EM DIODOS COM CAMADA ATIVA DE DERIVADOS DE POLI( $p$-FENILENO VINILENO) (PPV)
}

SÃO CARLOS-SP 
Tese apresentada ao Programa de PósGraduação Interunidades em Ciência e Engenharia de Materiais da Universidade de São Paulo para obtenção do título de Doutor em Ciência e Engenharia dos Materiais.

Área de Concentração: Desenvolvimento, Caracterização e Aplicação de Materiais.

Orientador: Prof. Dr. Roberto Mendonça Faria

\section{SÃO CARLOS-SP}




\begin{abstract}
AUTORIZO A REPRODUÇÃO E DIVULGAÇÃO TOTAL OU PARCIAL DESTE TRABALHO, POR QUALQUER MEIO CONVENCIONAL OU ELETRÕNICO, PARA FINS DE ESTUDO E PESQUISA, DESDE QUE CITADA A FONTE.
\end{abstract}

Ficha catalográfica elaborada pelo Serviço de Biblioteca e Informação IFSC/USP

Cazati, Thiago

Efeito da fotocondução em diodos com camada ativa de derivados de Poli(p-fenileno vinileno) (PPV)/Thiago Cazati; orientador Prof. Dr. Roberto Mendonça Faria. São Carlos, 2007.

$133 p$.

Tese (Doutorado - Programa de Pós-Graduação em Interunidades Ciência e Engenharia de Materiais. Área de concentração: Desenvolvimento, Caracterização e Aplicação de Materiais) - Escola de Engenharia de São Carlos, Instituto de Física de São Carlos, Instituto de Química de São Carlos da Universidade de São Paulo.

1.Diodos orgânicos. 2.Polímeros conjugados. 3..Fotocondutividade. 4.Espectro de fotocorrente. I. Título. 


\section{DEDICATÓRIA}

Esta tese é dedicada à minha esposa Bruna, à minha filha Clara e aos meus pais. 


\section{AGRADECIMENTOS}

- Ao Prof. Dr. Roberto Mendonça Faria, que vem acompanhando e participando da minha formação acadêmica desde a iniciação científica, pela paciência, orientação e confiança e dedicação na conclusão desse trabalho.

- Ao Prof. Dr. Lucas Fugikawa Santos, pelas valiosas discussões científicas e por me ajudar nos momentos mais difíceis deste trabalho e, sobretudo pela amizade.

- Ao Prof. Dr. Rodrigo Fernando Bianchi, que sempre me auxiliou no trabalho, nas decisões. Agradeço pelo companheirismo e pela experiência a mim transmitida.

- Ao prof. Dr. Francisco G. Guimarães que esteve sempre presente na minha formação, desde o curso de Física I até o final do meu doutorado. Agradeço pela amizade e pela preciosa ajuda nos momentos mais difíceis da minha vida acadêmica.

- Aos Professores do Grupo: Prof. Dr. Paulo B. Miranda, Prof. Dr. Valtencir Zucolltto, Prof. Dr. Osvaldo Novaes de Oliveira Jr. (Chu), Prof(a). Dr(a). Débora Gonçalves e Mariângela T. Figueiredo, Prof. Dr. Guilherme F. Leal Ferreira, pelos quais tenho profundo respeito e admiração.

- Ao os meus amigos do Grupo de Polímeros: Luciano, Néia, Thais, Tony, Frank, Vanessa, Junior, Thiers, Marli, Ângelo, Chicão, Lílian, Luana, Miguelito, Kleber, Heurison, Maurício, David pelo convívio e pela amizade. Especial agradecimento aos amigos: Edivaldo, Rafael, Carlos, Felipe Penha, Adriana, Giovanni, Washington, Alexandre, Rogério Valaski pela cumplicidade, pelas discussões científicas e pela participação direta e indiretamente neste trabalho.

- Ao Pessoal Técnico: Ademir, Níbio, Bertho, Débora Balogh, a secretária Rosângela, pelo imprescindível apoio e amizade ao longo desses anos. Em especial agradeço ao Ronny Ribeiro pela preciosa ajuda nas simulações e na confecção dos dispositivos, ao Felippe Pavinatto pelo apoio e amizade. A todos da biblioteca do IFSC e CPG.

- Finalmente e mais importante, eu agradeço aos meus pais, Adalberto e Marli, pela indescritível apoio, amor e pela confiança que eles têm por mim. A minha esposa Bruna, que me auxiliou enormemente na concretização deste trabalho, pelo incentivo, amor e companheirismo. A minha filha Clara pela inspiração, pelo carinho e compreensão nos momentos em que me ausentei. 
"Há quem diga que a ciência acabou, que a história acabou. Isso é uma besteira; como se fôssemos Deus e conhecêssemos a estrutura de todo o

Universo. (...) Há sempre coisas novas, há sempre perguntas a fazer" JOSÉ LEITE LOPES

Físico Brasileiro 


\section{RESUMO}

O trabalho desenvolvido ao longo dessa tese visou esclarecer alguns pontos essenciais sobre o espectro de fotocondução de estruturas de diodo tipo ITO/Polímero/Metal, tendo como polímero ativo, derivados de poli(p-fenileno vinileno): o MEH-PPV, o OC10-PPV e o copolímero denominado de Super-Yellow (SY). Como eletrodos metálicos foram usados o alumínio (Al), o magnésio $(\mathrm{Mg})$ e o cobre $(\mathrm{Cu})$. Esses três metais foram escolhidos pelas suas funções trabalho, sendo a do $\mathrm{Cu}$ bem próxima à do ITO, a do $\mathrm{Mg}$ bem menor, e a do $\mathrm{Al}$ intermediária aos outros dois. As propriedades ópticas dos filmes poliméricos, importantes para o estudo de fotocondução, foram analisadas através dos espetros de absorção e de fluorescência estacionária na região do visível. O comportamento fotocondutivo dos dispositivos foi realizado através de medidas de corrente-tensão (I-V) e da espectroscopia de fotocorrente no estado estacionário em regime dc sob incidência de luz com diferentes comprimentos de onda, ora através do ITO, ora através dos eletrodos metálicos semitransparentes, tendo como parâmetro experimental importante a tensão elétrica aplicada ao dispositivo. De nossos estudos, foi possível obter importantes informações quantitativas sobre as componentes intrínseca e extrínseca da fotocondutividade, e extrair parâmetros de relevância dos polímeros estudos, sobretudo da eficiência de fotogeração e da relação funcional da fotocorrente com o comprimento de onda da luz incidente. Foi também desenvolvido um modelo teórico que explicou com razoável precisão quantitativa as curvas de fotocondução intrínseca e extrínseca.

Palavras-chave - Diodos Orgânicos, Polímeros Conjugados, Fotocondutividade, Espectro de Fotocorrente. 


\begin{abstract}
In this thesis we present a detailed study of spectral response photoconductivity in ITO/Polymer/Metal structures, having as active polymer poly(p-phenylene vinylene) derivatives: MEH-PPV, OC10-PPV and the copolymer called by Super-Yellow (SY). As electrodes we used aluminum $(\mathrm{Al})$, magnesium $(\mathrm{Mg})$ and cupper $(\mathrm{Cu})$. While $\mathrm{Cu}$ has a workpotential close to that of ITO, the work-potential of $\mathrm{Mg}$ is smaller, being that of $\mathrm{Al}$ an intermediate value. The optical properties of the polymeric films, which are of fundamental importance for this work, were analyzed by the absorption and the stationary fluorescence spectra in the visible region. On the other hand, the photoconductive behavior of the devices was investigated using the current-voltage curves $(I-V)$ and the photocurrent spectroscopy at steady state, in dc regime, measured under the incident light of different wavelengths. As experimental parameters we varied the incident side of the device (trough ITO or metal), and the voltage-intensity and the polarity of the bias. From our study it was possible to obtain important quantitative information about both components of the photoconduction: the intrinsic and the extrinsic components. By a model developed for the photoconduction dynamic we got relevant parameters of the active polymeric layers as the efficiency of carrierphotogeneration and the functional relation between the photocurrent and the intensity of the incident light.
\end{abstract}

Keywords - Organic diodes, Conjugated polymers, Photoconductivity, Photocurrent action spectra. 


\section{LISTA DE FIGURAS}

Figura 1.1: Estrutura química de alguns exemplos de polímeros conjugados.

Figura 1.2: (a) Ilustração esquemática do diagrama de energia na representação de coordenadas. (b) Estrutura eletrônica do PPV, as letras $d$ e $d^{*}$ indicam estados localizados e não localizados, respectivamente.

Figura 1.3: Desenho esquemático de um pólaron negativo em um polímero com o estado fundamental não-degenerado: a) PPV; b) PPP. Diagramas de bandas representando os níveis eletrônicos intermediários no gap criado pelos defeitos: c) pólaron negativo; d) bipólaron negativo; e) pólaron positivo; f) bipólaron positivo; g) éxciton-pólaron singleto.

Figura 1.4: Esquema das transições eletrônicas radiativas e não-radiativas entre os estados excitados em uma molécula conjugada (diagrama de Jablonski). As setas retas verticais representam as transições ópticas e as setas sinuosas representam decaimentos não-radiativos.

Figura 1.5: llustração dos processos de absorção e emissão de luz em polímeros conjugados provenientes das transições entre os níveis vibracionais do estado eletrônico fundamental e do primeiro estado excitado de uma molécula (Franck-Condon).

Figura 1.6: Ilustração da estrutura típica sanduíche de camada única dos dispositivos

PLEDs e OPVs.

Figura 1.7: Representação esquemática das bandas de energia de um polímero conjugado, neste exemplo o MEH-PPV. a) Fora do equilíbrio, antes do estabelecimento dos contatos. b) No modo reverso e c) no modo direto, no caso específico de uma estrutura ITO/polímero/Ca. Ilustração é adaptação da ref..

Figura 1.8: Curva característica $I-V$ para um dispositivo fotovoltaico sob iluminação para diferentes tensões aplicada, onde é possível determinar a corrente de curtocircuito $\left(I_{S C}\right)$ e a tensão de circuito aberto $\left(V_{O C}\right)$. Ilustração foi adaptada da ref

Figura 1.9: Ilustração de feixe de luz de intensidade $I_{0}$ incidente através de um dos eletrodos metálicos semitransparentes com refletividade $R$ de um dispositivo tipo sanduíche de espessura $I$, e o perfil da intensidade $I(x)$ ao longo do eixo $x$.

Figura 1.10: Esquema do diagrama de energia em um sólido desordenado ilustrando transporte dos buracos (HOMO) e dos elétrons (LUMO) em material desordenado pelo mecanismo "hopping".

Figura 3.1: Ilustração do dispositivo com estrutura tipo "sanduíche" com camada única de polímero e os respectivos eletrodos metálicos.

Figura 3.2: Gráfico da transmissão do eletrodo de ITO e do vidro/ITO na região do espectro visível. 
Figura 3.3: Etapas do procedimento adotado para a remoção da camada de ITO da superfície do substrato (Decapagem).

Figura 3.4: Estrutura química dos polímeros utilizados neste trabalho. a) MEH-PPV, b) OC10-PPV e c) SY $(x=0,42, y=0,58)$.

Figura 3.5: Espectro de Absorção dos filmes poliméricos de OC10-PPV, MEH-PPV e SY a $300 \mathrm{~K}$.

Figura 3.6: a) Representação esquemática da vista lateral do dispositivo polimérico fabricado para este trabalho; b) Vista superior dos eletrodos de $\mathrm{Al}, \mathrm{Mg}$ e $\mathrm{Cu}$ metalizados sobre o polímero

Figura 3.7: Gráfico da transmitância dos eletrodos de $\mathrm{Al}, \mathrm{Cu}$ e $\mathrm{Mg} / \mathrm{Al}$ na região do visível.

Figura 3.8: a) Esquema da montagem experimental utilizada nos experimentos de fotocorrente. b) Representação de um dispositivo polimérico durante 0 experimento, com incidência de luz através de um dos eletrodos.

Figura 3.9: a) Corrente do fotodiodo e a intensidade da lâmpada em função do comprimento de onda selecionado pelo monocromador, curva de resposta do fotodiodo. b) Radiância espectral e o fluxo radiante das componentes espectrais da lâmpada selecionadas pelo monocromador.

Figura 4.1: Curvas experimentais de corrente vs tensão aplicada (I-V) do dispositivo ITO/polímeros/eletrodos à 295K. Os gráficos superiores são as curvas para o dispositivo com MEH-PPV: a) no escuro e b) sob iluminação (500 nm) e os gráficos inferiores são curvas do dispositivo com OC10-PPV, c) no escuro e d) sob iluminação $(500 \mathrm{~nm})$.

Figura 4.2: Dependência das curvas I-V dos dispositivos de ITO/MEH-PPV/eletrodos com diferentes comprimentos de onda de luz incidente através do ITO para:

a) eletrodo de $\mathrm{Al}$; b) eletrodo de $\mathrm{Mg} \mathrm{e} \mathrm{c)} \mathrm{eletrodo} \mathrm{de} \mathrm{Cu}$

Figura 4.3: llustração do dispositivo sob incidência de luz através do ITO: a) em comprimentos de onda bem absorvidos pelo polímero (espessura $\mathrm{x}=1$ ), e b) menos absorvidos e mais energéticos. Em detalhes são mostrados os sentidos do campo elétrico resultante $\left(E_{R}\right)$ no modo direto e reverso, e o perfil de absorção da luz e da foto-geração de portadores (buracos $\odot$ e elétrons $\Theta$ ) na região iluminada.

Figura 4.4: Dependência das curvas I-V dos dispositivos de ITO/MEH-PPV/eletrodos com os diferentes comprimentos de onda da luz incidente através: a) do eletrodo de $\mathrm{Al}$; b) eletrodo de $\mathrm{Mg}$ e do c) eletrodo de Cu.

Figura 4.5: Ilustração do dispositivo sob incidência de luz através dos cátodos: a) em comprimento de onda bem absorvido pelo polímero (espessura $\mathrm{x}=1$ ), e b) menos absorvido e mais energético. Em detalhes são mostrados os sentidos do campo elétrico resultante $\left(E_{R}\right)$ no modo direto e reverso, e o perfil de absorção da luz e da foto-geração de portadores (buracos $\odot$ e elétrons $\Theta$ ) na região iluminada.

Figura 4.6: Espectro de fotocorrente normalizado no estado estacionário do dispositivo ITO/MEH-PPV/AI sob incidência no eletrodo ITO com diferentes tensões (a) 
positivas e (b) negativas aplicadas. Para comparação, o espectro de absorção normalizado do MEH-PPV é mostrado.

Figura 4.7: Comparação entre os espectros de fotocorrente normalizados para luz incidente no ITO, para tensões aplicadas positiva e negativamente no dispositivo ITO/MEH-PPV/Al, e o espectro de absorção do polímero.

Figura 4.8: Espectros de fotocorrente do dispositivo ITO/MEH-PPV/eletrodo a) de Cu e b) de Mg sob incidência de luz através do ITO e o espectro de absorção normalizado do MEH-PPV para análise comparativa.

Figura 4.9: Espectros de fotocorrente em estado estacionário do dispositivo ITO/MEHPPV/AI com incidência no eletrodo Al para diferentes valores de tensões aplicadas.

Figura 4.10: Comparação entre os espectros de fotocorrente normalizados para luz incidente através do Al semitransparente, para tensões aplicadas positiva e negativamente no dispositivo ITO/MEH-PPV/Al e o espectro de absorção do polímero.

Figura 4.11: Espectros de fotocorrente do dispositivo ITO/MEH-PPV/eletrodo sob diferentes tensões aplicadas e com incidência de luz através do eletrodo a) de $\mathrm{Cu}$ e b) de Mg e o espectro de absorção normalizado do MEH-PPV.

Figura 4.12: Espectro de fotocorrente normalizado no estado estacionário do dispositivo ITO/OC10-PPV/AI sob incidência no eletrodo ITO com diferentes tensões (a) positivas e (b) negativas aplicadas. O espectro de absorção normalizado do OC10-PPV é mostrado para comparação.

Figura 4.13: Espectros de fotocorrente do dispositivo ITO/OC10-PPV/eletrodo a) de Cu e b) de Mg sob incidência de luz através do ITO e o espectro de absorção normalizado do OC10-PPV para análise comparativa.

Figura 4.14: Espectros de fotocorrente normalizados do dispositivo ITO/OC10-PPV/AI com incidência através do eletrodo semitransparente de Al para diferentes valores de tensões aplicadas.

Figura 4.15: Espectros de fotocorrente do dispositivo ITO/OC10-PPV/eletrodo sob diferentes tensões aplicadas e com incidência de luz através do eletrodo a) de $\mathrm{Cu}$ e b) de $\mathrm{Mg}$ e o espectro de absorção normalizado do OC10-PPV.....

Figura 4.16: Espectro de fotocorrente do dispositivo ITO/SY/AI sob diferentes valores de tensões aplicadas com incidência de luz através: a) do eletrodo ITO e b) através do eletrodo Al.

Figura 4.17: Espectro de absorção do SY normalizado em relação aos espectros de fotocorrente para duas polaridades de tensão aplicada (+3 V e $-3 \mathrm{~V}) \mathrm{com}$ iluminação através a) do ITO e através do b) eletrodo de Al......

Figura 4.18: Ilustração do diagrama de bandas do dispositivo ITO/polímero/AI, para cada região do dispositivo utilizado para explicar qualitativamente 0 comportamento da fotocorrente com a tensão aplicada. Nesta figura, as regiões I e III estão exageradamente aumentadas por se tratar de uma ilustração. A polaridade das tensões aplicadas é relativa ao eletrodo de ITO......96 
Figura 4.19: Espectros de fotocorrente em função da tensão aplicada no dispositivo de ITO/OC10-PPV/Mg, com incidência de luz através do ITO, quando fresca e após o período de 7 dias de exposição à luz.

Figura 5.1: Fluxo de fótons absorvidos (linha continua) e as eficiências internas para o espectro da luz incidente no dispositivo ITO/SY/AI, a) através do ITO e b) através do eletrodo semitransparente de $\mathrm{Al}$, sob diferentes tensões aplicadas.

Figura 5.2: Fluxo de Fótons absorvidos (linha continua) e a eficiência interna para todo o espectro da luz incidente no dispositivo ITO/MEH-PPV/AI, a) através do ITO e b) através do eletrodo semitransparente de $\mathrm{Al}$, em curto circuito $(\mathrm{V}=0 \mathrm{~V}) \mathrm{e}$ sob tensões plicadas de $-3 \mathrm{~V}$ e $+3 \mathrm{~V}$.

Figura 5.3: Fluxo de Fótons absorvidos (linha continua) e a eficiência interna para todo o espectro da luz incidente no dispositivo ITO/OC10-PPV/AI, a) através do ITO e b) através do eletrodo semitransparente de $\mathrm{Al}$, em curto circuito $(\mathrm{V}=0 \mathrm{~V})$ e sob tensões plicadas de $-3 \mathrm{~V}$ e $+3 \mathrm{~V}$.

Figura 5.4: Dependência fotocorrente do dispositivo ITO/SY/AI em função das intensidades da luz monocromática de $470 \mathrm{~nm}$.

Figura 5.5: Dependência fotocorrente do dispositivo ITO/MEH-PPV/AI em função das intensidades da luz monocromática de $550 \mathrm{~nm}$.

Figura 5.6: Dependência fotocorrente do dispositivo ITO/OC10-PPV/AI em função das intensidades da luz monocromática de $550 \mathrm{~nm}$.

Figura 5.7: Espectros de absorção dos filmes a) SY, b) MEH-PPV e c) OC10-PPV em comparação com as curvas geradas pelas funções teóricas (linha continua) do espectro de absorção utilizados posteriormente no ajustes teóricos dos espectros de fotocorrente.

Figura 5.8: Ajustes das curvas deconvoluídas do espectro de fotocorrente com diferentes tensões aplicadas positivas no dispositivo ITO/SY/AI iluminado pelo ITO.

Figura 5.9: Ajustes das curvas deconvoluídas do espectro de fotocorrente com diferentes tensões aplicadas negativas no dispositivo ITO/SY/AI iluminado pelo Al.

Figura 5.10: Ajustes das curvas deconvoluídas do espectro de fotocorrente com diferentes tensões aplicadas positivas no dispositivo ITO/MEH-PPV/AI iluminado pelo ITO.

Figura 6.1: Componente real da condutividade complexa do dispositivo ITO/OC10PPV/Al em curto-circuito $\left(V_{d c}=0 \mathrm{~V}\right)$, no escuro e sob iluminação em diferentes comprimentos de onda. 


\section{LISTA DE TABELAS}

Tabela 3.1: Absorção Óptica (Abs), Luminescência (PL) e eletroluminescência (El) dados em comprimento de onda no máximo da banda e Peso molecular, para os polímeros conjugados MEH-PPV, OC10-PPV e SY a T $=300 \mathrm{~K}$

Tabela 5.1: Eficiência interna para dispositivos de MEH-PPV com diferentes eletrodos metálicos, sob diferentes tensões e comprimentos de onda incidentes no ITO.

Tabela 5.2: Eficiência interna para dispositivos de MEH-PPV com diferentes eletrodos metálicos, sob diferentes tensões e comprimentos de onda incidentes nos eletrodos metálicos.

Tabela 5.3: Eficiência interna para dispositivos de OC10-PPV com diferentes eletrodos metálicos, sob diferentes tensões e comprimentos de onda incidentes no ITO.

Tabela 5.4: Eficiência interna para dispositivos de OC10-PPV com diferentes eletrodos metálicos, sob diferentes tensões e comprimentos de onda incidentes nos eletrodos metálicos.

Tabela 5.5: Valores do rendimento quântico obtidos dos ajustes das curvas A e B deconvoluídas do espectro de fotocorrente do dispositivo ITO/SY/Metal iluminado ora pelo ora pelos eletrodos metálicos (Al,Cu e Mg), sob diferentes tensões aplicadas.

Tabela 5.6: Valores do rendimento quântico obtidos dos ajustes das curvas $A$ e B deconvoluídas do espectro de fotocorrente do dispositivo ITO/MEH-PPV/Metal iluminado ora pelo ora pelos eletrodos metálicos (Al,Cu e Mg), sob diferentes tensões aplicadas.

Tabela 5.7: Rendimentos quânticos obtidos dos ajustes das curvas deconvoluídas do espectro de fotocorrente do dispositivo ITO/OC10PPV/Al iluminado ora pelo ora pelos eletrodos metálicos (Al, $\mathrm{Cu}$ e $\mathrm{Mg}$ ), sob diferentes tensões aplicadas. 


\section{LISTA DE SÍMBOLOS E ABREVIATURAS}

\begin{tabular}{|c|c|}
\hline LEDs & Light-Emitting Diodes \\
\hline PLEDs & Polymeric Light-Emitting Diodes \\
\hline$O P V s$ & Organic Photovoltaics \\
\hline PPP & Poli(p- fenileno) \\
\hline PPV & Poli(p- fenileno vinileno) \\
\hline OC10-PPV & Poli [2-metoxi-5-(3'-7'-dimetiltiloxi)-1,4-fenileno vinileno] \\
\hline MEH-PPV & Poli [2-metóxi, 5-(2'-etil-hexilóxi)-1,4-fenileno vinileno] \\
\hline SY & Super-Yellow \\
\hline ITO & Óxido de Estanho Índio \\
\hline HOMO & Highest Occupied Molecular Orbital \\
\hline LUMO & Lowest Unoccupied Molecular Orbital \\
\hline $\mathrm{S}_{0}$ & Estado fundamental \\
\hline $\mathrm{S}_{\mathrm{n}}$ & Estado Excitado (onde $\mathrm{n}$ representa os níveis $\mathrm{n}=1,2,3, \ldots$ ). \\
\hline$v$ & Níveis vibracionais. \\
\hline IC & Conversão Interna \\
\hline ISC & Cruzamento Inter-sistemas \\
\hline Abs & Absorção Óptica \\
\hline PL & Luminescência \\
\hline El & Eletroluminescência \\
\hline UV-Vis & Ultravioleta-Visível \\
\hline $\mathrm{I}-\mathrm{V}$ & Corrente versus tensão incidente \\
\hline$V_{c}$ & Potencial de Contato \\
\hline$V_{B}$ & Potencial de built-in" \\
\hline$\Delta V_{c}$ & Diferença entre as funções trabalho dos eletrodos \\
\hline$\Phi$ & Função-trabalho \\
\hline$\phi_{A l, C u, M g}$ & Função-trabalho dos eletrodos metálicos de $\mathrm{Al}, \mathrm{Cu}$ e $\mathrm{Mg}$. \\
\hline$V$ & Potencial Aplicado nos dispositivos \\
\hline$J_{t}$ & Densidade de Corrente Total \\
\hline$V_{O C}$ & Tensão de circuito aberto \\
\hline$\Delta n$ & Densidade de elétrons \\
\hline$I_{0}$ & Intensidade da luz Incidente $\left(\mathrm{W} / \mathrm{m}^{2}\right)$ \\
\hline$R$ & Refletividade, \\
\hline$y$ & Distância percorrida pela radiação dentro do material (metros); \\
\hline$l$ & Espessura Total do filme polimérico \\
\hline$L_{D}$ & Comprimento de Difusão \\
\hline$\beta$ & Inverso do Comprimento de Difusão. \\
\hline$\alpha$ & Coeficiente de absorção do material \\
\hline$\kappa(\lambda)$ & Coeficiente neperiano de absorção molar \\
\hline $\mathrm{c}$ & Concentração $\left(\mathrm{mol} \mathrm{m}^{-3}\right.$ ou $\left.\mathrm{mmol} \mathrm{L}^{-1}\right)$ \\
\hline$T$ & Transmitância (razão entre a intensidade incidente e a transmitida), \\
\hline$G(x)$ & Taxa de geração de portadores \\
\hline
\end{tabular}




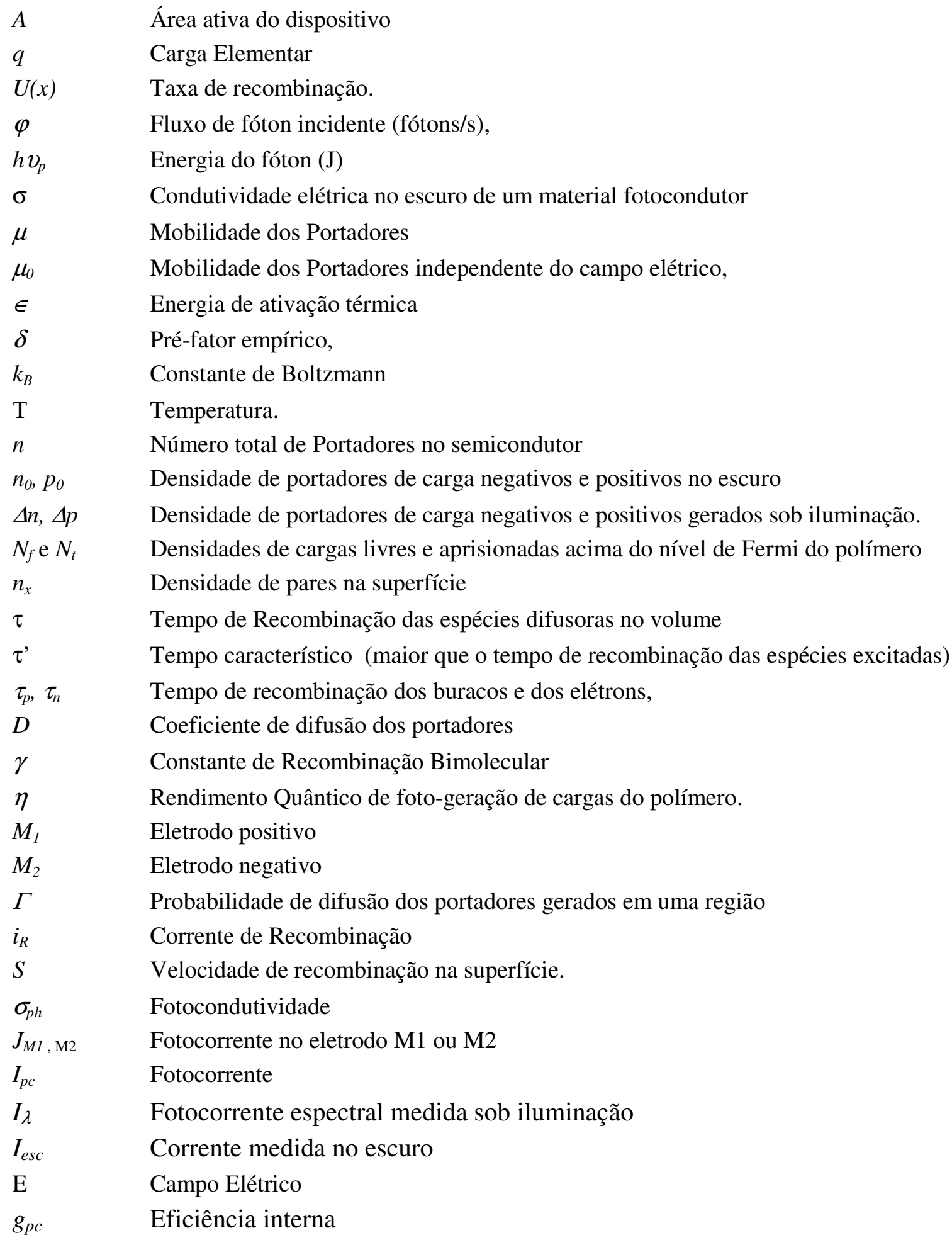




\section{SUMÁRIO}

\section{PREFÁCIO}

1.1 Propriedades E APLICAÇões dos Polimeros ConJugados: .................................. 16

1.1.1 ESTRUTURA E PROPRIEDADES ELETRÔNICAS ............................................................ 16

1.1.2 PROCESSOS RAdIATIVOS E NÃO-RAdIATIVOS EM POLIMEROS CONJUGADOS................. 21

1.1.3 ABSORÇÃO E EMISSÃo DE LUZ EM POLÍMEROS CONJUGADOS: ................................... 23

1.1.4 APLICAÇÕES DE POLÍMEROS CONJUGAdOS EM DisPositivos ....................................25

1.1.5 ESTRUTURA E PRINCÍPIO DE FUNCIONAMENTO DOS DISPOSITIVOS .............................. 26

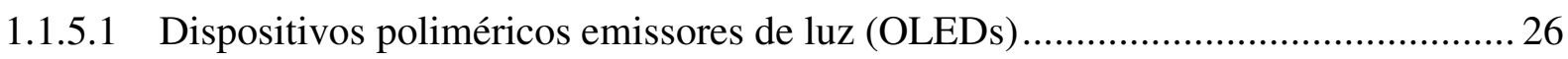

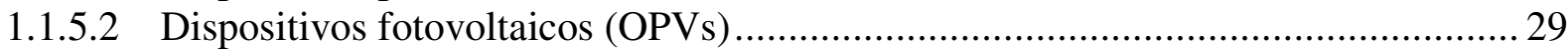

1.2 CONCEITOS DE FOTOCONDUTIVIDADE EM DISPOSITIVOS ORGÂNICOS ........................31

1.2.1 FOTO-GERAÇÃO DE PORTADORES DE CARGA EM POLÍMEROS CONJUGADOS: ................. 31

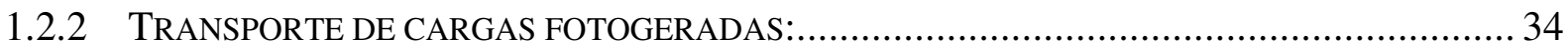

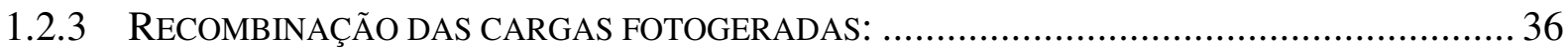

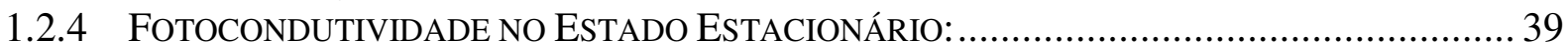

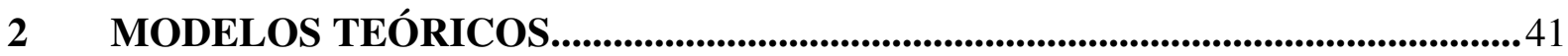

2.1 MODELOS PARA ESPECTRO DE FOTOCORRENTE: .......................................................4 41

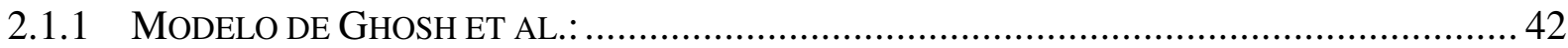

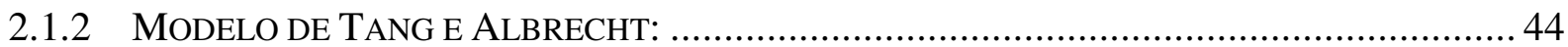

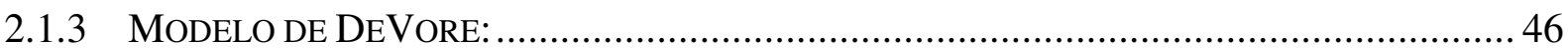

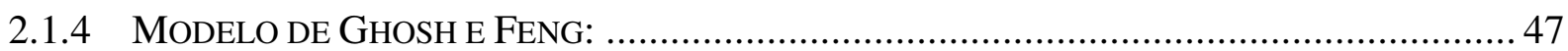

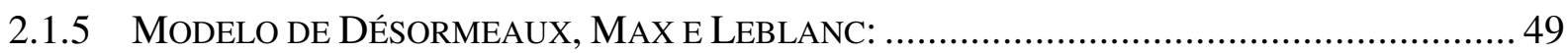

2.2 TEORIA DO TRANSPORTE DAS CARGAS FOTOGERADAS: ...................................................50

3 PREPARAÇÃO DE DISPOSITIVOS E METODOLOGIA EXPERIMENTAL. .55

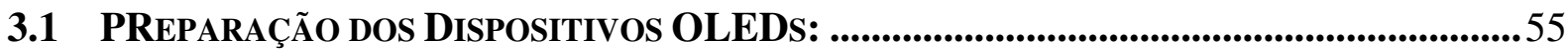

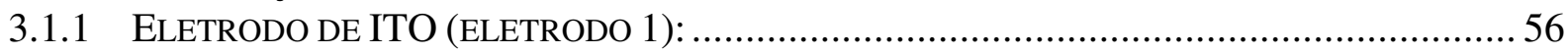

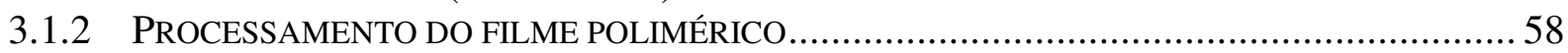

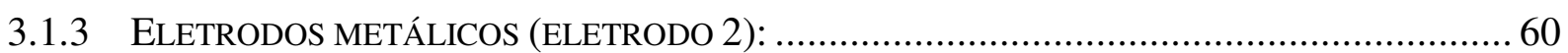

3.2 TÉCNICAS DE CARACTERIZAÇÃO: .......................................................................62

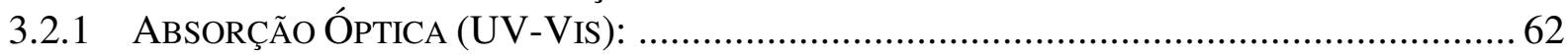

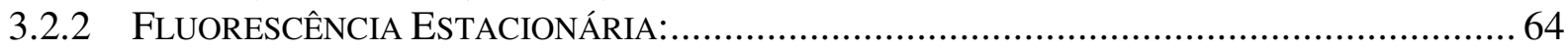

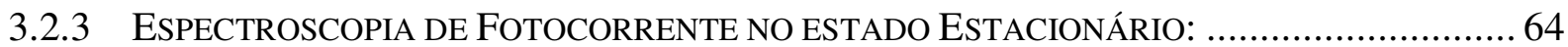

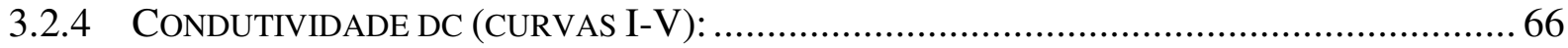

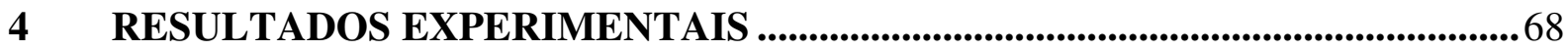

4.1 RESULTADOS EXPERIMENTAIS DA FOTOCONDUTIVIDADE DC (CURVAS I-V) DOS DISPOSITIVOS: 


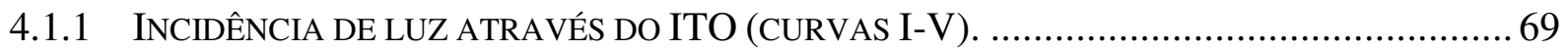

4.1.2 INCIDÊNCIA DE LUZ ATRAVÉS DOS METAIS (CURVAS I-V) .................................. 76

4.2 ESPECTROS DE FOTOCORRENTE NO ESTADO ESTACIONÁRIO DOS DISPOSITIVOS:...... 79

4.2.1 DISPOSITIVO ITO/MEH-PPV/AL - INCIDÊNCIA ATRAVÉS DO ITO................................ 80

4.2.2 DISPOSITIVO ITO/MEH-PPV/CU E ITO/MEH-PPV/MG - INCIDÊNCIA ATRAVÉS DO ITO.... 83

4.2.3 DISPOSITIVO ITO/MEH-PPV/METAIS - INCIDÊNCIA ATRAVÉS DOS METAIS..................8 85

4.2.4 DISPOSITIVO ITO/OC10-PPV/METAIS - INCIDÊNCIA ATRAVÉS DO ITO....................... 88

4.2.5 DisPOSITIVO ITO/OC10-PPV/METAIS - INCIDÊNCIA ATRAVÉS DOS METAIS. ............... 91

4.2.6 DISPOSITIVO ITO/SY/AL. .......................................................................... 93

4.2.7 DEPENDÊNCIA DO SINAL DA FOTOCORRENTE DOS DiSPOSITIVOS COM A TENSÃO

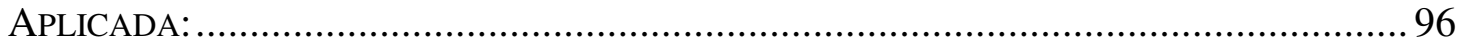

4.2.8 EXPLICAÇÃO PARA O COMPORTAMENTO ANTIBÁTICO E SIMBÁTICO DA FOTOCORRENTE: ..... 98

4.2.9 RENDIMENTO QUÂNTICO NA FOTOCONDUTIVIDADE INTRÍNSECA E EXTRÍNSECA: ...........99

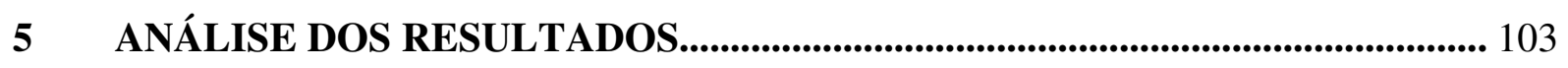

5.1 CÁlCULO DA EFICIÊNCIA INTERNA DOS DISPOSITIVOS: .......................................... 103

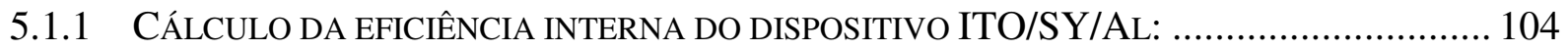

5.1.2 CÁlCULO DA EFICIÊNCIA INTERNA DO DISPOSITIVO ITO/MEH-PPV/METAIS: ........... 105

5.1.3 CÁlCULO DA EFICIÊNCIA INTERNA DO DISPOSITIVO ITO/OC10-PPV/METAIS: ........... 108

5.2 DEPENDÊNCIA FOTOCORRENTE DOS DISPOSITIVOS COM A INTENSIDADE INCIDENTE

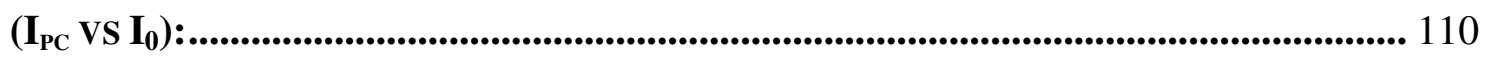

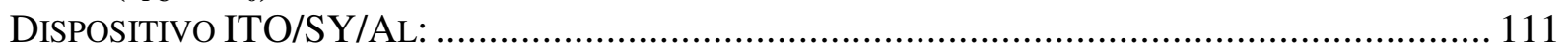

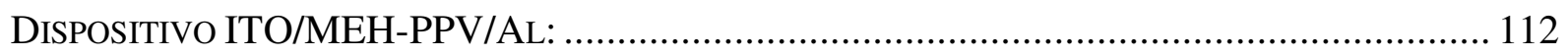

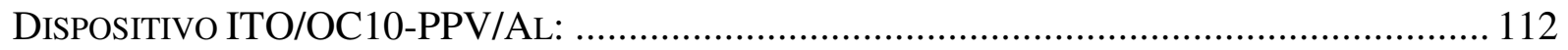

5.3 AJUSTE DOS ESPECTROS DE FOTOCORRENTE:.......................................................... 113

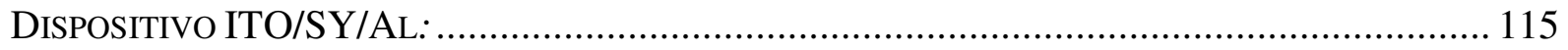

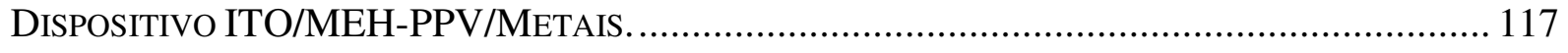

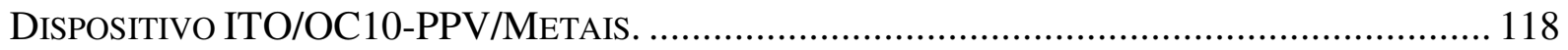

6 DISCUSSÕES E PERSPECTIVAS..................................................................... 120

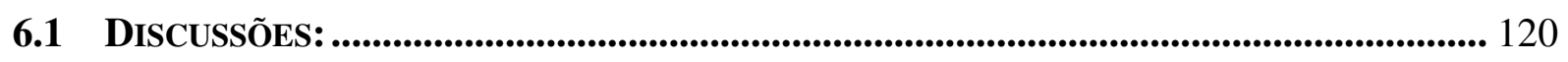

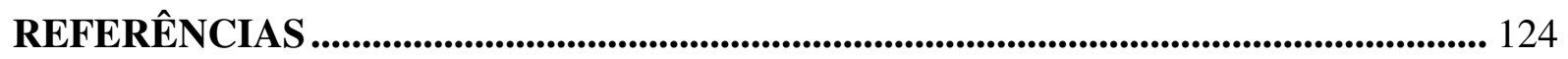




\section{Prefácio}

Os processos envolvidos na fotocondução dos dispositivos poliméricos e suas descrições teóricas ainda não estão totalmente esclarecidos na literatura. Neste trabalho, realizou-se o estudo sobre as propriedades de fotocondução em diodos poliméricos com estrutura (eletrodo1/polímero/eletrodo2) de camada única de derivados do poli ( $p$-fenileno vinileno) (PPV) com o objetivo de compreender e descrever o comportamento da fotocondutividade. Para isso, os diodos foram construídos seguindo as etapas de fabricação e caracterizados pelas técnicas de medidas óptica e elétrica. $\mathrm{O}$ trabalho descreve os conceitos teóricos, os resultados experimetais e as discussões e considerações finais divididos em capítulos. No Capitulo 1 são apresentados as propriedades e as aplicações dos polímeros conjugados em dispositivos opto-eletrônicos e o principio de funcionamento desses dispositivos. Os conceitos fundamentais sobre a fotocondutividade em polímeros conjugados também são apresentados neste capítulo. O Capitulo 2 apresenta uma revisão dos modelos de fotocorrente encontrados na literatura e a descrição do modelo utilizado no ajuste dos espectros de fotocorrente. Os materiais utilizados, o método de fabricação dos dispositivos e a descrição das técnicas de caracterização são apresentados no Capítulo 3. No capitulo 4 estão os resultados obtidos do estudo da fotocondutividade em regime dc, através das curvas de corrente em função da tensão e do espestro de fotocorrente no estado estacionário. Os cáculos de eficiência interna dos dispositivos e os ajuste das fotocorrentes estão no capítulo 5. As discussões sobre o estudo fotocondutivo desses dispositivos poliméricos e perspectivas são apresentadas no Capítulo 6. 


\section{Fundamentos Teóricos.}

Neste capítulo é feito uma breve introdução dos conceitos envolvidos na compreensão do comportamento de dispositivos orgânicos a base de polímeros conjugados. Assim, primeiramente faz-se uma apresentação dos processos fotofísicos associados aos polímeros conjugados. Em seguida trata-se das aplicações desses materiais em dispositivos orgânicos para os quais é fundamental a compreensão dos Conceitos de Fotocondutividade.

\subsection{PROPRIEDADES E APLICAÇÕES DOS POLIMEROS CONJUGADOS:}

\subsubsection{Estrutura e Propriedades Eletrônicas}

Os polímeros são moléculas longas cujo nome deriva do termo grego, poli (muito) e mero (partes) e sua estrutura é resultado do processo químico de polimerização de unidades estruturais (grupos funcionais) menores e idênticos chamados unidades monoméricas. Os polímeros orgânicos são compostos por elementos como carbono e hidrogênio, eventualmente ligados a estes aparecem o oxigênio, nitrogênio e halogênios. Uma classe de moléculas orgânicas de especial interesse e com grande potencial de aplicação em dispositivos optoeletrônicos é a dos polímeros conjugados.

Polímeros conjugados são caracterizados pela alternância entre ligações simples e duplas entre os carbonos da cadeia principal (estrutura denominada por conjugação), e apresentam propriedades semicondutoras (Figura 1.1). 


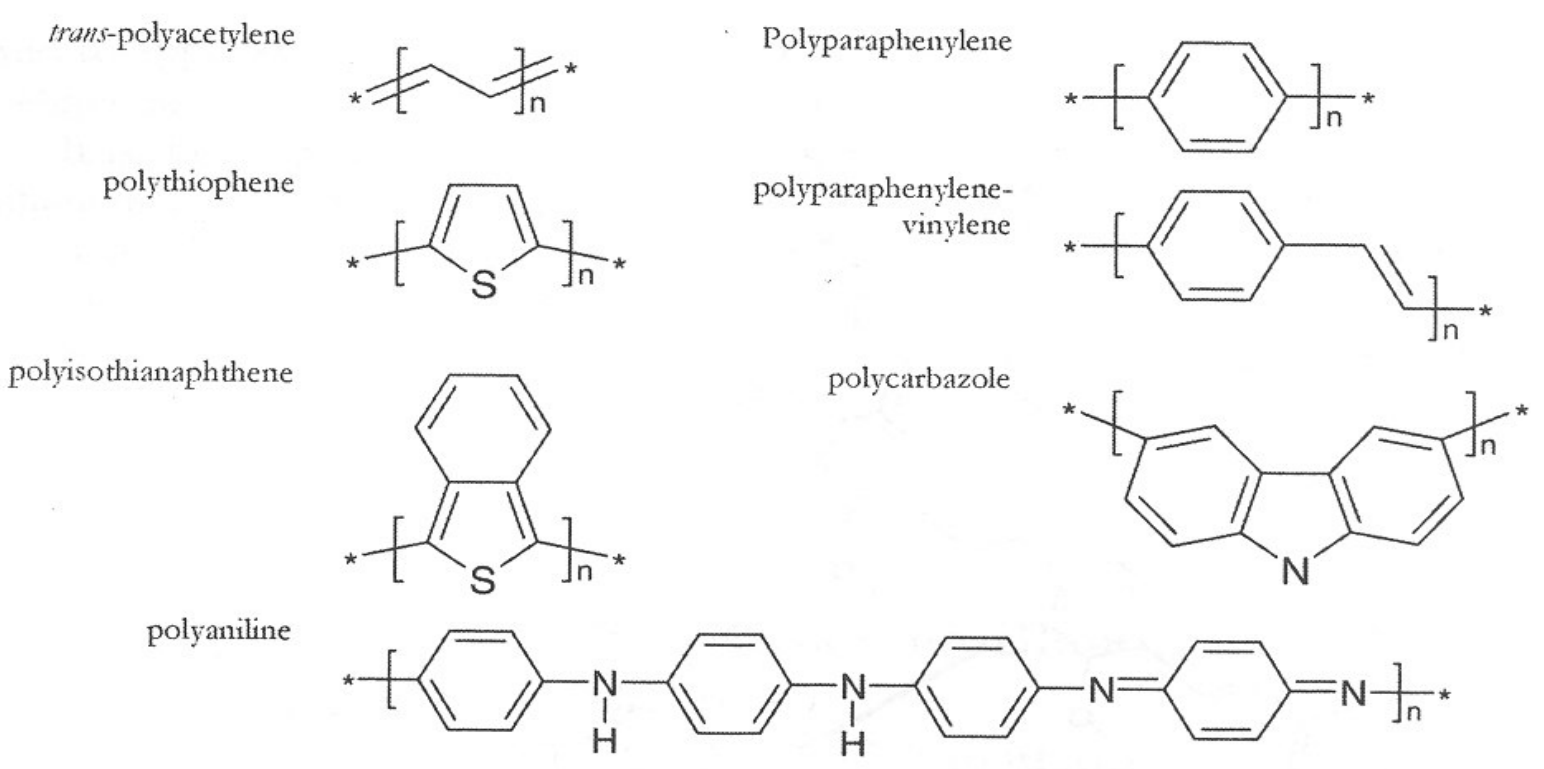

Figura 1.1: Estrutura química de alguns exemplos de polímeros conjugados.

A estrutura eletrônica de moléculas conjugadas é determinada basicamente pelas ligações entre carbonos chamadas de ligações $\sigma$, formadas pela superposição de orbitais híbridos $s p^{2}$ ao longo do plano da molécula. Em adição, existem as ligações $\pi$ formadas pela superposição lateral dos orbitais atômicos $p_{z}$ entre carbonos adjacentes, perpendicular ao plano da molécula ${ }^{1}$. Por esse motivo, os elétrons dos orbitais moleculares $\pi$ se comportam de modo especial. Esses elétrons são deslocalizados e podem se mover ao longo do segmento conjugado ao invés de estarem confinados a uma região particular da molécula, como estão os elétrons da ligação $\sigma$. A não localização dos estados, gerada pela superposição dos orbitais $p_{z}$ pode ser descrita através da teoria de bandas aplicada a uma cadeia unidimensional, periódica e infinita. Como os orbitais moleculares entre carbonos adjacentes possuem somente um elétron por sítio, a banda de valência ou a banda $\pi$ (estados ligantes) de menor energia é totalmente preenchida. A banda de valência está separada dos estados superiores desocupados, denominadas bandas de condução ou bandas $\pi^{*}$ (estados antiligantes) por uma lacuna de energia proibida (gap) da ordem de 2,0 eV, o que confere um caráter semicondutor 
aos polímeros conjugados, como ilustrado na Figura 1.2-a pelo diagrama de energia. A estrutura de banda do PPV em particular, é ilustrada pela Figura 1.2-b.

(a)

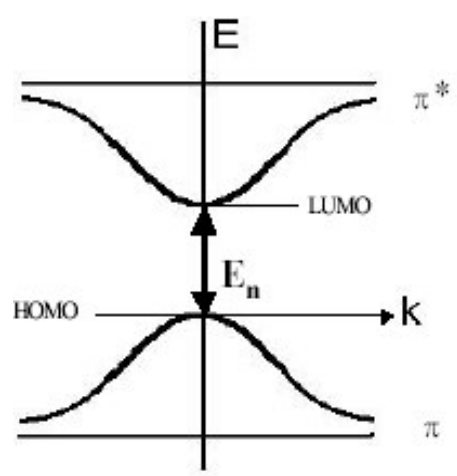

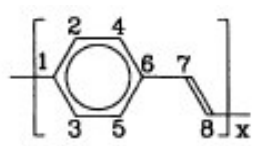

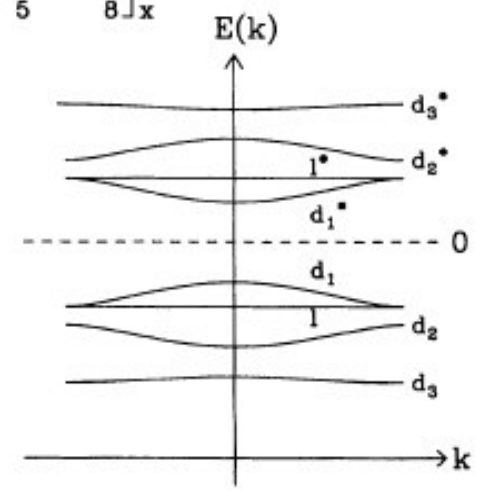

(b)

Figura 1.2: (a) Ilustração esquemática do diagrama de energia na representação de coordenadas. (b) Estrutura eletrônica do PPV, as letras d e $\mathrm{d}^{*}$ indicam estados localizados e não localizados, respectivamente.

Em polímeros conjugados, a criação de defeitos estruturais na cadeia dá origem a estados eletrônicos, associados aos defeitos conformacionais, degenerados e não-degenerado. A formação desses defeitos, que podem se mover ao longo da cadeia, pode carregar consigo cargas elétricas sendo, com isso, responsável pelo aumento da condutividade elétrica desses materiais. Esses defeitos estruturais são comumente designados por sólitons, pólarons ou bipólarons ${ }^{2}$. Um pólaron pode ser imaginado como um estado ligado formado por um sóliton carregado e um sóliton neutro cujos estados de energia se hibridizaram para formar dois níveis no meio do gap, devido à quebra de degenerescência do estado fundamental. Um sóliton neutro não contribui com carga $(q=0)$, mas contribui com um spin eletrônico $(S=1 / 2)$ ao passo que um sóliton carregado contribui com uma carga eletrônica $(q= \pm e)$, mas nenhum momento de spin $(S=0)$. O resultado disso é a criação de uma quase-partícula, dotada de carga eletrônica $(q= \pm e)$ e momento de spin $(\mathrm{S}=1 / 2)$ que carrega consigo uma relaxação geométrica local do comprimento da ligação $C$ - $C$. Em outras palavras, um pólaron atua 
efetivamente como um portador de carga e de spin eletrônicos. A representação esquemática de um pólaron em um polímero com o estado fundamental não degenerado como o PPV ou o PPP é mostrada nas Figura 1.3-a e Figura 1.3-b.

Nestes polímeros, a primeira inversão na alternância entre ligações simples e duplas (quebra de conjugação) causada pelo sóliton negativo (-) é compensada pela nova inversão causada pelo sóliton neutro $(\bullet)$, tornando o defeito energeticamente estável. Bipólarons carregados, por outro lado, são estados ligados formados por dois sólitons carregados com carga de mesma natureza ou por dois pólarons de mesma carga cujos sólitons neutros se aniquilaram devido à superposição da distorção da cadeia causada por cada uma das espécies separadamente. Dessa forma, um bipólaron deve ter a carga correspondente à $(q= \pm 2 e) \mathrm{e}$ soma total nula de seus momentos de $\operatorname{spin}(S=0)$. Os diagramas de bandas de energia com os níveis energéticos intermediários ao gap formados pelos tipos mais comuns de excitações em um polímero conjugado com o estado fundamental não degenerado são representados pela Figura 1.3-c a 1.3-g. Particularmente, o estado excitado representado pelo diagrama da Figura 1.3-g, usualmente denominado éxciton-pólaron, é de fundamental importância no estudo das propriedades ópticas de polímeros conjugados, já que praticamente todo interesse na utilização destes materiais principalmente em dispositivos eletroluminescentes decorre de sua existência. Esta espécie, desprovida de carga líquida e com momento total de spin igual a 0 (singleto) ou 1 (tripleto), pode ser imaginada como um bipólaron neutro, formado pela fusão de dois sólitons carregados com cargas de sinais opostos e com a configuração de spin apropriada. Da mesma forma que as outras excitações carregadas discutidas acima, éxcitonspólarons também podem se mover ao longo da cadeia e transportar tanto a relaxação estrutural quanto a energia associada à sua formação. 


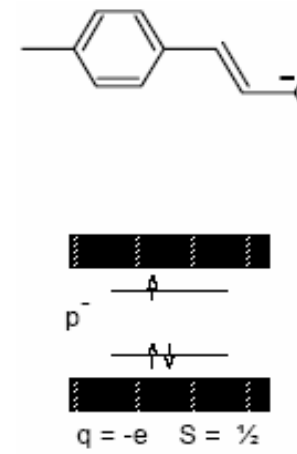

c) a)

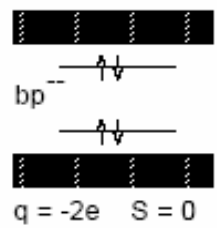

d)
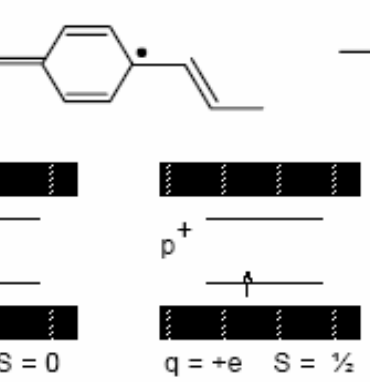

e)

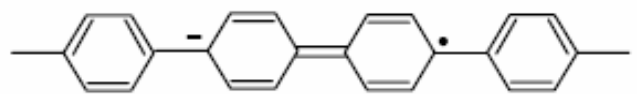

b)

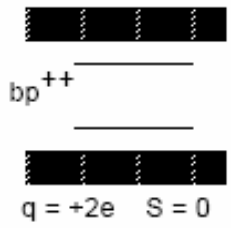

f)

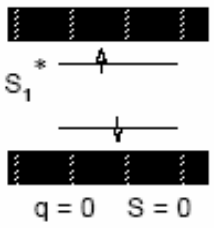

g)

Figura 1.3: Desenho esquemático de um pólaron negativo em um polímero com o estado fundamental não-degenerado: a) PPV; b) PPP. Diagramas de bandas representando os níveis eletrônicos intermediários no gap criado pelos defeitos: c) pólaron negativo; d) bipólaron negativo; e) pólaron positivo; f) bipólaron positivo; g) éxciton-pólaron singleto.

O éxciton, em semicondutores inorgânicos é definido como um estado excitado formado por um par elétron-buraco ligado por atração eletrostática. Como os elétrons e buracos que dão origem a esse éxciton são quase-partículas pertencentes ao sistema multieletrônico formado pela rede cristalina, essa interação eletrostática pode se estender por várias células unitárias, resultando em uma energia potencial de ligação relativamente baixa ${ }^{3}$. A esse tipo de espécie é dado o nome de éxciton de Wannier, com energia de ligação da ordem de $50 \mathrm{meV}$. Por outro lado, em cristais moleculares, as excitações eletrônicas neutras formadas dentro de moléculas isoladas também podem se mover ao longo da rede, devido ao acoplamento inter-molecular. Esse tipo de excitação geralmente apresenta energias de ligação comparativamente maiores que dos éxcitons de Wannier, devido à maior interação eletrostática (menor raio de deslocalização) e recebe a denominação de éxciton molecular ou éxciton de Frenkel ${ }^{4}$, com energia de ligação da ordem de $0,5 \mathrm{eV}$. Os éxcitons são, portanto, estados eletrônicos deslocalizados. No entanto, na presença de acoplamento elétron-rede, um éxciton pode ser acompanhado por uma relaxação da rede, formando o que se costuma denominar de éxciton-pólaron ou éxciton auto-localizado ${ }^{5}$. Embora os éxcitons-pólarons 
sejam a princípio, móveis, efeitos atribuídos à desordem térmica ou estática fazem com que os mesmos sejam localizados.

Em polímeros conjugados, a determinação da natureza dos éxcitons é mais complicada. Se considerar o material polimérico como um cristal tridimensional formado por várias cadeias poliméricas, as excitações eletrônicas geradas no interior de cada cadeia podem mover-se através do "cristal" devido ao acoplamento intermolecular entre as cadeias, tal como um éxciton de Frenkel. Por outro lado, se olharmos para a estrutura eletrônica de cada cadeia polimérica separadamente, a qual pode ser tratada como um semicondutor unidimensional, então um éxciton pode ser descrito como um éxciton de Wannier dentro de cada cadeia.

\subsubsection{Processos Radiativos e Não-radiativos em Polímeros Conjugados}

A energia que separa o orbital molecular preenchido mais alto energeticamente (Highest Occupied Molecular Orbital - HOMO) e o orbital molecular vazio mais baixo energeticamente (Lowest Unoccupied Molecular Orbital - LUMO) de um polímero conjugado é de alguns elétron-volts. Contudo, essa energia pode variar em virtude da distribuição de segmentos com diferentes graus de conjugação (número de unidades monoméricas com ligações simples e duplas sem interrupção), de modo que os estados eletrônicos $\pi$ e $\pi^{*}$ são mais ou menos localizados. Em analogia ao modelo de elétron numa caixa de potencial, o tamanho da conjugação equivaleria à largura da caixa. Baixos graus de conjugação implicariam no aumento da energia de gap entre HOMO-LUMO, do contrário, a energia do gap seria menor. No PPV, cujo tamanho médio efetivo de conjugação é maior que 15 unidades monoméricas, a energia do gap é em torno de 2,5 eV ( $\approx 500 \mathrm{~nm})$. Dessa maneira, transições eletrônicas entre essas bandas podem ocorrer por excitação óptica na região do espectro visível. 
Quando um fóton com energia suficiente para excitar um elétron do estado fundamental $\left(S_{0}\right)$ para um nível eletrônico de maior energia $S_{n}(n=1,2, . . n)$ é absorvido, ocorre uma transição óptica entre estes estados. Cada um desses níveis eletrônicos é ainda caracterizado por vários níveis vibracionais $(v=0,1,2 \ldots)$ para os quais transições ópticas diretas podem ocorrer. O fóton de menor energia absorvido pelo material tem uma energia igual à diferença de energia entre os níveis $S_{0}$ e $S_{1}$ da Figura 1.4, e quando fótons com energia maior que essa diferença são absorvidos, resultam em transições eletrônicas para níveis de maior energia $\left(\mathrm{S}_{2}\right)$. Nos estados excitados mais energéticos, no entanto, o tempo de vida das espécies excitadas é muito curto (de $10^{-14}$ a $10^{-11} \mathrm{~s}$ ), e relaxam muito rapidamente para o nível vibracional mais baixo do primeiro nível eletrônico excitado $\left(S_{1}, v=0\right)$, que tem um tempo de vida mais longo (entre $10^{-9}$ a $10^{-7} \mathrm{~s}$ ). Este processo de decaimento não-radiativo entre níveis de mesma multiplicidade $(\mathrm{M}=2 \mathrm{~S}+1)$ é usualmente conhecido como conversão interna (IC). Analogamente à absorção, a forma de linha do espectro de fluorescência está estreitamente relacionada com os níveis vibracionais dos estados de menor energia.

Após a relaxação de um nível excitado mais energético para o primeiro estado excitado $\left(\mathrm{S}_{1}\right)$, existe a possibilidade da ocorrência de um "cruzamento inter-sistemas" (ISC) dando origem, após relaxações não-radiativas (IC), a um éxciton em um estado tripleto. “Cruzamento Inter-Sistemas" é um termo utilizado para designar transições entre níveis de diferente multiplicidade, que é o caso entre singletos $(\mathrm{M}=1)$ e tripletos $(\mathrm{M}=3)$. Como pode se observar no diagrama da Figura 1.4, o primeiro nível de tripleto está, em geral, situado a uma energia mais baixa que o primeiro nível de singleto. Isto se deve ao não emparelhamento dos elétrons que formam um éxciton tripleto. Como eles se repelem mutuamente pelo princípio de exclusão de Pauli, é de se esperar que os mesmos tenham uma energia de ligação menor que éxcitons singleto. Como a multiplicidade de um estado tripleto é diferente da do estado fundamental, uma transição óptica direta é dita proibida e, conseqüientemente, o tempo 
de vida de éxcitons tripleto é consideravelmente mais longo do que o de éxcitons singleto. Basicamente, existem dois mecanismos de decaimento do nível de tripleto menos energético: i) ocorrência de um novo cruzamento inter-sistemas para um nível vibracional do estado fundamental de maior energia e posterior relaxação não-radiativa para $\mathrm{S}_{0}$; e ii) decaimento radiativo de $T_{1}$ para $S_{0}$, em um processo usualmente conhecido por fosforescência.

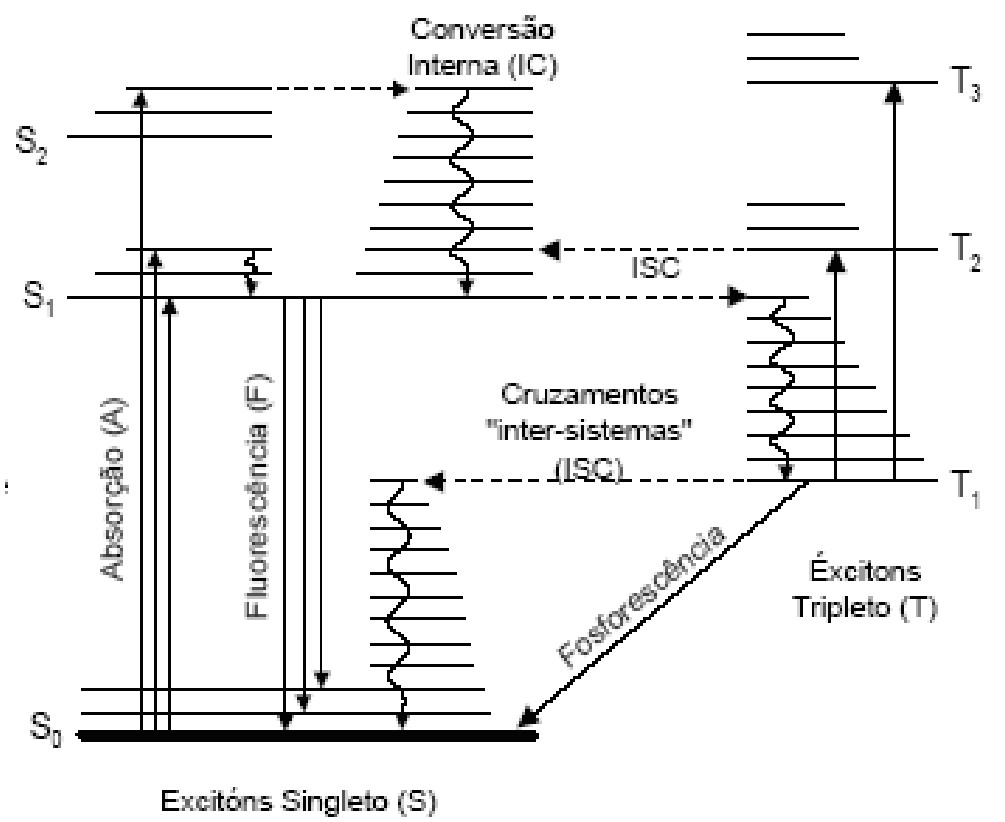

Figura 1.4: Esquema das transições eletrônicas radiativas e nãoradiativas entre os estados excitados em uma molécula conjugada (diagrama de Jablonski). As setas retas verticais representam as transições ópticas e as setas sinuosas representam decaimentos não-radiativos.

\subsubsection{Absorção e Emissão de Luz em Polímeros Conjugados:}

No processo de absorção da luz pelo polímero, o fóton de mais baixa energia é responsável pela transição entre o primeiro nível vibracional do estado fundamental $\left(\mathrm{S}_{0}\right)$ e o do primeiro estado eletrônico excitado $\left(S_{1}\right)$, dando origem à banda situada a maior comprimento de onda (0-0) no espectro ilustrado na Figura 1.5. As transições para o segundo e terceiro níveis vibracionais do estado excitado requerem fótons mais energéticos, dando origem às bandas (0-1) e (0-2). A intensidade relativa entre os picos é um reflexo da 
probabilidade relativa de cada transição ocorrer e está relacionada com o acoplamento entre os níveis vibracionais ${ }^{6}$.

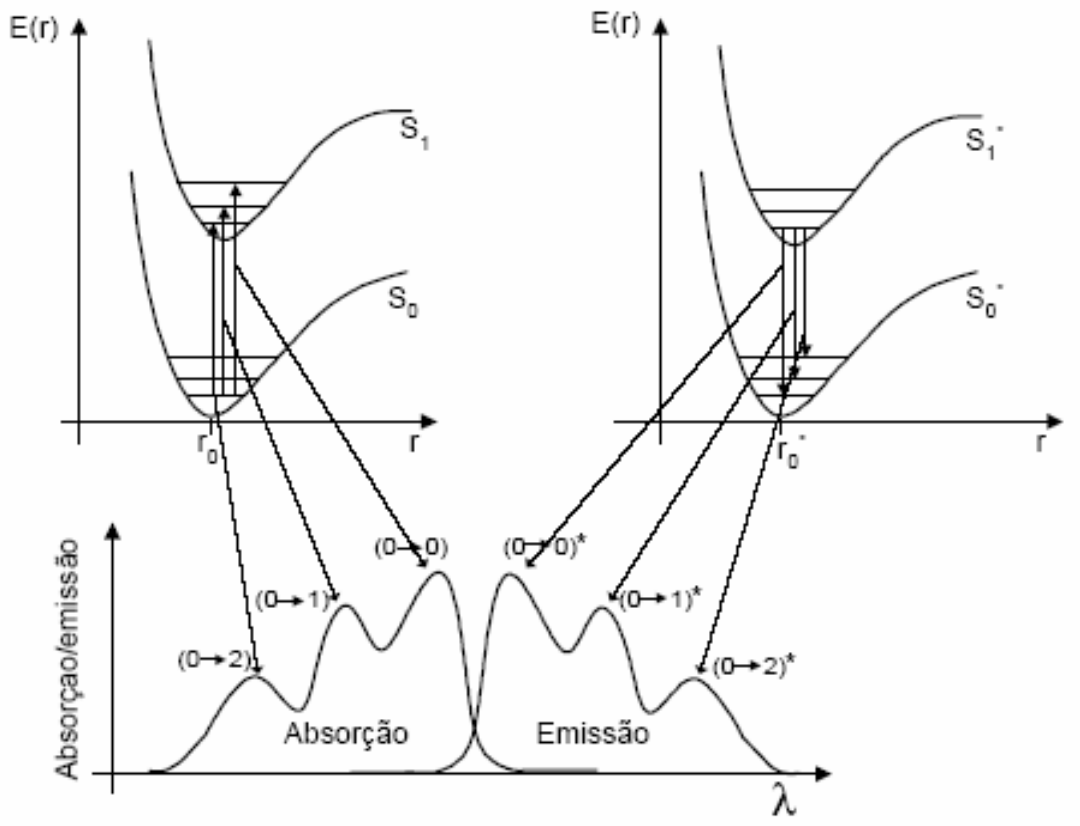

Figura 1.5: llustração dos processos de absorção e emissão de luz em polímeros conjugados provenientes das transições entre os níveis vibracionais do estado eletrônico fundamental e do primeiro estado excitado de uma molécula (Franck-Condon).

O processo de emissão, por outro lado, é dado pelo decaimento radiativo a partir do primeiro nível vibracional do primeiro nível eletrônico excitado $\left(\mathrm{S}_{1} *\right)$ para os níveis vibracionais do nível eletrônico fundamental $\left(\mathrm{S}_{0}{ }^{*}\right)$. O fóton mais energético emitido dá origem à banda $(0-0)^{*}$ enquanto suas progressões dão origem às bandas $(0-1)^{*}$ e $(0-2)^{*}$ observadas a maiores comprimentos de onda. Se a estrutura vibracional do estado excitado se assemelha à do estado fundamental, espera-se que o espectro de emissão seja a imagem especular do espectro de absorção.

A diferença de energia freqüentemente observada entre as bandas atribuídas à transição (0-0) nos espectros de absorção e emissão, conhecida por deslocamento Stokes, deve-se ao fato da distribuição das densidades de cargas no estado fundamental e no estado excitado serem diferentes e, portanto, os estados eletrônicos terem posições de equilíbrio 
diferentes $\left(r_{0}\right.$ e $\left.r_{0}^{*}\right)$. As transições eletrônicas acontecem em tempos muito mais curtos que o tempo que o sistema leva para relaxar, assim a energia do fóton absorvido reflete a configuração do estado fundamental. Porém, antes do decaimento radiativo da espécie excitada, o sistema tem tempo suficiente para assumir a configuração de equilíbrio do estado excitado, de menor energia, emitindo fótons de comprimentos de onda maiores.

\subsubsection{Aplicações de Polímeros Conjugados em Dispositivos}

Devido às propriedades semicondutoras dos materiais orgânicos, os polímeros conjugados têm sido amplamente estudados devido ao seu grande potencial tecnológico como materiais ativos em dispositivos opto-eletrônicos. Nos últimos anos, inúmeras aplicações têm sido desenvolvidas e aperfeiçoadas, como em diodos emissores de luz (LEDs- Light-Emitting Diodes), resultando em dispositivos de características e desempenho comparáveis aos dispositivos comerciais de materiais inorgânicos.

Após a descoberta da eletroluminescência em poli( $p$ - fenileno vinileno) (PPV) por Burroughes et. al. em $1990^{7}$, esses materiais se tornaram bastante promissores para serem utilizados em diodos poliméricos emissores de luz (PLEDs - Polymeric Light-Emitting Diodes) e fotovoltaicos orgânicos (OPVs - Organic Photovoltaics) ${ }^{\mathbf{8}}$. Nos PLEDs, a potencialidade de aplicação é devido a boa estabilidade térmica e elétrica, excelente processabilidade na forma de filmes finos e baixo custo em relação aos dispositivos inorgânicos. Comparado com outras tecnologias, os PLEDs apresentam grandes vantagens como: baixo peso e espessura, grande área emissora, amplo ângulo de visão, flexibilidade, alta luminescência, e baixa potência de consumo. Em dispositivos fotovoltaicos, as excelentes propriedades de absorção de luz desses materiais e a facilidade de processamento na forma de filmes finos os tornam promissores. Apesar da atual inferioridade da eficiência de conversão 
de luz em energia em relação aos dispositivos a base de silício, o custo dos processos de manufatura utilizando materiais orgânicos é muito menor.

\subsubsection{Estrutura e Princípio de Funcionamento dos Dispositivos}

A estrutura básica utilizada nos dispositivos emissores de luz e fotovoltaicos consiste em depositar filme fino de polímeros entre dois eletrodos metálicos (Anodo e Catodo), sendo pelo menos um deles semitransparente (Figura 1.6). Esta estrutura é denominada sanduíche de camada única, e é a estrutura mais simples utilizadas em PLEDs e OPVs. Entretanto, apesar da semelhança entre a estrutura dos dispositivos emissores de luz (PLEDs) e os fotovoltaicos (OPVs), o princípio de funcionamento é diferente.

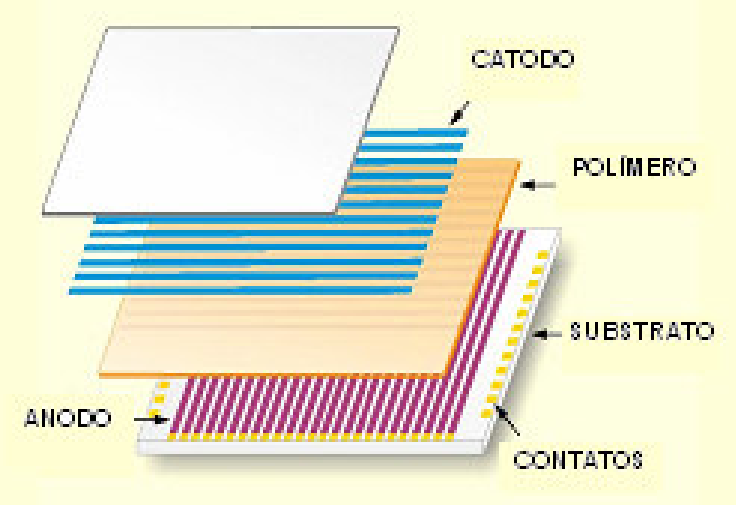

Figura 1.6: Ilustração da estrutura típica sanduíche de camada única dos dispositivos PLEDs e OPVs.

\subsubsection{Dispositivos Poliméricos Emissores de Luz (OLEDs)}

Nos dispositivos polimérico emissores de luz (PLEDs) a emissão de luz é resultado da eletroluminescência na camada polimérica. Eletroluminescência é o fenômeno no qual se obtém luminescência causada pela injeção de cargas pelos eletrodos. Considere a representação esquemática dos diagramas de energia do polímero, e das funções trabalhos de vários metais utilizados como eletrodos, mostrada pela Figura 1.7-a. Após estabelecer os 
contatos entre os eletrodos e o polímero, o equilíbrio termodinâmico é atingido e os níveis de Fermi dos metais se equiparam com o nível de Fermi do polímero nas interfaces formando o contato Schottky ${ }^{9}$. Nesse tipo de contato, ocorre a formação do chamado "potencial de contato" $\left(V_{c}\right)$ entre as interfaces polímero/eletrodo. A diferença entre os potenciais de contato das interfaces é denominada "potencial de built-in" $\left(V_{B}\right)$, dado pela diferença entre as funçõestrabalho dos eletrodos $\left(V_{B}=\Delta V_{c}=\left(\Phi_{1}-\Phi_{2}\right) / q\right)$. O campo elétrico gerado por esse potencial tem direção perpendicular à superfície dos eletrodos. Considere o dispositivo com estrutura ITO/MEH-PPV/Ca. Quando um potencial negativo $V$ é aplicado no eletrodo de ITO (em relação ao de $\mathrm{Ca}$ ), costuma-se dizer, que o dispositivo está polarizado no modo reverso. Neste caso, a configuração das bandas é tal como representada pela Figura 1.7-b, na qual o ITO atua como injetor de elétrons e o eletrodo de Cálcio $(\mathrm{Ca})$ como injetor de buracos. No entanto, como as barreiras de energia para a injeção de elétrons pelo ITO e de buracos pelo Ca são altas, a densidade de corrente total $\left(J_{t}\right)$ que flui através do dispositivo é bastante reduzida em função da baixa densidade de portadores de carga disponíveis. Ao aplicar-se tensão positiva $V$ no ITO (em relação ao Ca) (Figura 1.7-c), o que é denominado por polarização no modo direto, dois regimes de operação distintos podem ser destacados. Primeiramente, quando a tensão aplicada é menor que o potencial de built-in $\left(V_{B}\right)$, a configuração ainda é a mesma de quando o dispositivo está polarizado no modo reverso e, conseqüentemente, a corrente no dispositivo ainda é muito baixa. Quando a tensão aplicada é maior que $V_{B}$, entretanto, a deformação das bandas de energia do polímero se inverte em relação ao modo reverso e a situação para a injeção de buracos a partir do ITO, passa a ser favorável (Figura 1.7-c). Nesse regime, o eletrodo de Ca passa a injetar elétrons e o ITO passa a injetar buracos através de barreiras dadas pela diferença entre as funções-trabalho dos eletrodos e das energias do HOMO/LUMO do polímero. Estas barreiras são da ordem de 0,1 a $0,6 \mathrm{eV}$ e podem ser vencidas por ativação térmica ou por tunelamento (que depende da intensidade do campo 
elétrico), mais facilmente do que no caso de polarização reversa, resultando em correntes consideravelmente maiores do que na primeira situação. Portanto, o gráfico de uma medida de corrente versus tensão $(I-V)$ em um dispositivo deste tipo deve ter a forma de uma curva característica de um diodo convencional: "conduzindo" no modo direto e "retificando" no modo reverso. Por esse motivo, esse tipo de dispositivo é também denominado de diodo. Adicionalmente, como ambos os tipos de portadores são injetados pelos eletrodos e transportados através do volume, correntes mais elevadas fazem com que tenham maiores taxas de recombinação destes portadores, resultando em maiores intensidades de luz emitida.

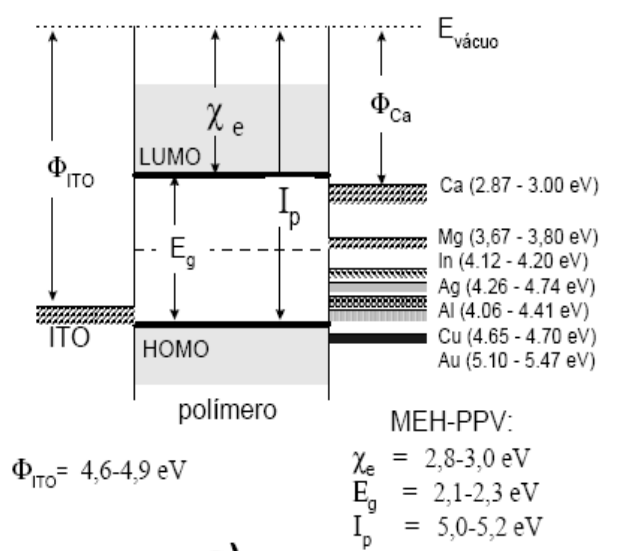

a)

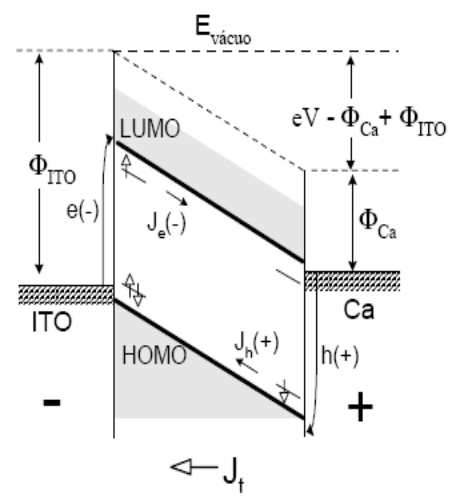

b)

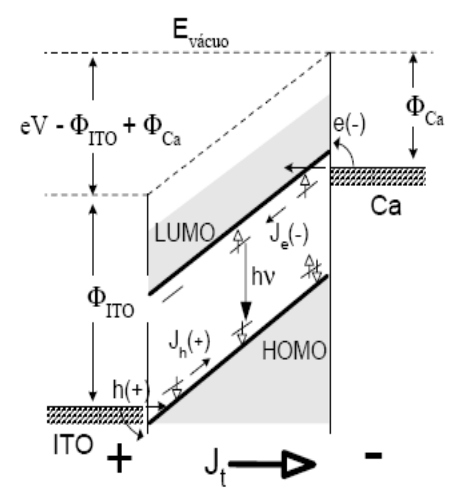

c)

Figura 1.7: Representação esquemática das bandas de energia de um polímero conjugado, neste exemplo o MEH-PPV. a) Fora do equilíbrio, antes do estabelecimento dos contatos. b) No modo reverso e c) no modo direto, no caso específico de uma estrutura ITO/polímero/Ca. Ilustração é adaptação da ref.10.

Como a emissão de luz em PLEDs ocorre, preferencialmente, com o dispositivo polarizado no modo direto, A escolha dos metais que compõe os eletrodos é um fator fundamental no desempenho e no funcionamento dos PLEDs, pois eles controlam diretamente a injeção dos elétrons e dos buracos no interior do polímero ${ }^{\mathbf{1 1 1 1}}$. Assim, os cátodos devem possuir baixo valor de função trabalho, facilitando a injeção de elétrons, enquanto os ânodos, 
por outro lado, devem possuir altos valores de função trabalho, justamente para facilitar a injeção de buracos.

\subsubsection{Dispositivos Fotovoltaicos (OPVs)}

Os dispositivos fotovoltaicos orgânicos (OPVs), operam no sentido inverso dos PLEDs. Os OPVs convertem a radiação incidente em resposta elétrica (potencial elétrico). O funcionamento desses dispositivos depende da intensidade e do comprimento de onda da radiação incidente e é baseado no princípio da fotocondução, onde a absorção de luz pelo material dá origem aos portadores de carga livres que são conduzidos ao circuito externo pelo campo elétrico intrínseco do dispositivo gerado pelo potencial de built-in $\left(V_{B}\right)$, criando assim uma diferença de potencial elétrico, o qual da origem ao efeito fotovoltaico. Na ausência do campo elétrico intrínseco não haveria a condução das cargas e, conseqüentemente, não haveria resposta elétrica. Assim, todo dispositivo fotovoltaico é fotocondutor, mas nem todo dispositivo fotocondutor é fotovoltaico. A partir da curva de corrente versus tensão aplicada $(I-V)$ do dispositivo sob iluminação é possível obter informações sobre suas características fotovoltaicas. A Figura 1.8 mostra a curva característica $I$ - $V$ para um dispositivo iluminado sob diferentes tensões, a) $V<0$, b) $V=0$, c) $V=V_{\mathrm{B}}$ e d) $V>0$. As principais informações são obtidas nas seguintes condições: i) Em $V=0$ (curto-circuito), obtêm-se a corrente de curto circuito $\left(I_{S C}\right)$, resultado do campo interno criado pelos eletrodos e das propriedades de transporte do material. ii) Em $V=V_{B}$ é encontrado o valor da diferença de potencial chamada “tensão de circuito aberto" $\left(V_{O C}\right)$ obtido na curva $I-V$ para $I=0$. A tensão de circuito aberto, em um dispositivo de única camada ativa, é em princípio determinada pela diferença dos valores das funções trabalho dos eletrodos $V_{o c}=-\left(\phi_{\text {catodo }}-\phi_{\text {anodo }}\right) / q$. 


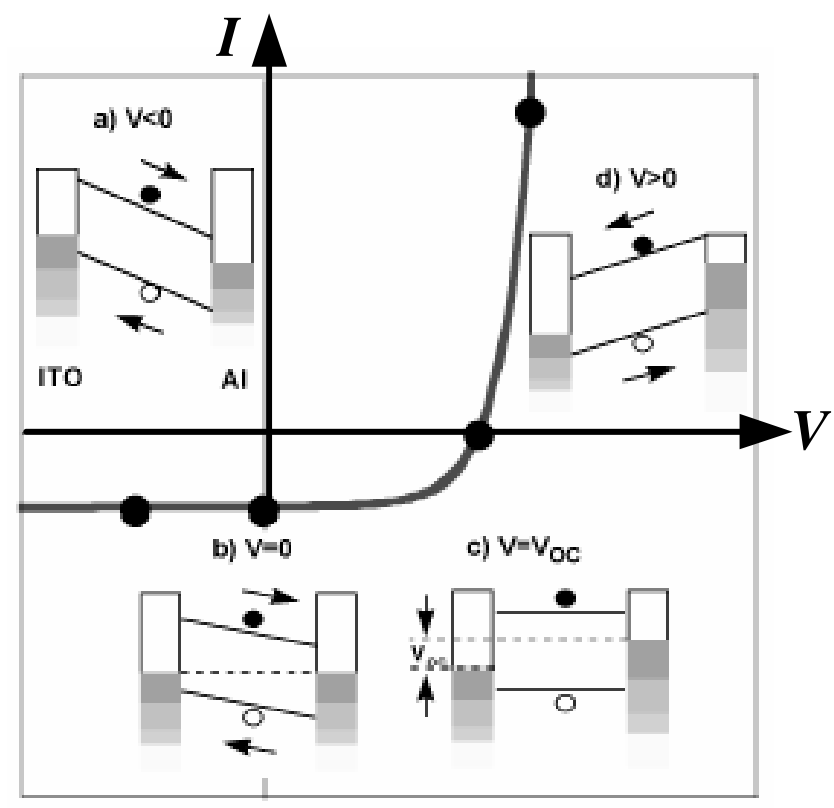

Figura 1.8: Curva característica $I-V$ para um dispositivo fotovoltaico sob iluminação para diferentes tensões aplicada, onde é possível determinar a corrente de curto-circuito $\left(I_{S C}\right)$ e a tensão de circuito aberto $\left(V_{O C}\right)$. Ilustração foi adaptada da ref 12.

A eficiência de conversão de energia luminosa em energia elétrica depende muito da eficiência de geração e coleta das cargas livres. Polímeros conjugados são bons materiais para a foto-geração de cargas, no entanto, como a taxa de recombinação é bastante alta nestes materiais, geralmente utilizam-se heteroestruturas com materiais aceitadores/transportadores de cargas para aumentar a eficiência ${ }^{13,14,15}$. A utilização de compostos como Fulerenos junto aos derivados do $\mathrm{PPV}^{\mathbf{1 6}}$ tem resultado em células fotovoltaicas com eficiências externas de até $5 \%{ }^{17,18}$.

Para o dispositivo fotocondutivo a base de polímeros, uma possibilidade de aplicação é em fotodiodos e fotodetectores. A simplicidade das estruturas utilizadas, o baixo custo dos processos de fabricação, a abrangência de praticamente todo o espectro visível, a alta resposta fotocondutiva e o rápido tempo de resposta são aspectos que os tornam comercialmente viáveis. 


\subsection{CONCEITOS DE FOTOCONDUTIVIDADE EM DISPOSITIVOS ORGÂNICOS}

A Fotocondutividade é o fenômeno associado à variação de condutividade em um semicondutor, ou isolante, devido à incidência de radiação sobre ele ${ }^{\mathbf{1 9 , 2 0 , 2 1}}$. Entretanto, esse é um fenômeno que envolve a interação local entre fótons (da radiação incidente) e elétrons ligados aos átomos que compõem a estrutura do material; por isso é um efeito que ocorre no domínio quântico. A fotocondutividade foi primeiramente observada em 1873 por W. Smith 22 em Selênio amorfo. Já o primeiro material orgânico em que se observou o fenômeno de fotocondutividade foi o cristal de antraceno. Num semicondutor inorgânico e cristalino, o fenômeno da fotocondutividade ocorre quando a densidade de elétrons $\Delta n$ promovidos à banda de condução pela interação com a luz, é significativamente superior à concentração $n_{o}$ dos elétrons termicamente gerados. A magnitude da condutividade depende do número de portadores produzidos por fótons absorvidos pelo material (eficiência interna) e da mobilidade dos portadores fotos-gerados. O tempo de duração deste fenômeno depende do tempo de exposição do material à radiação e do tempo de vida das espécies excitadas. Apesar da complexidade, a fotocondutividade é uma ferramenta muito útil para a compreensão das propriedades eletrônicas de polímeros conjugados semicondutores ${ }^{\mathbf{2 3}}$, e seu efeito é utilizado em fotodetectores e dispositivos fotovoltaicos, como mostrado anteriormente. A seguir, são descritos os mecanismos envolvidos no processo de fotocondutividade após a absorção de luz pelo material: foto-geração de portadores de carga, transporte e recombinação de cargas.

\subsubsection{Foto-geração de Portadores de Carga em Polímeros Conjugados:}

A foto-geração de cargas em um material fotocondutor pode ser um processo intrínseco (primário) ou extrínseco (secundário). A foto-geração intrínseca ocorre quando portadores de cargas livres e de sinais opostos são gerados pela transição entre bandas através 
da absorção da luz incidente no material. A foto-geração é um processo extrínseco quando os portadores de carga são gerados através de processos secundários, resultantes da dissociação de éxcitons através da interação com a interface (eletrodo/material), impurezas, defeitos e com campos elétricos. Nos materiais inorgânicos, os processos envolvidos na fotocondução estão bem estabelecidos, sendo a foto-geração um processo quase sempre intrínseco. Por outro lado, nos materiais orgânicos os processos envolvidos na foto-geração de portadores de carga são difíceis de serem discriminados ${ }^{24}$ e as discussões que tratam esses processos são controversas $^{25,26}$. Na fotocondução dos dispositivos poliméricos conjugados, a polêmica está relacionada ao modelo da estrutura eletrônica do material, ou seja, até onde é válida sua comparação com o modelo clássico de estrutura de bandas de um semicondutor cristalino. No entanto, é bem aceita a idéia de que há formação de éxcitons em sua estrutura, apesar de ainda haver muita controvérsia sobre quais são as suas características e, o mais importante, qual o valor de sua energia de ligação ${ }^{\mathbf{2 7 , 2 8}}$. Portanto, há que se considerar a atração coulombiana entre as cargas positivas e negativas em pares encadeados de elétron-buraco. Em poli (diacetilenos) altamente cristalinos, há uma diferença de energia entre o início da absorção e o início da fotocondutividade de $0,5 \mathrm{eV}$, o que é aceito como evidência da importância das interações elétron-elétron neste material ${ }^{29}$. Para os poli( $p$-fenileno vinilenos) (PPVs) o início da fotocondutividade e da absorção ocorre geralmente na mesma energia ${ }^{30,31}$, sendo uma evidência do modelo de bandas com foto-geração direta de portadores livres, positivos e

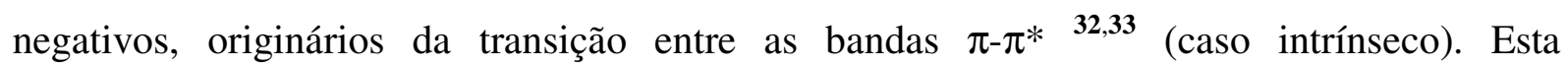
interpretação é conflitante com a fotocondução em muitos semicondutores orgânicos ${ }^{34}$, nos quais a geração de cargas é um processo secundário ${ }^{\mathbf{3 5 , 3 6 , 3 7}}$, resultado da dissociação de éxcitons assistida pelo campo elétrico ${ }^{38}$, pela interação com os eletrodos na interface ${ }^{39}$, defeitos ${ }^{40}$, impurezas ${ }^{41}$ e por transferência de carga ${ }^{42}$ e de energia entre as moléculas ${ }^{43}$ (caso extrínseco). Considerando a atração entre os pares elétrons-buracos, os portadores de cargas 
gerados diretamente pela excitação entre as bandas $\pi-\pi^{*}$ seriam provenientes de éxcitons fracamente ligados, do tipo éxcitons de Wannier. Do contrário, um modelo alternativo de éxciton para foto-excitação de portadores assumiria que a excitação primária geraria éxcitons de Frenkel (altamente correlacionados) e os portadores de cargas livres resultariam dos processos secundários via dissociação desses éxcitons.

No processo de foto-geração de cargas em polímeros as etapas de absorção da luz pelo material e de geração dos portadores, estão diretamente envolvidas. Ao se incidir um feixe de luz de intensidade $I_{0}$ através de um dos eletrodos metálicos semitransparentes com refletividade $R$, parte da luz é refletida e a outra parte transmitida para o interior do dispositivo. A luz transmitida é absorvida pelo material polimérico de espessura $l$. Considerando que o material absorva linearmente a luz transmitida, o perfil de intensidade ao longo do eixo $x$ da amostra é descrito pela lei de Lambert-Beer, neste caso;

$$
I(x)=(1-R) I_{0} \cdot e^{-\alpha x}, \frac{d I}{d x}=-\alpha \cdot I(x)
$$

onde $\alpha$ é o coeficiente de absorção do material. Os mecanismos envolvidos na absorção da luz pelo dispositivo iluminado estão ilustrados na Figura 1.9.

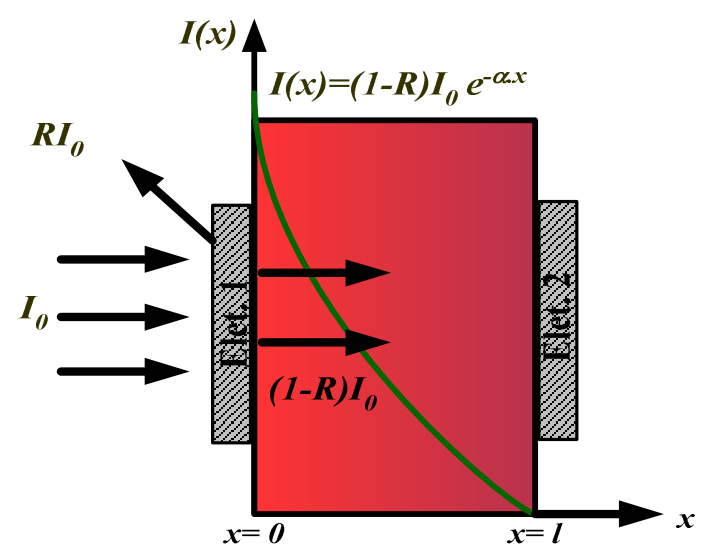

Figura 1.9: Ilustração de feixe de luz de intensidade $I_{0}$ incidente através de um dos eletrodos metálicos semitransparentes com refletividade $R$ de um dispositivo tipo sanduíche de espessura $I$, e o perfil da intensidade $I(x)$ ao longo do eixo $x$. 
Neste caso, a taxa de geração de portadores $G(x)$, isto é, o número de par elétronburaco gerado por unidade de volume $\left[\mathrm{m}^{-3} \mathrm{~s}^{-1}\right]$ via absorção da luz, é escrita como:

$$
G(x)=-\eta \frac{d I}{d x}=\eta(1-R) \alpha I_{0} e^{-\alpha x}
$$

onde $\eta$ é o rendimento quântico do material o qual representa o número de pares elétronsburacos gerados por fótons incidente em um fotocondutor intrínseco, e o número de elétrons e buracos livres por fóton incidente em um fotocondutor extrínseco. É importante notar que na Equação 1.2, que $\eta, R$ e $\alpha$ também são dependentes da energia do fóton $(h v)$ da luz incidente. Na maioria dos materiais ativos em dispositivos, a dependência de $\eta$ e $\alpha$ com o comprimento de onda da luz são muito mais intenso do que $R$.

\subsubsection{Transporte de Cargas Fotogeradas:}

Os portadores da carga fotogerados nos polímeros semicondutores são transportados dentro do material orgânico sob ação do campo elétrico até ser coletado pelos elétrodos. Os semicondutores poliméricos são materiais desordenados e por este motivo existe uma distribuição de energia de estados localizados que são sítios de residência para os portadores $^{44}$. Durante o transporte dos portadores no interior do polímero, os elétrons localizados nos orbitais moleculares de mais baixa energia (LUMO) de uma molécula têm uma probabilidade finita de saltar para os sítios vizinhos, assim como os buracos em saltar entre os sítios localizados nos orbitais moleculares de mais alta energia (HOMO), como ilustrado pela Figura 1.10. Os sucessivos saltos caracterizam a condução conhecida por "Hopping" influencia diretamente na densidade de sítios e na distância entre eles ${ }^{46}$. 


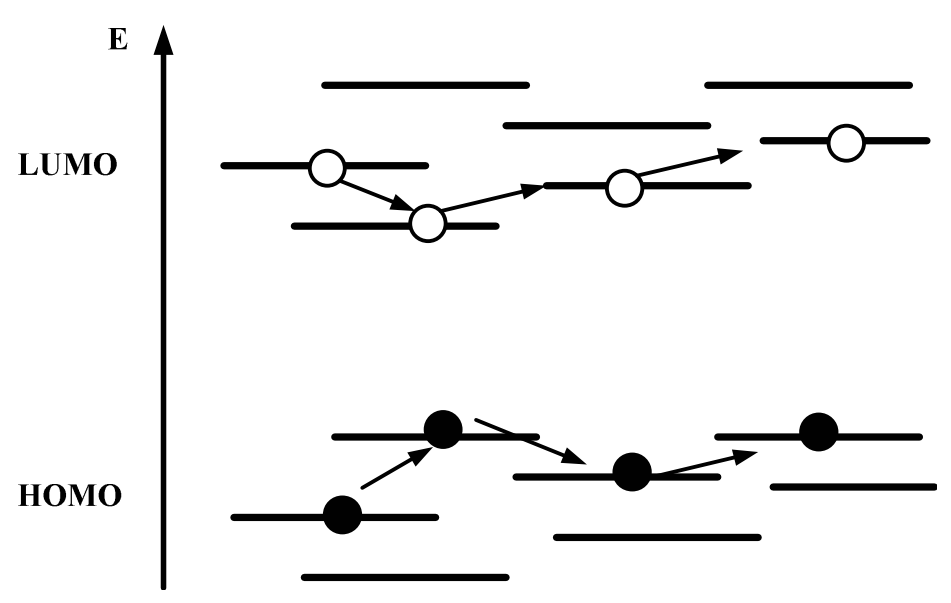

Figura 1.10: Esquema do diagrama de energia em um sólido desordenado ilustrando transporte dos buracos (HOMO) e dos elétrons (LUMO) em material desordenado pelo mecanismo "hopping".

A velocidade de condução desenvolvida pelos portadores sob ação do campo elétrico por unidade de campo elétrico, é definida como mobilidade ${ }^{13}$. A mobilidade dos elétrons e buracos nos polímeros da família dos PPVs é bem diferente apesar da largura da banda de condução e da banda de valência serem similares ${ }^{47}$. No PPV, a mobilidade dos buracos $\left(\mu_{p}\right)$ é da ordem de $10^{-4} \mathrm{~cm}^{2} / \mathrm{V} . \mathrm{s}^{\mathbf{4 8 , 4 9}}$, e em torno de 100 vezes menor é a mobilidade dos elétrons $\left(\mu_{n}\right)$. Na presença de armadilhas, esta mobilidade pode ser ainda menor. Antoniadis et al. ${ }^{\mathbf{5 0}}$ mostrou que o produto mobilidade-tempo de vida $(\mu \tau)$ no PPV é da ordem de $10^{-9}$ e $10^{-12}$ $\mathrm{cm}^{2} / \mathrm{V}$ para os buracos e para elétrons, respectivamente. Assim para um campo de até $10^{5} \mathrm{~V} / \mathrm{m}$ a escala de distância percorrida para os buracos seria de $1 \mu \mathrm{m}$ e para os elétrons $1 \mathrm{~nm}$.

Em termos macroscópicos, a condutividade elétrica no escuro de um material fotocondutor $(\sigma)$ com densidade de portadores $n_{0}$ e $p_{0}$ é expressa como ${ }^{51}$ :

$$
\sigma_{\text {escuro }}=q\left(n_{0} \mu_{n}+p_{0} \mu_{p}\right)
$$


Onde $q$ é a carga elementar, $n_{0}$ e $p_{0}$ a concentração de elétrons e buracos, e $\mu_{n}$ e $\mu_{p}$ é a mobilidade dos portadores negativos e positivos, respectivamente, que dependem do campo elétrico aplicado (tipo Poole-Frenkel ${ }^{\mathbf{5 2}}$ ) e da temperatura da seguinte maneira:

$$
\mu(E, T)=\mu_{0} \cdot \exp (\sqrt{\delta E}) \cdot \exp \left(-\in / k_{B} \mathrm{~T}\right)
$$

onde $\mu_{0}$ é a mobilidade independente do campo elétrico, $\in$ é a energia de ativação térmica e $\delta$ é um pré-fator empírico, $k_{B}$ é a constante de Boltzmann e T é a temperatura. Sob iluminação, a condutividade varia devido ao aumento de portadores de cargas fotogerados ( $\Delta n$ e $\Delta p)$, assim:

$$
\Delta \sigma=\sigma_{\text {escuro }}+\sigma_{\text {iluminado }}=q\left[\left(n_{0}+\Delta n\right) \mu_{n}+\left(p_{0}+\Delta p\right) \mu_{p}\right]
$$

A mobilidade pode também estar relacionada com o coeficiente de difusão dos portadores $(D)$ através da relação de Einstein, $\mu=q D / k_{B} \mathrm{~T}$.

\subsubsection{Recombinação das Cargas Fotogeradas:}

O transporte de cargas é afetado principalmente pela recombinação dos portadores de carga de sinais opostos (elétrons e buracos) durante a condução em direção aos eletrodos. Neste item são apresentados os principais mecanismos de recombinações que ocorrem em materiais orgânicos semicondutores.

Considerando que a equação geral da taxa de recombinação dos portadores de carga no volume do semicondutor e na ausência de centros de recombinação e armadilhas seja dada por:

$$
\frac{d n}{d t}=\frac{d p}{d t}=G(x)-\gamma\left[\left(n_{0}+\Delta n\right)\left(p_{0}+\Delta p\right)-n_{0} p_{0}\right]
$$


Onde $n_{0}$ e $p_{0}$ representam a densidade de portadores de carga negativos (elétrons) e positivos (buracos) no escuro, respectivamente, e $\Delta n$ e $\Delta p$ representam a densidade de portadores de carga negativos e positivos gerados na iluminação. Assumindo que elétrons e buracos são fotogerados com a mesma taxa, $\Delta n=\Delta p$ a Equação 1.6 é escrita como:

$$
\frac{d n}{d t}=G(x)-\gamma\left[\left(n_{0}+p_{0}\right)+\Delta n\right] \Delta n=G-\frac{\Delta n}{\tau}
$$

onde $\tau=\left[\gamma\left(n_{0}+p_{0}+\Delta n\right)\right]^{-1}$ é uma definição formal do tempo de vida dos portadores em excesso. Dependendo do nível de excitação, dois casos são esperados ${ }^{34}$ :

1. Se $\Delta n<<n_{0}+p_{0} \quad$ (baixo nível de excitação), o tempo de vida é constante $\tau=\left[\gamma\left(n_{0}+p_{0}\right)\right]^{-1}$ e a recombinação é chamada de monomolecular, desde que envolva uma probabilidade de recombinação proporcional a densidade da foto-excitação.

2. Se $\Delta n>>n_{0}+p_{0}$ (alto nível de excitação), a Equação 1.8 pode ser reescrita como:

$$
\frac{d n}{d t}=G(x)-\gamma \Delta n^{2}
$$

e a recombinação é chamada de bimolecular, desde que envolva uma probabilidade de recombinação que é proporcional ao quadrado da densidade da foto-excitação. Neste caso, não é possível definir uma constante de tempo de vida de recombinação, visto que este tempo diminui com o aumento da intensidade da excitação.

A recombinação monomolecular e bimolecular são freqüentemente associadas com as recombinações germinativas e não-germinativas, respectivamente. A primeira se refere à recombinação de um elétron e um buraco gerados pelo mesmo fóton absorvido pelo material. 
Desde que os pares germinados sejam isolados um dos outros, a recombinação será monomolecular, governada pelo tempo de vida característico $\tau$ do par. Do contrário, elétrons e buracos não-geminados agem como partículas independentes e a taxa de recombinação é proporcional ao produto de suas duas densidades e a recombinação é então chamada nãogerminativa.

No estado estacionário, onde $d n / d t=0$, a densidade de portadores fotos-gerados será:

1. Para recombinação monomolecular:

$$
\Delta n=G \tau
$$

2. Para recombinação bimolecular:

$$
\Delta n=\sqrt{G / \gamma}
$$

O excesso de portadores fotogerados na condição do estado estacionário é linearmente dependente da intensidade da luz monocromática de excitação para recombinações monomoleculares (germinativas) e proporcionais à raiz quadrada da intensidade para as recombinações bimoleculares (não-germinativas). Ou seja, a dependência da intensidade incidente $\left(I_{0}\right)$ e a fotocorrente $\left(I_{p c}\right)$ pode ser descrita como:

$$
I_{p c}=\left(I_{0}\right)^{m}, \quad m=f\left(N_{f} / N_{t}\right)
$$

onde $N_{f}$ e $N_{t}$ são as densidades de cargas livres e aprisionadas acima do nível de Fermi do polímero. Se a recombinação dos portadores de carga for bimolecular, $m$ se aproxima de 0,5 , se for do tipo monomolecular, a dependência da fotocorrente é linear com intensidade ( $m \approx$ 1). A recombinação bimolecular geralmente ocorre para altas intensidades onde a densidade de portadores gerados é elevada. 


\subsubsection{Fotocondutividade no Estado Estacionário:}

Neste trabalho, o estudo do comportamento da fotocondutividade dos dispositivos poliméricos foi realizado no estado estacionário, no qual a foto-geração de cargas é realizada através da incidência contínua de radiação. Através da dependência espectral da fotocondutividade, informações importantes a respeito dos processos de absorção da luz e de foto-geração de cargas em dispositivos podem ser obtidas. A fotocondutividade pode ser monitorada em função da intensidade e do comprimento de onda da luz incidente sobre o polímero e pelo campo elétrico aplicado, fornecendo informações sobre a dinâmica de transporte e recombinação dos portadores de carga. A distribuição espectral da fotocondutividade pode ser realizada através dos espectros de fotocorrente dos dispositivos fotocondutivos, que se baseia na combinação entre o efeito de absorção da luz em diferentes comprimentos de onda pela camada ativa do dispositivo e sua resposta elétrica (corrente). A resposta espectral é limitada pela competição entre os processos: quantidade de luz absorvida e localização da região de absorção do material. Quanto maior a absorção do filme polimérico para um determinado comprimento de onda, menor a penetração e, conseqüentemente, mais próximo da interface metal/polímero iluminada ocorre a foto-geração dos portadores. Este efeito é conhecido como efeito de filtro interno. Sob a ação do campo elétrico, os portadores gerados são arrastados e coletados pelos eletrodos. A relação entre os espectros de fotocorrente e de absorção pode ser classificada em dois tipos: i) se há uma boa correlação entre eles, isto é, se o máximo da fotocorrente é obtido na região espectral de maior absorção da luz, a resposta de fotocorrente é dita Simbática; ii) se o espectro de fotocorrente for mais intenso na região de mais fraca absorção, neste caso a resposta de fotocorrente é dita Antibática.

A fotocondutividade no estado estacionário não é uma técnica com resolução temporal, isto é, na qual é possível aferir o tempo de foto-geração e o tempo de vida das 
espécies excitadas, que em polímeros conjugados como o PPV e o MEH-PPV o tempo de foto-geração de portadores é menor que $100 \mathrm{fs}^{\mathbf{5 3}}$ e o tempo de vida dos éxcitons da ordem de 300 ps. 


\section{Modelos Teóricos.}

Neste capítulo é apresentada uma breve revisão dos modelos teóricos mais clássicos desenvolvidos para descrever o comportamento da fotocorrente em dispositivos fotocondutores, bem como o modelo desenvolvido a partir da teoria de transporte de cargas utilizado para ajustar os espectros de fotocorrente dos dispositivos estudados neste trabalho.

\subsection{MODELOS PARA ESPECTRO DE FOTOCORRENTE:}

Os modelos teóricos apresentados a seguir foram desenvolvidos com base nos conceitos e nas observações experimentais de fotocondutividade para relatar o comportamento da resposta de fotocorrente em relação ao espectro de absorção. Entretanto, as suposições de cada modelo diferem-se a respeito da natureza das espécies inicialmente fotoexcitada e do mecanismo de geração e transporte das cargas. Neste capítulo, são considerados os modelos desenvolvidos por Ghosh et al. ${ }^{\mathbf{5 4}}$, Tang e Albrecht ${ }^{\mathbf{5 5}}$, DeVore ${ }^{\mathbf{5 6}}$, Ghosh e Feng ${ }^{\mathbf{5 7}}$ e Désormeaux et $a l .^{\mathbf{5 8}}$, que podem ser divididos em duas categorias: A primeira categoria incluem os modelos de Ghosh et al. e Tang e Albrecht e consideram que a geração de portadores é somente bem sucedida numa região foto-ativa estreita (região de barreiras), bem próxima a um dos eletrodos. Na segunda categoria estão os modelos de DeVore, Ghosh e Feng, e Désormeaux et al. os quais resolvem explicitamente a equação da difusão para os éxcitons e para cargas livres para diferentes condições de contorno. O modelo proposto neste trabalho, utilizado para ajustar os espectros de fotocorrente na presença de campos elétricos, resolve a equação da condução dos portadores de cargas livres, negligenciando o processo de difusão das cargas. 


\subsubsection{Modelo de Ghosh et al.:}

Primeiramente, considere que a taxa de portadores fotogerados no volume a uma distância $x$ do eletrodo iluminado é proporcional à intensidade da luz em $x$ é dada pela equação 2.1, onde $\alpha(E)$ é o coeficiente de absorção do polímero em função da energia do fóton, $I_{0}$ é a densidade do fluxo de fóton incidente e $\eta$ representa o rendimento quântico de foto-geração de cargas do material denotados por.

$$
\frac{d n}{d t}=\eta I_{0} \alpha \exp (-\alpha x)
$$

O intervalo limitado pelo comprimento de difusão $\left(L_{D}\right)$ tanto dos éxcitons quando dos portadores de cargas é dado por $L_{D}=1 / \beta=\sqrt{D \tau}$, onde $\tau$ representa o tempo de recombinação das espécies difusoras no volume, $D$ o coeficiente de difusão e $\beta$ o inverso do comprimento de difusão.

Em 1974, Ghosh et al desenvolveu um modelo para explicar o comportamento da fotocorrente de dispositivos inorgânicos onde considerava que os éxcitons eram facilmente dissociados em portadores livres e o espectro de fotocorrente era determinado pela difusão dos éxcitons. Em seu trabalho, a estreita região foto-ativa bem próxima ao eletrodo foi atribuída à barreira Schottky, que agiria como um absorvedouro de cargas minoritárias (neste caso, elétrons) e uma barreira para as cargas positivas (buracos). Este modelo assumia as seguintes suposições: (1) A foto-excitação produziria elétrons e buracos livres ou pelo menos éxcitons que imediatamente formam portadores livres no volume devido, como por exemplo, à interação com impurezas ou armadilhas. (2) A região mais fotossensível no dispositivo seria a região bem próxima ao eletrodo (região da barreira). (3) A fotocorrente dependeria da habilidade do portador minoritário (elétrons) em alcançar a região de barreira, que agiria como um absorvedouro; caso contrário, o acúmulo de carga espacial que ocorreria dentro do 
volume do filme impediria o transporte de carga. Conseqüentemente, os portadores minoritários seriam gerados tanto no volume e subseqüentemente difundir até a barreira como também ser gerados dentro da região da barreira.

A Figure 2.1 ilustra a estreita região fotossensível denotada por $I_{b}$ (região de barreiras), enquanto a espessura total do filme entre dois eletrodos $\left(\mathrm{M}_{1}\right.$ e $\left.\mathrm{M}_{2}\right)$ é denotado por $l$, para iluminação do lado do eletrodo positivo $\mathrm{M}_{1}$.

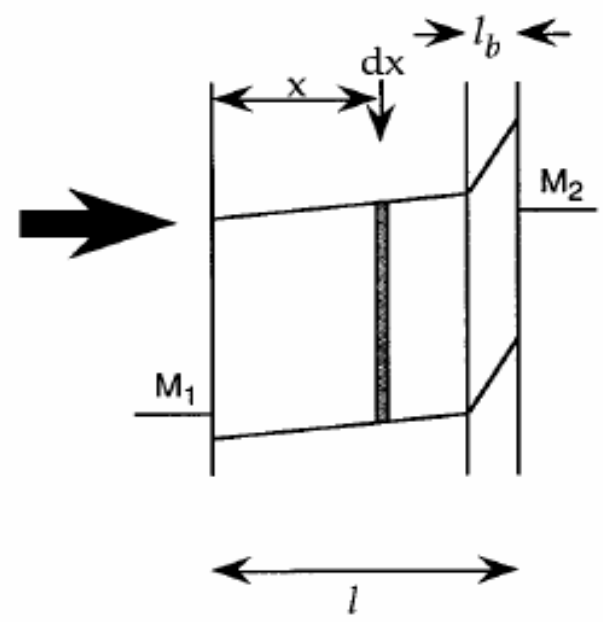

Figure 2.1: llustração da seção de um dispositivo com iluminação do lado oposto à região de barreiras $(x=0)$. A espessura total do filme é representada por $l$, a região infinitesimal de foto-geração no volume por $\mathrm{dx}$, enquanto a espessura da barreira é denotada por $I_{b}$.

1- Para iluminação através do eletrodo $\left(\mathrm{M}_{1}\right)$ longe da barreira, o número de portadores fotogerados no intervalo de $x+d x$ da amostra seria dado pela Eq.2.2.

$$
n(x+d x)=\eta I_{0} \alpha \exp (-\alpha x) d x
$$

Além disso, a probabilidade dos portadores gerados a uma distância $x$ do eletrodo de difundirse até a junção seria dada por:

$$
\Gamma=\exp \left[-\beta\left(l-l_{b}-x\right)\right]
$$


onde $\beta$ o inverso do comprimento de difusão. Dessa forma, o número total de portadores $n$ na junção seria dado pela contribuição dos portadores gerados na região de barreiras e pelos portadores gerados no volume que se difundiram até a junção:

$$
\begin{array}{lr}
n=\int_{0}^{l-l_{b}} \eta I_{0} \alpha \exp (-\alpha x) \exp \left[-\beta\left(l-l_{b}-x\right)\right] d x & \text { (volume) } \\
+\int_{l-l_{b}}^{l} \eta I_{0} \alpha \exp (-\alpha x) d x & \text { (barreira) }
\end{array}
$$

O primeiro termo corresponde ao número de portadores gerados no volume que chegam até a barreira, e o segundo termo corresponde aos portadores gerados dentro da região da barreira. Integrando a Eq. 2.4 obtêm-se:

$$
n(x)=\eta I_{0}\left([\alpha /(\alpha-\beta)]\left\{\exp \left[-\beta\left(l-l_{b}\right)\right]-\exp \left[-\alpha\left(l-l_{b}\right)\right]\right\}+\exp (-\alpha l)\left[\exp \left(\alpha l_{b}\right)-1\right]\right)
$$

2- Para iluminação através do eletrodo $\mathrm{M}_{2}$ próximo à barreira, o número de portadores $n$ na junção é dado por:

$$
\begin{array}{ll}
n=\int_{0}^{l_{b}} \eta I_{0} \alpha \exp (-\alpha x) d x \quad \text { (barreira) } & \\
+\int_{l_{b}}^{l} \eta I_{0} \alpha \exp (-\alpha x) \exp \left[-\beta\left(x-l_{b}\right)\right] d x & \text { (volume) }
\end{array}
$$

onde o primeiro termo corresponde ao portadores gerados dentro da barreira de espessura $l_{b}$, e o segundo termo aos portadores gerados no volume. Resolvendo a integral, obtém-se:

$$
n(x)=\eta I_{0}\left(1-\exp \left(-\alpha l_{b}\right)+[\alpha /(\alpha+\beta)] \exp \left(\beta l_{b}\right) \cdot\left\{\exp \left[-(\alpha+\beta) l_{b}\right]-\exp [-(\alpha+\beta) l]\right\}\right) .
$$

\subsubsection{Modelo de Tang e Albrecht:}

O modelo sugerido por Tang e Albrecht é essencialmente uma versão mais simplificada do modelo de Ghosh et al, onde a contribuição da foto-excitação no volume é 
omitida da Eq. 2.4 e 2.6, negligenciando a difusão dos portadores fotogerados no volume até a barreira fotossensível. Segundo eles, a contribuição para a fotocorrente seria apenas dada pelos portadores fotogerados na região de barreiras, cujas larguras das barreiras não influenciavam nas respostas antibáticas da fotocorrente ao ajustar as curvas.

Os modelos de DeVore, Ghosh e Feng, e Désormeaux, Max e Leblanc partem da equação da continuidade $(1 / q \cdot \nabla \cdot \vec{J}+\partial \rho / \partial t=0)$ e compartilham da mesma equação de difusão descrita pela Eq. 2.8 e 2.9. Uma vez gerados, os portadores de cargas podem tanto difundir como recombinar-se. A taxa da densidade de portadores a uma profundidade $x$ é dada por.

$$
\frac{d n(x)}{d t}=\eta I_{0} \alpha \exp (-\alpha x)-\frac{d i}{d x}-\frac{n}{\tau}
$$

O primeiro termo da Eq. 2.8 representa a foto-geração, o segundo termo representa o movimento dos portadores pela difusão $(i=-D \cdot d n / d x)$ e o terceiro termo representa a recombinação de cargas em uma escala de tempo dada por $\tau$ (tempo de recombinação).

No estado estacionário, a densidade de cargas não muda com o tempo, portanto, $d n(x) / d t$ é zero. Rearranjando a Eq. 2.8 obtêm-se uma equação diferencial de segunda ordem independente do tempo:

$$
\frac{d^{2} n(x)}{d x^{2}}=\frac{n}{D \tau}-\frac{\eta I_{0} \alpha \exp (-\alpha x)}{D}
$$

Cuja solução geral é dada pela Eq. 2.10:

$$
n(x)=B \exp (-\beta x)+C \exp (\beta x)+\frac{\eta I_{0} \alpha \exp (-\alpha x)}{D\left(\beta^{2}-\alpha^{2}\right)}
$$


onde os valores de B e C são constantes e dependem da condição de contorno imposta por cada modelo, como será mostrado em seguida. Nos modelos de Ghosh e Feng, e Désormeaux, Max e Leblanc, as equações de difusão foram aplicadas para a difusão de éxcitons, onde $n(x)$ representa a densidade de éxcitons.

\subsubsection{Modelo de DeVore:}

Este modelo foi desenvolvido em 1956 para descrever o espectro de fotocorrente em semicondutores inorgânico, onde a foto-excitação resultaria diretamente na formação de pares elétrons-buracos livres, cujas recombinações ocorreriam na superfície a uma taxa que poderia ser representada pela corrente de recombinação descrita como $i_{R}=n_{x} S$, onde $n_{x}$ é a densidade de pares nas interfaces ( $\mathrm{x}=0$ e $\mathrm{x}=l$ ) e $S$ a velocidade de recombinação na superfície. Assim, na primeira interface, que seria a iluminada $(x=0)$ :

$$
\left(i_{R}\right)_{0}=-D(d n / d x)_{x=0}=-n_{0} S
$$

Na outra superfície $(x=l)$, longe da iluminação:

$$
\left(i_{R}\right)_{l}=-D(d n / d x)_{x=l}=-n_{l} S .
$$

A equação de difusão (Eq. 2.9) é resolvida assumindo as duas condições de contorno acima, onde os valores de B e C são obtidos.

$$
B=\frac{\eta I_{0} \alpha / D}{\left(\beta^{2}-\alpha^{2}\right)}\left\{\frac{(S-\alpha D)(D \beta-S) \exp (-\alpha l)+(S+\alpha D)(D \beta+S) \exp (\beta l)}{(D \beta-S)^{2} \exp (-\beta l)-(D \beta+S)^{2} \exp (\beta l)}\right\}
$$




$$
C=\frac{\eta I_{0} \alpha / D}{\left(\beta^{2}-\alpha^{2}\right)}\left\{\frac{(S-\alpha D)(D \beta+S) \exp (-\alpha l)+(S+\alpha D)(D \beta-S) \exp (-\beta l)}{(D \beta-S)^{2} \exp (-\beta l)-(D \beta+S)^{2} \exp (\beta l)}\right\}
$$

Para um dispositivo com geometria planar, o aumento da condutividade causado pela radiação seria proporcional ao número total de pares de portadores $(N)$, obtido pela somatória das densidades de portadores gerados $(n)$ no intervalo que compreende a espessura do filme, $N=\int_{0}^{l} n(x) d x$. A fotocondutividade seria dada por $\sigma_{p h}=N / I_{0} \tau$. Entretanto, para dispositivos com geometrias sanduíche, a fotocondutividade seria dada pela Eq. 2.14, que infelizmente não apresenta solução analítica.

$$
\sigma_{p h} \propto \frac{1}{\int_{0}^{l} \frac{1}{n(x)} d x}
$$

De acordo com este modelo, a resposta antibática ocorreria porque a fotocorrente é limitada na região mais resistiva do filme, geralmente a região mais afastada da iluminação. Assim, quando uma luz fortemente absorvida incidisse através do filme, a alta densidade de portadores gerados seria confinada numa região bem próxima à superfície iluminada. Do contrário, quando uma luz fracamente absorvida incidisse sobre o filme, a alto poder de penetração geraria portadores em todo o volume, tornando a amostra menos resistiva. Conseqüentemente, para filmes relativamente grossos, o modelo prediz um pico de fotocorrente na região de baixa energia do espectro de absorção.

\subsubsection{Modelo de Ghosh e Feng:}

O modelo proposto por Ghosh e Feng em 1978 foi desenvolvido para dispositivo com geometria sanduíche e utilizava a mesma equação de difusão de DeVore, porém sob outras condições de contorno. Neste modelo, a densidade de éxcitons tenderia a zero apenas nos 
eletrodos, ou seja, $n=0$ em $x=0$ e em $x=l$, onde $l$ seria a espessura do filme. Para tais condições de contorno, o modelo assumia que toda a região do filme $(0<x<l)$ seria fotossensível. Dessa forma, a solução para a equação de difusão (Eq. 2.9) seria dada por:

$$
n(x)=\frac{\eta I_{0} \alpha}{\beta^{2}-\alpha^{2}}\left[\left(\frac{e^{\beta l}-e^{-\alpha l}}{e^{-\beta l}-e^{\beta l}}\right) e^{-\beta x}-\left(\frac{e^{-\beta l}-e^{-\alpha l}}{e^{-\beta l}-e^{\beta l}}\right) e^{\beta x}+e^{-\alpha x}\right]
$$

Além disso, a fotocorrente é tida como sendo proporcional ao gradiente da densidade do éxcitons nos elétrodos iluminados.

Para iluminação através de um dos eletrodos do dispositivo $\left(\mathbf{M}_{1}\right)$ cuja barreira na interface seria tipo Schottky, a fotocorrente $\left(J_{M 1}\right)$ é dada pela Eq. 2.16, resultando na resposta simbática.

$$
J_{M 1}=-D\left(\frac{d n}{d x}\right)_{x=0}
$$

$$
J_{M 1}=\frac{\alpha \eta I_{0} D}{\left(\beta^{2}-\alpha^{2}\right)} \cdot\left[\frac{\beta\left(e^{\beta l}-e^{-\alpha l}\right)+\beta\left(e^{-\beta l}-e^{-\alpha l}\right)+\alpha\left(e^{-\beta l}-e^{\beta l}\right)}{\left(e^{-\beta l}-e^{\beta l}\right)}\right] .
$$

Os éxcitons gerados a uma distância $x$ do eletrodo iluminado $\mathrm{M}_{1}$ teriam uma fração proporcional a $\exp (-x / L)$ de difundir-se até a interface $\mathrm{M}_{1} /$ filme. $\mathrm{O}$ número total de éxcitons que chegariam a esta interface seria:

$$
n=\int_{0}^{l} \eta I_{0} \alpha \exp (-\alpha x) \exp (-x / L) d x=\eta I_{0} \frac{\alpha}{\alpha+\beta}\{1-\exp [-(\alpha+\beta) l]\}
$$

Para iluminação através do outro eletrodo $\left(\mathrm{M}_{2}\right)$, cujo contato seria ôhmico, a fotocorrente $\left(J_{M 2}\right)$ é dada pela Eq. 2.18, resultando na resposta antibática para um filme de espessura igual a $l$ : 


$$
J_{M 2}=D\left(\frac{d n}{d x}\right)_{x=l}
$$

$$
J_{M 2}=\frac{\alpha \eta I_{0} D}{\left(\beta^{2}-\alpha^{2}\right)} \cdot\left[\frac{2 \beta-e^{-\alpha l}\left(\beta e^{-\beta l}+\beta e^{\beta l}-\alpha e^{-\beta l}+\alpha e^{\beta l}\right)}{\left(e^{-\beta l}-e^{\beta l}\right)}\right] .
$$

Neste caso, o número total de éxcitons que chegariam a esta interface seria dado por:

$$
n=\int_{0}^{l} \eta I_{0} \alpha \exp (-\alpha x) \exp [-(l-x / L)] \cdot d x=\eta I_{0} \frac{\alpha}{\alpha-\beta}[\exp (-\beta l)-\exp (-\alpha l)]
$$

\subsubsection{Modelo de Désormeaux, Max e Leblanc:}

O modelo proposto por Désormeaux, Max e Leblanc é de certa maneira uma fusão de duas aproximações feitas por Ghosh et al e Ghosh e Feng, porém em especial para fotodiodos com estrutura sanduíche. Este modelo assumia que a fotocorrente era proporcional à geração de éxcitons criados através da absorção da luz e dissociados apenas pelo campo elétrico na região de barreiras (região de depleção). Contudo, esse modelo aplicava-se também ao processo de geração de portadores de cargas. Segundo as condições de contorno, a densidade de éxcitons ou a densidade de portadores nos eletrodos seria diferente de zero e proporcional à integral da luz absorvida dentro da região da barreira de espessura $l_{b}$, como indicado pela Eq. 2.20, para a luz incidente através do eletrodo $M_{1}$, e a Eq. 2.21 para luz incidente através do eletrodo $M_{2}$, longe da barreira.

$$
\begin{gathered}
n_{M 1}=\int_{0}^{l_{b}} \eta I_{0} \alpha \exp (-\alpha x) d x=\eta I_{0}\left[1-\exp \left(-\alpha l_{b}\right)\right], \\
n_{M 2}=\int_{0}^{l_{b}} \eta I_{0} \alpha \exp [-\alpha(l-x)] d x=\eta I_{0}\left\{\exp \left[-\alpha\left(l-l_{b}\right)\right]\right\}\left[1-\exp \left(-\alpha l_{b}\right)\right] .
\end{gathered}
$$


Seguindo o perfil do modelo de Ghosh et al, a fotocorrente seria resultante da contribuição do volume e da barreira, assim a corrente seria proporcional ao gradiente da densidade de portadores na barreira e proporcional a densidade de portadores gerados diretamente na região da barreira. Segundo este modelo, a resposta de fotocorrente é dada pela Eq. 2.22 para luz incidente através do eletrodo $M 1$ e pela Eq. 2.23 quando a iluminação se dá através do eletrodo $M 2$, longe da região da barreira.

$$
\begin{aligned}
& J_{M 1}=-D\left(\frac{d n}{d x}\right)_{l_{b}}+n_{M 1}, \\
& J_{M 1}=\frac{\alpha \eta I_{0} \beta e^{-\alpha l_{b}}}{\left(\beta^{2}-\alpha^{2}\right)} \cdot\left[\frac{1-e^{\beta\left(l-l_{b}\right)}\left[2 e^{-\alpha\left(l-l_{b}\right)}-e^{\beta\left(l-l_{b}\right)}\right]}{\left[1-e^{-2 \beta\left(l-l_{b}\right)}\right]}\right]+\eta I_{0}\left[1-\frac{\beta^{2} e^{-\alpha l_{b}}}{\left(\beta^{2}-\alpha^{2}\right)}\right], \\
& J_{M 2}=-D\left(\frac{d n}{d x}\right)_{l_{b}}+n_{M 2}, \\
& J_{M 2}=\frac{\alpha \eta I_{0} \beta e^{-\alpha\left(l-l_{b}\right)}}{\left(\beta^{2}-\alpha^{2}\right)} \cdot\left[\frac{1-e^{\beta\left(l-l_{b}\right)}\left[2 e^{\alpha\left(l-l_{b}\right)}-e^{\beta\left(l-l_{b}\right)}\right]}{\left[1-e^{-2 \beta\left(l-l_{b}\right)}\right]}\right]-\eta I_{0} e^{-\alpha l}\left[1-\frac{\beta^{2} e^{\alpha l_{b}}}{\left(\beta^{2}-\alpha^{2}\right)}\right] .
\end{aligned}
$$

\subsection{TEORIA DO TRANSPORTE DAS CARGAS FOTOGERADAS:}

Os modelos teóricos apresentados anteriormente descrevem com sucesso os fenômenos de fotocondutividade em semicondutores inorgânicos. Porém, não podem ser aplicados diretamente em polímeros conjugados, nos quais o transporte de carga e as propriedades semicondutoras dependem fortemente da morfologia das cadeias poliméricas e principalmente dos mecanismos de foto-geração dos portadores de carga. Atualmente, diferentes modelos vêm sendo propostos para descrever o espectro de fotocorrente de 
dispositivos fotovoltaicos ${ }^{\mathbf{5 9}}$. Alguns desses modelos são misturas do modelo de Ghosh e Feng, Tang e Albrecht e Désormeaux ${ }^{\mathbf{6 0 , 6 1}}$, e levam em consideração apenas a difusão dos portadores gerados, negligenciando a dependência da tensão aplicada no transporte elétrico das cargas fotogeradas. O modelo proposto, entretanto, considera apenas o processo condutivo, resultante da ação do campo elétrico sobre os portadores livres de sinais opostos, no transporte das cargas geradas.

De maneira geral, a fotocorrente é constituída pela corrente de condução e pela corrente de difusão dos portadores fotogerados (buracos e elétrons), dadas por:

$$
\begin{gathered}
J_{n}(x)=J_{c o n d, n}(x)+J_{d i f, n}(x)=q \mu_{n} n(x) E+q D_{n} \frac{d n(x)}{d x} \\
J_{p}(x)=J_{c o n d, p}(x)+J_{d i f, p}(x)=q \mu_{p} p(x) E-q D_{p} \frac{d p(x)}{d x} \\
J_{T}(x)=J_{p}(x)=J_{n}(x)
\end{gathered}
$$

Na teoria do transporte de cargas, o movimento das cargas no interior do material é descrito pela equação da continuidade ${ }^{62}$, onde:

$$
\frac{1}{q} \vec{\nabla} \cdot \vec{J}=-\frac{\partial n}{\partial t}
$$

No estado estacionário (incidência contínua de radiação), a densidade de portadores $n$ é constante no tempo e, portanto, $\partial n / \partial t=0$. Os portadores fotogerados são coletados pelos eletrodos ou se recombinam decaindo radiativamente ou não-radiativamente. Dessa maneira, após um tempo característico $\tau$ ’ (mais longo que o tempo de recombinação das espécies 
excitadas) a densidade dos portadores fotogerados diminui a zero e a Equação da continuidade em 1D é descrita como:

$$
\frac{1}{q} \frac{\partial J}{\partial x}+G(x)-U(x)=0
$$

onde $G(x)$ é a taxa de geração de portadores e $U(x)$ é a taxa de recombinação. A taxa de geração de portadores pode ser escrita como $G(x)=-\eta \cdot d I / d x$, onde $I(x)=I_{0} e^{-\alpha x}$ é a intensidade da luz no interior do material ao longo da direção $x, \alpha(\lambda)$ é o coeficiente de absorção do material, $I_{0}$ a intensidade da luz incidente transmitida, e $\eta$ é o rendimento quântico.

Substituindo as eqs. 2.24 e 2.25 na eq. 2.28 obtêm-se equações diferenciais de segunda ordem que descrevem o transporte dos elétrons e buracos, respectivamente, no material:

$$
\begin{aligned}
& D_{n} n^{\prime \prime}(x)+\mu_{n} \frac{V}{l} n^{\prime}(x)-U(x)+\alpha(\lambda) \eta I_{0} e^{-\alpha x}=0 \\
& D_{p} p^{\prime \prime}(x)-\mu_{p} \frac{V}{l} p^{\prime}(x)+U(x)-\alpha(\lambda) \eta I_{0} e^{-\alpha x}=0
\end{aligned}
$$

onde $\mu_{p}$ e $\mu_{n}$ são a mobilidade dos buracos e dos elétrons, respectivamente.

Considerando que recombinação dos portadores de cargas pode ser tanto monomoleculares, onde a taxa de recombinação é proporcional à densidade de cargas $(n / \tau \mathrm{e}$ $p / \tau)$, quanto bimolecular, na qual a taxa é proporcional ao quadrado da densidade de cargas $\left(\gamma . n^{2}\right.$ ou $\left.\gamma . n . p\right)$, as Eqs. 2.29 e 2.30 são reescritas como:

$$
D_{n} n^{\prime \prime}(x)+\mu_{n} \frac{V}{l} n^{\prime}(x)-\frac{n(x)}{\tau_{n}}-\gamma \cdot n \cdot p+\alpha(\lambda) \eta I_{0} e^{-\alpha x}=0
$$




$$
D_{p} p^{\prime \prime}(x)-\mu_{p} \frac{V}{l} p^{\prime}(x)+\frac{p(x)}{\tau_{p}}+\gamma \cdot p \cdot n-\alpha(\lambda) \eta I_{0} e^{-\alpha x}=0
$$

Onde $\gamma$ é a constante de recombinação bimolecular e $\tau_{p}$ e $\tau_{n}$ é o tempo de recombinação dos buracos e dos elétrons, respectivamente.

Assumindo a condição de contorno, de que os eletrodos sejam bons coletores de cargas, dessa maneira a densidade de portadores é nula na interface do eletrodo $(x=0$ e $x=l)$, ou seja, $n(0)=p(0)=0$ e $n(l)=p(l)=0$. Leva-se em consideração que os portadores de carga fotogeradas apresentam mobilidades e se movem livremente sob ação do campo elétrico, sugerindo que o transporte das cargas livres fotogeradas é governado principalmente pela corrente de condução. Neste caso, a contribuição da corrente de difusão é negligenciada. Para uma recombinação do tipo monomolecular, as equações 2.31 e 2.32 são descritas por:

$$
\begin{aligned}
& \mu_{n} E(x) n^{\prime}(x)-\frac{n(x)}{\tau_{n}}+\alpha(\lambda) \eta I_{0} e^{-\alpha x}=0 \\
& \mu_{p} E(x) p^{\prime}(x)-\frac{p(x)}{\tau_{p}}+\alpha(\lambda) \eta I_{0} e^{-\alpha x}=0
\end{aligned}
$$

As equações 2.33 e 2.34 são solúveis analiticamente e as soluções são as densidades de portadores fotogerados ( $n$ elétrons e $p$ buracos) ao longo da amostra:

$$
\begin{aligned}
& n(x)=\frac{\tau_{n} \alpha(\lambda) \eta I_{0}}{\left(\alpha(\lambda) \tau_{n} \mu_{n} E+1\right)}\left(e^{-\alpha(\lambda) x}-e^{-\left(x / \tau_{n} \mu_{n} E\right)}\right) \\
& p(x)=\frac{\tau_{p} \alpha(\lambda) \eta I_{0}}{\left(\alpha(\lambda) \tau_{p} \mu_{p} E+1\right)}\left(e^{-\alpha(\lambda) x}-e^{-\left(x / \tau_{p} \mu_{p} E\right)}\right)
\end{aligned}
$$


onde a primeira componente exponencial $\left(e^{-\alpha x}\right)$ é relativa ao perfil de geração de portadores e a segunda componente exponencial $\left(e^{-(x / \tau \mu E)}\right)$ à dinâmica de transporte sob campo elétrico $E$. A fotocorrente para cada tipo de portador é representada pelas Eq. (2.37) e (2.38) sendo a fotocorrente total a somatória delas (2.39):

$$
\begin{gathered}
J_{n}(x)=J_{c o n d, n}(x)=e \mu_{n} n(x) E(x)=\frac{q \mu_{n} \tau_{n} \alpha(\lambda) \eta I_{0} E(x)}{\left(\alpha(\lambda) \tau_{n} \mu_{n} E(x)+1\right)}\left(e^{-\alpha(\lambda) x}-e^{-\left(x / \tau_{n} \mu_{n} E(x)\right)}\right) \\
J_{p}(x)=J_{c o n d, p}(x)=e \mu_{p} p(x) E(x)=\frac{q \mu_{p} \tau_{p} \alpha(\lambda) \eta I_{0} E(x)}{\left(\alpha(\lambda) \tau_{p} \mu_{p} E(x)+1\right)}\left(e^{-\alpha(\lambda) x}-e^{-\left(x / \tau_{p} \mu_{p} E(x)\right)}\right) \\
J_{p c}=J_{p}(x)+J_{n}(x)
\end{gathered}
$$

As Eqs. 2.37 e 2.38 foram utilizadas para ajustar os espectros de fotocorrente dos dispositivos estudados neste trabalho. 


\section{Preparação de dispositivos e metodologia experimental.}

Os materiais, os procedimentos e as etapas de preparação dos dispositivos OLEDs estudados são detalhados na primeira sessão deste capítulo. As técnicas e os arranjos experimentais utilizados para caracterização óptica e elétrica: espectroscopia UV-Vis, Espectroscopia de luminescência do estado estacionário, Espectroscopia de fotocorrente estacionária e de condutividade dc são apresentadas na segunda sessão.

\subsection{PREPARAÇÃO DOS DISPOSITIVOS OLEDS:}

Os dispositivos poliméricos foram fabricados com estruturas tipo sanduíche de camada única (eletrodo1/polímero/eletrodo2) de camada única. Nesta geometria, a camada de polímero entre os dois eletrodos metálicos estabelece duas interfaces, uma eletrodo1/polímero e outra polímero/eletrodo2 (Figura 3.1). Os dispositivos estudados neste trabalho foram fabricados seguindo um procedimento de 3 etapas: limpeza e preparação dos substratos com eletrodo de ITO (Óxido de Estanho Índio), deposição das soluções poliméricas (processamento dos filmes poliméricos) sobre o substrato e a evaporação dos eletrodos metálicos (metalização) sobre a camada ativa de polímero.

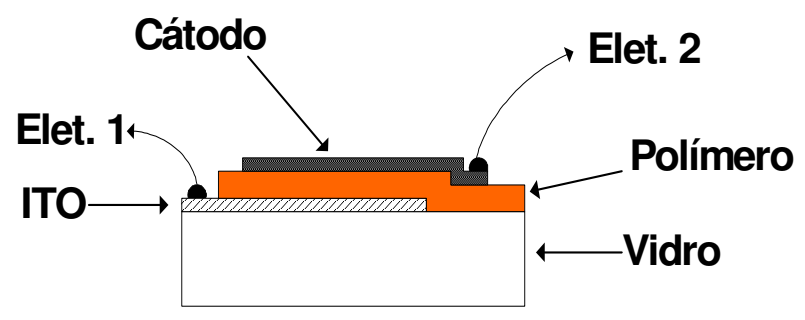

Figura 3.1: Ilustração do dispositivo com estrutura tipo "sanduíche" com camada única de polímero e os respectivos eletrodos metálicos. 
Como um dos objetivos deste trabalho foi estudar o efeito de diferentes metais como eletrodo 2 no comportamento do dispositivo, os eletrodos foram evaporados sobre o mesmo filme polimérico. Esse método de montagem garante que o estado da interface eletrodo1/polímero e a espessura da camada polimérica sejam as mesmas, devendo as diferenças no comportamento do dispositivo ser atribuído às interfaces polímero/eletrodos 2 . Neste capítulo, são detalhados as etapas e procedimentos adotados para obtenção de dispositivos com excelente qualidade e reprodutibilidade.

\subsubsection{Eletrodo de ITO (eletrodo 1):}

Os dispositivos foram fabricados sobre substrato de vidro, com dimensões de 12x14x1,1 mm, recobertos por uma fina camada $(120$ - $150 \mathrm{~nm}$ ) de ITO (Óxido de Estanho e Índio). O ITO utilizado neste trabalho (Delta Technologies) possui função trabalho $\left(\phi_{I T O}\right)$ em torno de $4,6 \mathrm{eV}$, resistência laminar entre 8 a $12 \Omega / \square$ e transmitância em torno de $84 \%$ na maior parte da região do visível, como mostra o espectro de transmitância da Figura 3.2. A boa relação condutividade/transmitância faz com que o ITO seja extensamente utilizado como eletrodo em dispositivos eletroluminescentes e fotocondutores ${ }^{63}$.

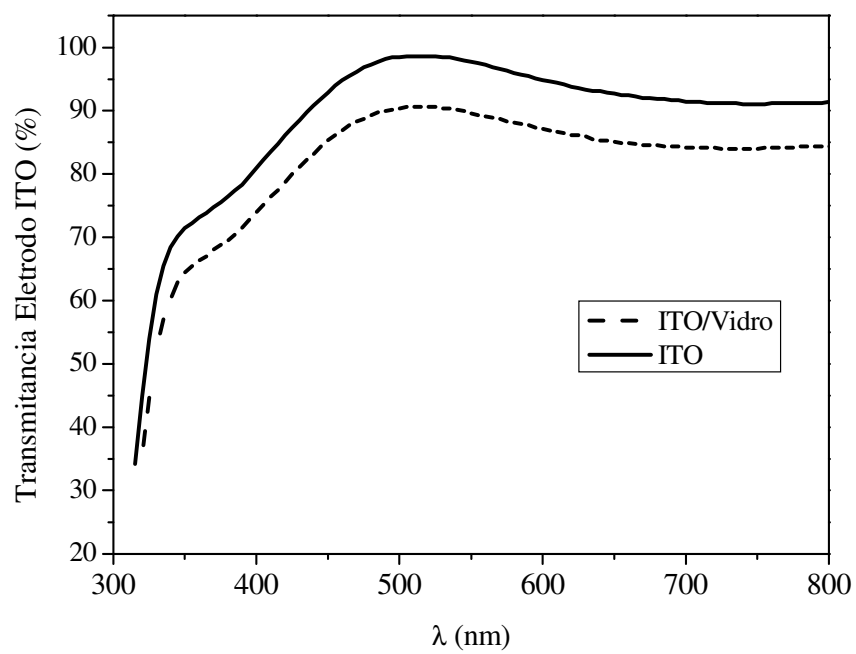

Figura 3.2: Gráfico da transmissão do eletrodo de ITO e do vidro/ITO na região do espectro visível. 
A geometria dos eletrodos de ITO, de grande importância para obter contatos elétricos desprovidos de curto-circuito e delimitar a região ativa do dispositivo, é feita através do procedimento denominado decapagem. Nesse processo, remove-se uma região escolhida da camada de ITO através de um ataque ácido usando suspensão aquosa de pó de zinco e uma solução concentrada de $\mathrm{HCl}(37 \%)$. As etapas de decapagem do ITO estão ilustradas na Figura 3.3. Sobre a lâmina de vidro com uma fina camada de ITO (A) é colocada uma "máscara" de fita adesiva (B) como proteção ao ataque químico. Após a remoção do ITO da região exposta (C), a fita protetora é retirada e as lâminas de ITO com geometrias delimitadas (D) são lavadas individualmente com detergente e água destilada para a remoção de gorduras e resíduos decorrente do processo.

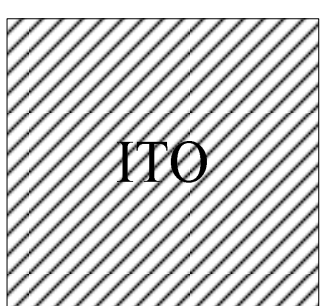

A)

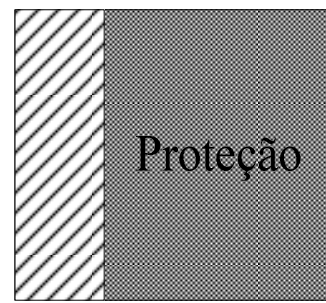

B)

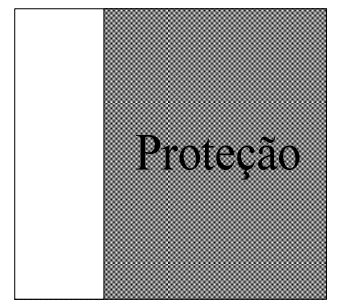

C)

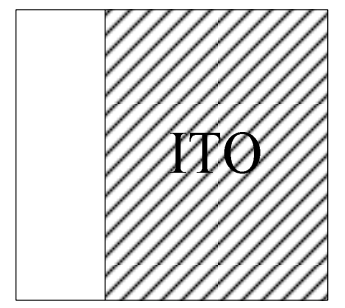

D)

Figura 3.3: Etapas do procedimento adotado para a remoção da camada de ITO da superfície do substrato (Decapagem).

A limpeza e o tratamento da superfície do eletrodo de ITO são fundamentais para fabricação de dispositivos de qualidade. A limpeza elimina as impurezas orgânica ou inorgânica que ocasionam mudanças nas propriedades químicas e/ou físicas da interface eletrodo 1/polímero, comprometendo o funcionamento do dispositivo e seu tempo de vida útil. O tratamento da superfície vidro/ITO foi feito colocando-as sob agitação em uma solução aquosa de Etanolamina ( $20 \%$ em volume) aquecida a $80{ }^{\circ} \mathrm{C}$ por 20 min. Após o enxágüe com água Mili-Q (destilada e deionizada), os substratos são agitados por mais 15 min no ultra-som 
imersos uma solução de água régia $\left(\mathrm{H}_{2} \mathrm{O}: \mathrm{HCl}: \mathrm{HNO}_{3}\right)$ na proporção 20:1:1 em volume e novamente enxaguados com água Mili-Q. Finalmente são levados ao forno e aquecidos a 100 ${ }^{\circ} \mathrm{C}$ por $1 \mathrm{~h}$ para a secagem. Após essas etapas, os substratos estão prontos para a deposição da solução polimérica (camada ativa do dispositivo). Esse tratamento melhora a aderência e a uniformidade do filme polimérico.

\subsubsection{Processamento do filme polimérico}

Os polímeros conjugados da mesma família do poli(fenileno-vinileno) (PPV) utilizados neste trabalho foram o poli[2-metoxi-5-(3'-7'-dimetiltiloxi)-1,4-fenileno vinileno] $(\mathrm{OC} 10-\mathrm{PPV})^{64}, \quad$ o poli[2-metóxi,5-(2'-etil-hexilóxi)-1,4-fenileno vinileno] (MEH-PPV) comprados da Aldrich e um derivado do PPV, com grupos fenis substituídos que formam um copolímero, denominado de Super-Yellow $(\mathrm{SY})^{65}$, comprado da Covion. As estruturas químicas dos polímeros estão mostradas na

Figura 3.4. A vantagem desses polímeros é solubilidade em vários solventes orgânicos (xileno, tolueno, clorofórmio, THF) e a isenção da etapa de conversão térmica. O OC10-PPV e o SY apresentam melhores propriedades de processabilidade e de formação de filmes em comparação ao MEH-PPV.

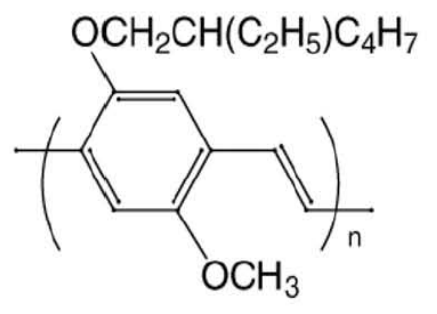

a)

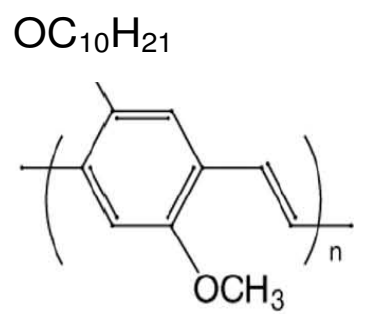

b)

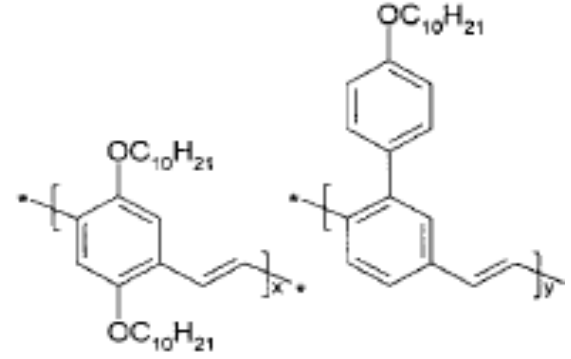

c)

Figura 3.4: Estrutura química dos polímeros utilizados neste trabalho. a) MEHPPV, b) OC10-PPV e c) SY $(x=0,42, y=0,58)$. 
As soluções poliméricas foram obtidas dissolvendo-se uma quantidade do polímero em pó num certo volume do solvente apropriado. Neste trabalho, as soluções utilizadas na preparação dos filmes foram preparadas à concentração de 8 mg.mL-1 em Clorofórmio $\left(\mathrm{CHCl}_{3}\right)$ e filtradas com filtro de porosidade $0,45 \mu \mathrm{m}$. A deposição da solução polimérica sobre o eletrodo de ITO foi realizada pela técnica de deposição drop-casting, que se baseia em espalhar a solução do polímero sobre o substrato e esperar pela evaporação natural de todo solvente. A espessura média dos filmes obtidos foi em torno de $450 \mathrm{~nm}$. Nessa técnica, o controle das condições de umidade e temperatura da sala é determinante para a evaporação uniforme do solvente e, consequentemente, para a boa formação dos filmes. A temperatura da sala foi estabilizada em $20{ }^{\circ} \mathrm{C}$ com 40 e $50 \%$ de umidade relativa. Após a deposição, as amostras contendo filme de polímero foram aquecidas no interior de um forno por $2 \mathrm{~h} \mathrm{a} 70^{\circ} \mathrm{C}$ sob vácuo $\left(10^{-2}\right.$ Torr) para a total evaporação dos solventes. Os espectros de absorção normalizado dos filmes poliméricos são apresentados na Figura 3.5.

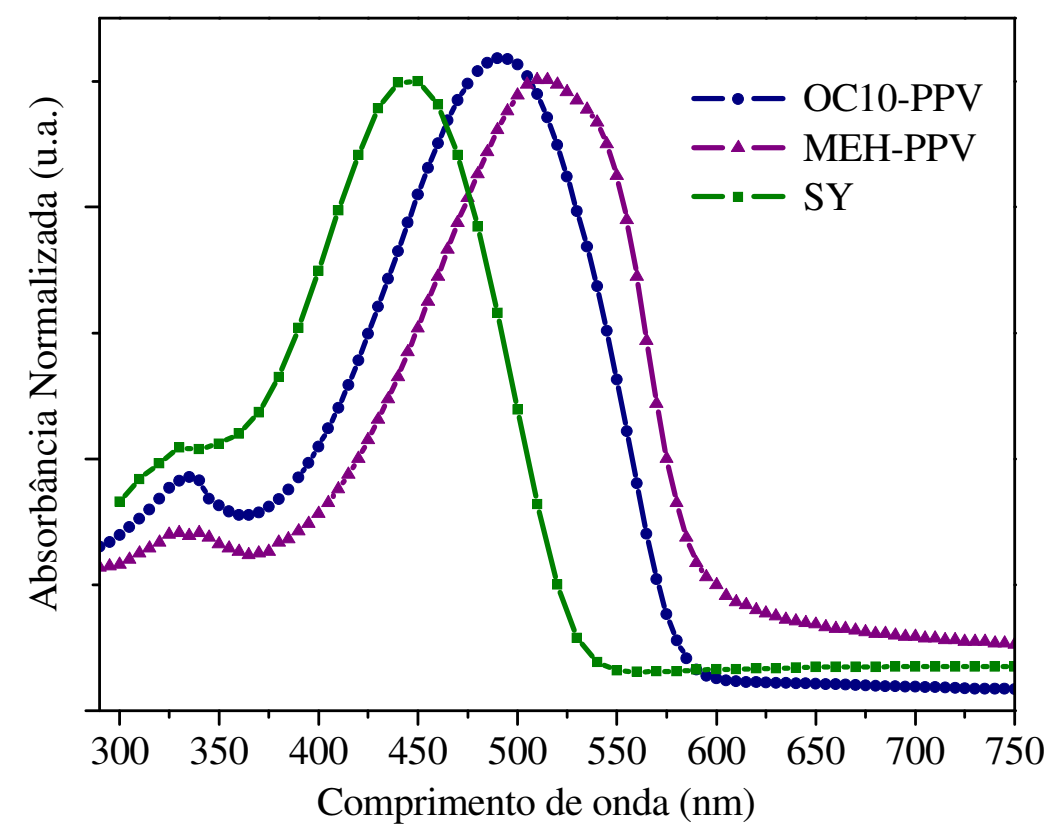

Figura 3.5: Espectro de Absorção dos filmes poliméricos de OC10-PPV, MEHPPV e SY a $300 \mathrm{~K}$. 
A Tabela 3.1 apresenta as propriedades características dos polímeros conjugados estudados a $T=300 \mathrm{~K}$, onde $A b s, P L$ e $E l\left(\lambda_{\max }\right)$ correspondem ao comprimento de onda do pico principal dos espectros de absorção, emissão e eletroluminescência, respectivamente.

Tabela 3.1: Absorção Óptica (Abs), Luminescência (PL) e eletroluminescência (El) dados em comprimento de onda no máximo da banda e Peso molecular, para os polímeros conjugados MEH-PPV, OC10-PPV e SY a T $=300 \mathrm{~K}$.

\begin{tabular}{|c|c|c|c|c|}
\hline $\begin{array}{c}\text { Polimero } \\
(\% \mathrm{~mol})\end{array}$ & $\begin{array}{c}\text { Peso molecular } \\
(\mathrm{g} / \text { mol })\end{array}$ & $\begin{array}{c}\text { Abs. }\left(\lambda_{\max }\right) \\
* \boldsymbol{M}_{W}-* \boldsymbol{M}_{\boldsymbol{n}}\end{array}$ & $\boldsymbol{P L}\left(\lambda_{\max }\right)$ & $\boldsymbol{E l}\left(\lambda_{\max }\right)$ \\
\hline MEH-PPV & $5,0 \times 10^{5}-1,5 \times 10^{5}$ & 500 & $(\mathbf{n m})$ & $(\mathbf{n m})$ \\
\hline OC10-PPV & $1,2 \times 10^{6}-1,7 \times 10^{5}$ & 490 & 610 & 584 \\
\hline SY & $1,4 \times 10^{6}-3,4 \times 10^{5}$ & 445 & 535 & 567 \\
\hline
\end{tabular}

* $M_{w}$ e $M_{n}$ representam a média molar de massa e numérica, respectivamente.

\subsubsection{Eletrodos metálicos (eletrodo 2):}

Os eletrodos metálicos foram depositados por evaporação térmica em alto vácuo $(<$ $10^{-6}$ mbar) sobre a camada polimérica. A geometria do eletrodo foi obtida utilizando máscaras mecânicas sobre o dispositivo durante a evaporação. Os eletrodos metalizados possuem uma área útil entre 20 e $40 \mathrm{~mm}^{2}$. Um dos objetivos deste trabalho foi estudar o efeito dos eletrodos 2 no comportamento dos dispositivos, para isso diferentes metais foram metalizados lado a lado sobre o filme polimérico como ilustrado pela Figura 3.6. Os metais utilizados como eletrodo e suas respectivas funções trabalho foram: $A l\left(\phi_{A l} \approx 4,1-4,4 \mathrm{eV}\right), C u\left(\phi_{C u} \approx 4,6-4,8\right.$ $e V)$ e $M g\left(\phi_{M g} \approx 3,6-3,7 \mathrm{eV}\right)$. Esses são valores tabelados e deve ser tomados como aproximados, o que não prejudica a análise que leva em consideração de que $\phi_{C u}>\phi_{A l}>\phi_{M g}$. 
A espessura de metalização variou para cada metal de maneira a produzir eletrodos semitransparentes que permitissem a passagem da luz incidente.
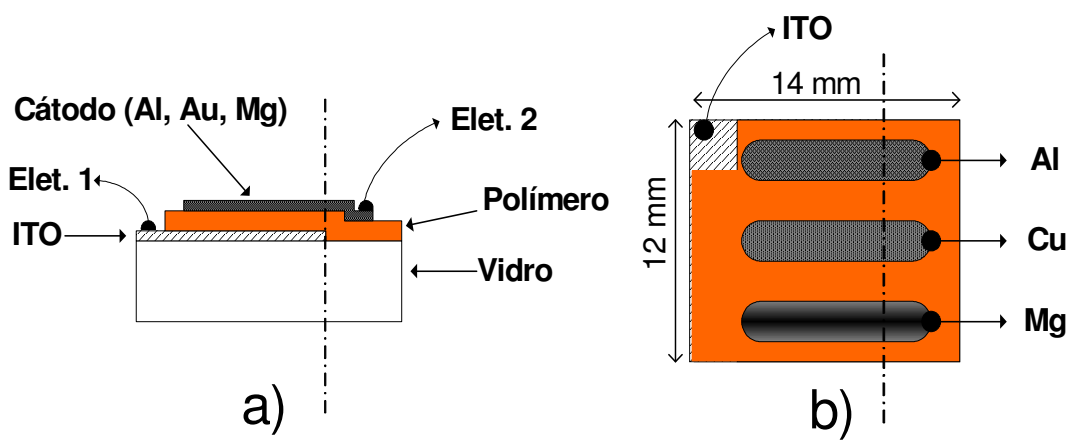

Figura 3.6: a) Representação esquemática da vista lateral do dispositivo polimérico fabricado para este trabalho; b) Vista superior dos eletrodos de Al, Mg e Cu metalizados sobre o polímero.

O Magnésio apresenta alta reatividade sendo sensível ao oxigênio e à presença de água. Assim, evaporou-se uma fina camada protetora de $A l$ sobre o $M g$, cuja espessura não comprometesse a semi-transparência do eletrodo. Ao final, as espessuras dos eletrodos metalizados foram: $A l=45 \mathrm{~nm}, C u=47 \mathrm{~nm}$ e $M g / A l=30 / 20 \mathrm{~nm}$. A Figura 3.7 mostra a transmitância dos eletrodos na região do visível. Durante todas as etapas de fabricação e caracterização procurou-se não expor os dispositivos à atmosfera ambiente e à luz para evitar contaminações e a degradação do filme polimérico. As amostras foram armazenadas em dessecadores de vidro, com sílica gel, no escuro e sob vácuo. 


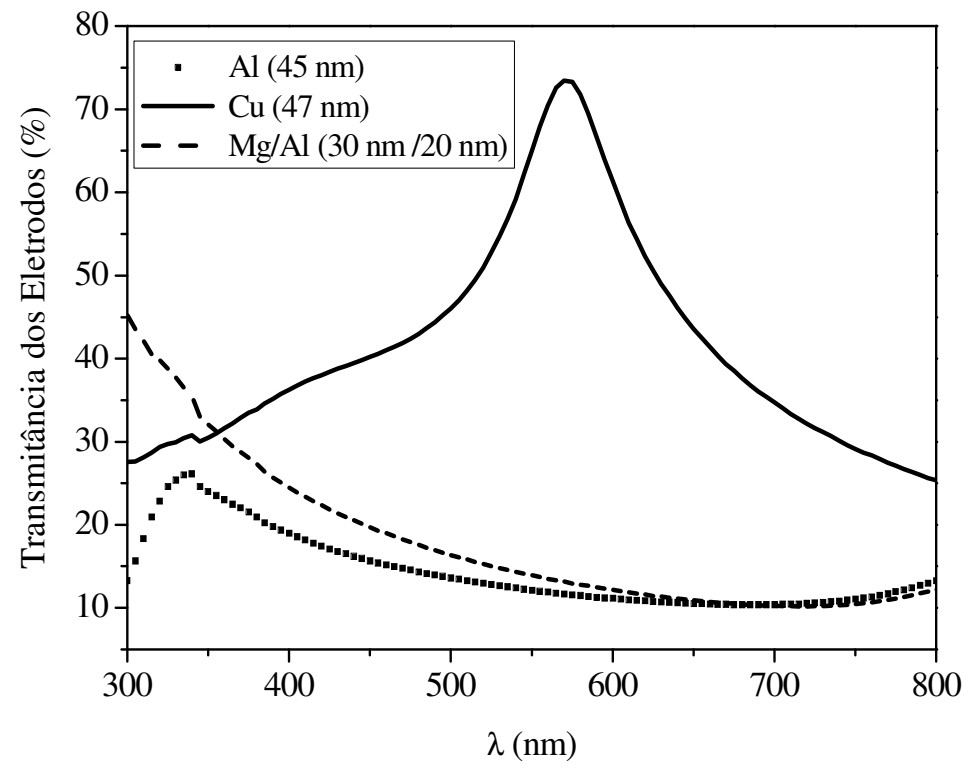

Figura 3.7: Gráfico da transmitância dos eletrodos de $\mathrm{Al}$, $\mathrm{Cu}$ e $\mathrm{Mg} / \mathrm{Al}$ na região do visível.

\subsection{TÉCNICAS DE CARACTERIZAÇÃO:}

Nessa Seção estão descritas as técnicas utilizadas na caracterização óptica dos materiais (absorção Óptica (UV-Vis) e Fluorescência Estacionária) e dispositivos bem como o estudo de suas propriedades: Espectroscopia de Fotocorrente no estado Estacionário e Condutividade de (curvas $I-V$ ).

\subsubsection{Absorção Óptica (UV-Vis):}

A técnica de absorção óptica na região do visível foi utilizada para obter os espectros de absorção dos filmes poliméricos e a transmissão dos eletrodos metálicos. Utilizou-se um espectrofotômetro Hitachi, modelo U-2001, que permite realizar medidas de absorção por transmitância. A absorção óptica de um material é a habilidade com que esse é capaz de absorver a luz nele incidente sendo a intensidade específica para cada comprimento de onda. 
Geralmente os espectrômetros que operam na região UV-VIS aferem a intensidade de absorção a partir da transmitância, definida pela razão:

$$
I(\lambda) / I_{0}(\lambda)
$$

onde $I_{0}$ e $I$ são as intensidades incidente e após atravessar a amostra em função do comprimento de onda $(\lambda)$ da radiação. Há uma relação entre a transmitância e a concentração da amostra definida através da Lei de Beer-Lambert:

$$
I_{0}(\lambda)=I(\lambda) e^{l c k(\lambda)}=I(\lambda) 10^{l c \alpha(\lambda)}
$$

onde: $l$ (unidade metros no SI) é a distância percorrida pela radiação dentro do material; $c$ (unidade $\mathrm{mol} \mathrm{m}^{-3}$ ou $\mathrm{mmol} L^{-1}$ ) é a concentração; $\kappa(\lambda)$ (unidade $m^{2} \mathrm{~mol}^{-1}$ ) é o coeficiente neperiano de absorção molar; $\alpha(\lambda)$ (unidade $m^{2} m o l^{-1}$ ) é o coeficiente de extinção ou de absorção. A grandeza que se mede experimentalmente é a transmitância $T$ a razão entre a intensidade incidente e a transmitida, dada pela Eq. 3.3:

$$
T=I(\lambda) / I_{0}(\lambda)
$$

Em relação a essa grandeza, a lei de Lambert-Beer assume a forma:

$$
T=10^{-l c \alpha(\lambda)}
$$

A absorbância $A$ é definida como uma grandeza física adimensional, dada por:

$$
A=-\log _{10} T
$$

Assim, em relação à absorbância (Eq. 3.5), a lei de Lambert-Beer é escrita como:

$$
A=-\log _{10} T=\log _{10}(1 / T)=\log _{10} 10^{\alpha l c}=\alpha(\lambda) l c
$$


Esta grandeza física adimensional $A$ é justamente o resultado que se obtém ao medir a absorção do material no espectrofotômetro.

\subsubsection{Fluorescência Estacionária:}

Utilizando-se o espectrofluorímetro modelo Spectrofluorophotometer Shimadzu RF5301 PC equipado com uma lâmpada de Xe foi possível medir o espectro de emissão (PL) dos filmes utilizados como camadas ativas nos dispositivos OLEDs. O feixe de excitação de comprimento de onda previamente selecionado incide sobre a superfície do filme e a intensidade da luz emitida pela amostra (luminescência) em função do comprimento de onda é coletada por um detector. Nesse equipamento, o ângulo entre o feixe de excitação e o detector pode variar de 0 a 90 graus. Além disso, a amostra pode ser posicionada de forma que a emissão seja coletada na mesma face de incidência (front face) ou na face oposta. O espectro de fotoluminescência dos filmes foi obtido posicionando o feixe incidente a 45 graus com o detector em condições ambientes de pressão e temperatura.

\subsubsection{Espectroscopia de Fotocorrente no estado Estacionário:}

O espectro de fotocorrente no estado estacionário mede a corrente de cargas fotogeradas no polímero (fotocorrente) para cada componente espectral de luz que incide de modo contínuo (estado estacionário) sobre a face do dispositivo. O sistema experimental utilizado para medir o espectro de fotocorrente dos dispositivos poliméricos estudados neste trabalho está ilustrado na Figura 3.8. A luz proveniente da lâmpada de Xenônio de 450 W (Oriel) é separada em componentes espectrais de aproximadamente $4 \mathrm{~nm}$ de largura de banda usando um monocromador de 0,25 m de distância focal antes de incidir na amostra. A luz proveniente do monocromador é focalizada por um sistema de lentes sobre uma região superficial da amostra. A corrente foto-gerada no circuito é registrada pelo amperímetro do 
eletrômetro (modelo Keithley 2400) em função do comprimento de onda da luz incidente (Figura 3.8-b). A varredura do comprimento de onda da luz incidente é automatizada e pode ser feita continuamente dentro de espectro visível e parte do ultravioleta a velocidades entre 24 e $240 \mathrm{~nm} / \mathrm{min}$, possibilitando ajustar velocidade da varredura com o tempo de reposta da fotocorrente dos dispositivos.

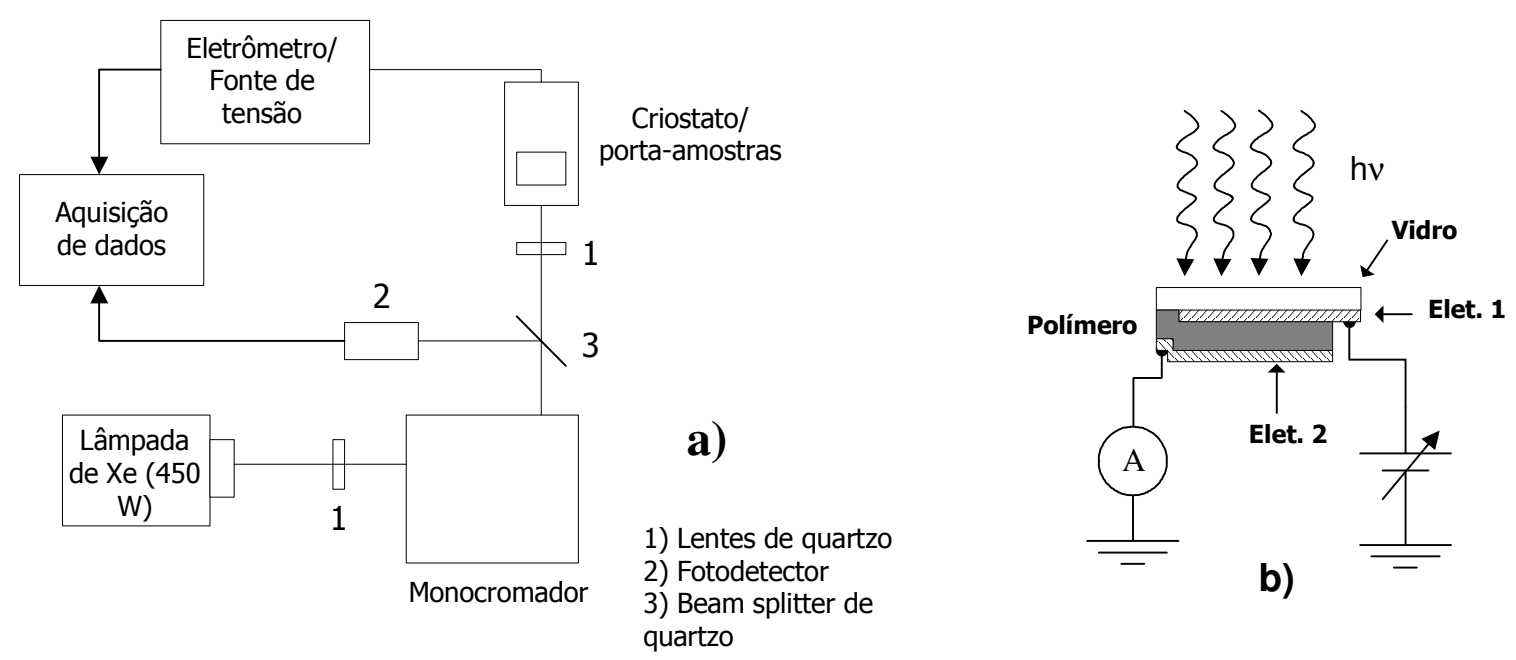

Figura 3.8: a) Esquema da montagem experimental utilizada nos experimentos de fotocorrente. b) Representação de um dispositivo polimérico durante o experimento, com incidência de luz através de um dos eletrodos.

Para cada medida, uma pequena fração da luz é desviada por um separador de feixe luminoso de quartzo para um fotodetector para registrar o espectro da lâmpada e posteriormente normalizar com os espectros de foto-corrente. A Figura 3.9-a mostra a corrente do fotodetector e a intensidade da lâmpada para o intervalo de $350 \mathrm{~nm}$ a $800 \mathrm{~nm}$. Os perfis da componente espectral da luz, cuja largura de banda é bastante estreita (entre 3 e 4 nm de largura a meia altura). A radiância espectral (potência emitida em função do comprimento de onda) da lâmpada e o fluxo radiante (definido como a taxa de transferência de energia radiante por unidade de tempo) de cada componente são apresentados na Figura 3.9-b. O fluxo radiante varia de 40 a $250 \mu \mathrm{W}$ para o intervalo considerado. Estas informações 
foram utilizadas na correção e normalização dos espectros de fotocorrente e para os cálculos da eficiência interna do dispositivo.
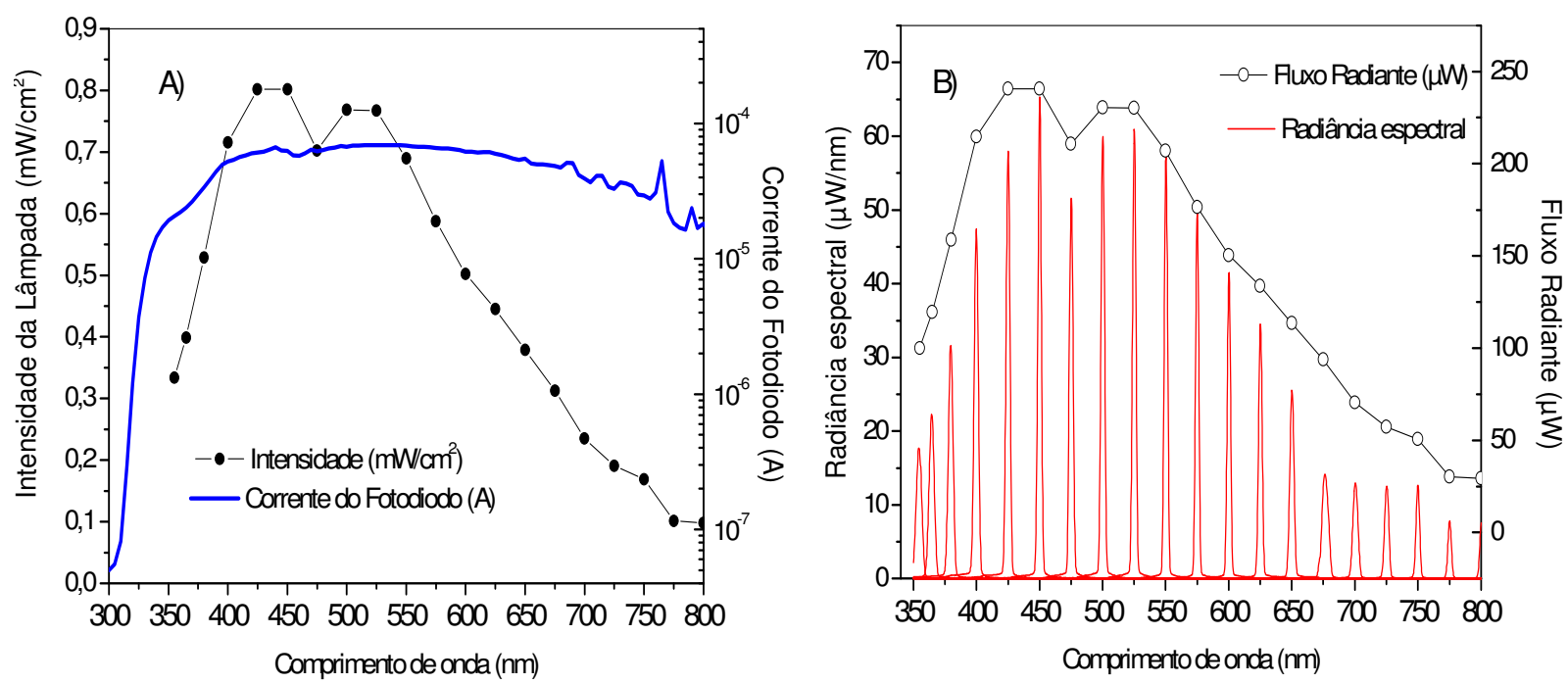

Figura 3.9: a) Corrente do fotodiodo e a intensidade da lâmpada em função do comprimento de onda selecionado pelo monocromador, curva de resposta do fotodiodo. b) Radiância espectral e o fluxo radiante das componentes espectrais da lâmpada selecionadas pelo monocromador.

As tensões nos eletrodos do dispositivo foram aplicadas pela fonte de tensão (Keithley 2400) durante a medida da fotocorrente, permitindo observar a dependência dos espectros de foto-corrente com o campo aplicado. Todos os equipamentos utilizados nos experimentos (eletrômetro, fontes de tensão e monocromador) foram controlados e monitorados através de um computador por programas desenvolvidos pelo pós-doutorando Lucas F. Santos.

\subsubsection{Condutividade de (curvas I-V):}

A caracterização elétrica básica dos dispositivos fabricados é realizada através de medidas de corrente-tensão $(I-V)$ em regime de corrente contínua $(d c)$. Nessas medidas, a condutividade dc do material é obtida ao registra-se a corrente que flui entre os eletrodos através do filme em função da tensão aplicada pelo eletrômetro Keithley 617 ou fontes de tensão/corrente (modelos Keithley 2400). O estudo do comportamento fotocondutivo dos 
dispositivos foi realizado medindo-se as curvas características $I-V$ do dispositivo em função dos comprimentos de onda incidente através dos eletrodos, utilizando a configuração ilustrada pela Figura 3.8.

Outra caracterização bastante interessante dos dispositivos em funcionamento é a curva da intensidade luminosa emitida pelo dispositivo (eletroluminescência) em função da tensão aplicada $(I-V)$ em regime de corrente contínua $(d c)$. Utilizou-se um eletrômetro Keithley 2400 para aplicar a tensão e medir a corrente do dispositivo, enquanto o Keithley 617 conectado ao fotodiodo calibrado registra a intensidade luminosa produzida pelo dispositivo na forma de corrente.

As caracterizações óptica e elétrica dos dispositivos foram realizadas no laboratório de dispositivos poliméricos emissores de luz e fotovoltaicos do Grupo de Polímero Bernhard Gross. 


\section{Resultados Experimentais}

Este capítulo apresenta medidas de corrente versus tensão (I-V) e de espectros de fotocorrente, em diodos com estrutura tipo ITO/polímero/metal, realizadas no escuro e sob iluminação com luz monocromática de diferentes comprimentos de onda. Os polímeros utilizados foram de SY, OC10-PPV e MEH-PPV com eletrodos semitransparentes de diferentes metais: alumínio ( $\mathrm{Al})$, magnésio $(\mathrm{Mg})$ e cobre $(\mathrm{Cu})$, com o intuito de verificar o papel da função trabalho do metal sobre as características elétricas do dispositivo quando estes atuam como cátodo. Os experimentos foram feitos com luz incidindo tanto através ITO quanto através dos metais, para diferentes valores de tensões aplicadas.

\subsection{RESULTADOS EXPERIMENTAIS DA FOTOCONDUTIVIDADE DC (CURVAS I-V) DOS DISPOSITIVOS:}

No estudo do comportamento fotocondutivo dos dispositivos (ITO/polímero/metal) realizaram-se medidas de corrente-tensão ( $I-V)$ no escuro e sob incidência de luz com diferentes comprimentos de onda. Os polímeros luminescentes utilizados foram dois derivados do poli( $p$-fenileno vinileno) (PPV): o OC10-PPV e o MEH-PPV. Os comprimentos de onda para irradiação foram selecionados de acordo com o espectro de absorção do material escolhendo-se comprimentos que são fortemente absorvidos e pouco absorvidos pelo polímero. O intuito foi investigar os processos de condução de portadores (buracos e elétrons) fotogerados através da amostra em duas situações distintas: somente próximos à interface iluminada, ou em todo o volume do filme polimérico. As curvas $I-V$ foram obtidas com incidência da luz tanto através do ânodo (ITO) quanto do cátodo de $\mathrm{Al}, \mathrm{Cu}$ e $\mathrm{Mg}$. 


\subsubsection{Incidência de luz através do ITO (curvas I-V).}

A Figura 4.1 mostra os gráficos em escala mono-logarítmica obtidos das curvas $I-V$ de dispositivos com filme de MEH-PPV $(l=450 \mathrm{~nm})$ e de OC10-PPV $(l=480 \mathrm{~nm})$, ambos com eletrodos de $\mathrm{Al}, \mathrm{Cu}$ e $\mathrm{Mg}$ semitransparente, sendo $\phi_{C u}(\sim 4,7 \mathrm{eV})>\phi_{A l}(\sim 4,2 \mathrm{eV})>\phi_{M g}(\sim 3,7$ eV). As medidas foram feitas no escuro e sob iluminação com comprimento de onda de 500 $\mathrm{nm}\left(\right.$ de $\left.0,75 \mathrm{~mW} \cdot \mathrm{cm}^{-2}\right)$ através dos eletrodos de ITO. O valor da função trabalho do ITO é próximo ao do cobre, com isso, espera-se que devido à simetria da estrutura eletrônica dos dispositivos ITO/polímero/Cu, as curvas direta e reversa também sejam simétricas, não havendo, portanto, retificação. No modo direto (tensões positivas no ITO), e na ausência de iluminação, foi observado que o diodo com o eletrodo de $\mathrm{Mg}$, de menor função trabalho, apresentou valores de corrente superiores, seguido pelo de $\mathrm{Al}$ e por último o de $\mathrm{Cu}$. Esse fenômeno se repetiu para todas as outras medidas feitas em condições semelhantes. No modo reverso, entretanto, os valores de corrente foram muito próximos, não sendo significativo o efeito do eletrodo metálico. Apesar de não ser objeto de estudo nesse trabalho, é bom registrar o baixo fator de retificação desses diodos, com e sem iluminação, o que se deve à simplicidade de sua estrutura. Observou-se que houve um aumento da corrente (em relação à medida no escuro) de aproximadamente duas ordens de grandeza no modo direto e uma ordem no modo reverso, quando os dispositivos de MEH-PPV (Figura 4.1-b). Para os dispositivos com OC10-PPV (Figura 4.1-d), os aumentos das curvas $I$ - $V$ iluminadas também ocorreram, mas o efeito foi menos pronunciado. 

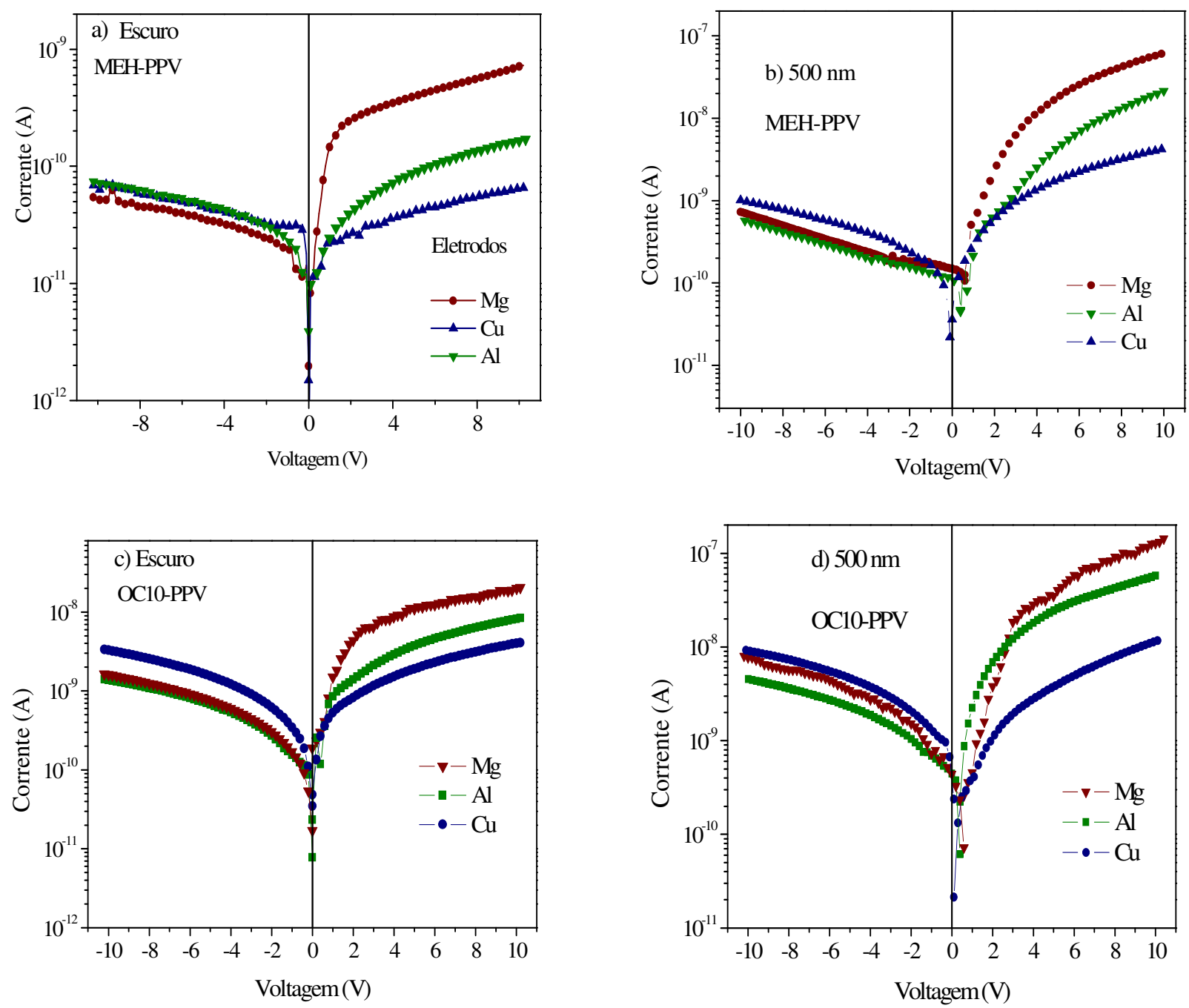

Figura 4.1: Curvas experimentais de corrente vs tensão aplicada (I-V) do dispositivo ITO/polímeros/eletrodos à $295 \mathrm{~K}$. Os gráficos superiores são as curvas para o dispositivo com MEH-PPV: a) no escuro e b) sob iluminação (500 $\mathrm{nm}$ ) e os gráficos inferiores são curvas do dispositivo com OC10-PPV, c) no escuro e d) sob iluminação (500 nm).

No modo direto o ITO injeta buracos, e sua função trabalho é próximo ao nível HOMO, formando uma pequena barreira para a injeção. Na outra interface (polímero/catodo) o problema é diferente, pois no contato existe uma barreira de altura $(\Delta)$ que se forma para a entrada dos elétrons. Quanto menor a função trabalho do metal ( $\left.\phi_{\mathrm{M}}\right)$, maior será a injeção de elétrons no polímero quando o dispositivo opera em modo direto. Portanto, a contribuição dos elétrons à corrente de condução é maior para o dispositivo com $\mathrm{Mg}$ e menor para o com $\mathrm{Cu}$. 
Em geral, a barreira numa interface metal/semicondutor é dada por $\Delta=\phi_{\mathrm{M}}-\phi_{\mathrm{S}}$ ( $\phi_{\mathrm{S}}$ é a função trabalho do semicondutor), mas é importante lembrar que o campo externo contribui com a diminuição dessa barreira, assim como o efeito da carga imagem, e nesse caso a barreira é dada por $\Delta^{\prime}=\phi_{\mathrm{M}}-\phi_{\mathrm{S}}-q E x-e^{2} / 16 \pi \varepsilon x$, onde $E$ é o campo externo na interface, $x$ a distância entre o elétron injetado e sua carga imagem e $q$ a carga eletrônica.

No modo reverso (tensões negativas no ITO), a situação se inverte, a barreira de potencial do ITO para injeção de elétrons é muito grande e a corrente é controlada pela injeção de buracos pelo metal. Nesse caso, era de se esperar que a corrente reversa para o $\mathrm{Cu}$ fosse maior (devido à maior função trabalho) que para o Mg. Entretanto, isso não ocorreu, o que indica que outros efeitos devem participar desse processo de injeção, como por exemplo, a existência de estados localizados na superfície do polímero, bem próxima da interface.

O aumento da corrente nas curvas $I-V$ dos dispositivos ao incidir luz através dos eletrodos ITO, tanto no modo reverso quanto no modo direto para ambos os polímeros, deve estar relacionados à diminuição da resistência do polímero devido ao aumento da densidade de portadores de cargas livres fotogerados (elétrons e buracos) no volume (fotocondutividade), visto que esse comprimento de onda incidente $(500 \mathrm{~nm})$ é bem absorvido por ambos os polímeros. As cargas fotos-geradas são susceptíveis ao campo elétrico e, portanto, participam do processo de transporte do dispositivo, contribuindo para o aumento da corrente observado nos gráficos da Figura 4.1-b e Figura 4.1-d. Os valores de tensão em circuito aberto $\left(\mathrm{V}_{\mathrm{OC}}\right)$ obtidos experimentalmente para cada eletrodo foram: $0,0 \mathrm{~V}$ para o $\mathrm{Cu}$, 0,5 V para o $\mathrm{Al}$ e 0,7 V para o Mg. Estes valores podem ser comparados com o potencial de built-in $\left(V_{B}\right)$, sendo que $V_{B}=-V_{o c}=\left(\phi_{\text {cátodo }}-\phi_{\text {ânodo }}\right) / q$. Sendo a função trabalho do ITO e do Cu muito próximas $(4,7 \mathrm{eV})$, obtém-se $V_{B} \approx 0,0 \mathrm{~V}$. Para o $\mathrm{Al}$, cuja função trabalho em torno de 4,2 eV, o $V_{B}$ é em torno de $-0,5 \mathrm{~V}$ e para o eletrodo de $\mathrm{Mg}\left(\phi_{M g}=3,7 \mathrm{eV}\right) V_{B}$ é em torno de 1,0 V. Entretanto, sabe-se que nas condições em que os dispositivos foram fabricados, não 
pode-se ignorar a presença de contaminação dos eletrodos e das interfaces, o que deve modificar o valor da função trabalho. Mas, pelos resultados obtidos, pode-se afirmar que sendo o potencial de built-in muito próximo a diferença entre a função trabalho dos eletrodos, o efeito de eventuais contaminações não prejudicaram as propriedades fundamentais do dispositivo.

Para verificar a dependência da fotocondutividade com a energia da radiação incidiuse sobre um mesmo eletrodo diferentes comprimentos de onda da luz, variando de $650 \mathrm{~nm} \mathrm{a}$ 350nm. A Figura 4.2 mostra a dependência das curvas $I-V$ do dispositivo ITO/MEHPPV/eletrodos, em escala mono-logarítmica, com o comprimento de onda de luz incidente através do ITO. Para análise comparativa, são apresentadas também as curvas $I-V$ na ausência de iluminação. No escuro e sob incidência de luz em 650nm, todos os dispositivos apresentaram comportamentos similares, ou então, não muitas ordens de grandeza maior aos observados no modo reverso, isto é, o fator de retificação não foi muito alto. Para o eletrodo de $\mathrm{Cu}$, isto já era esperado. As correntes dos dispositivos, no escuro, variaram entre $10^{-11}$ e $10^{-}$ ${ }^{10}$ A para tensões entre -15 e $15 \mathrm{~V}$, evidenciando baixas correntes de injeção nas interfaces e baixa densidade de portadores livres no interior do dispositivo. 

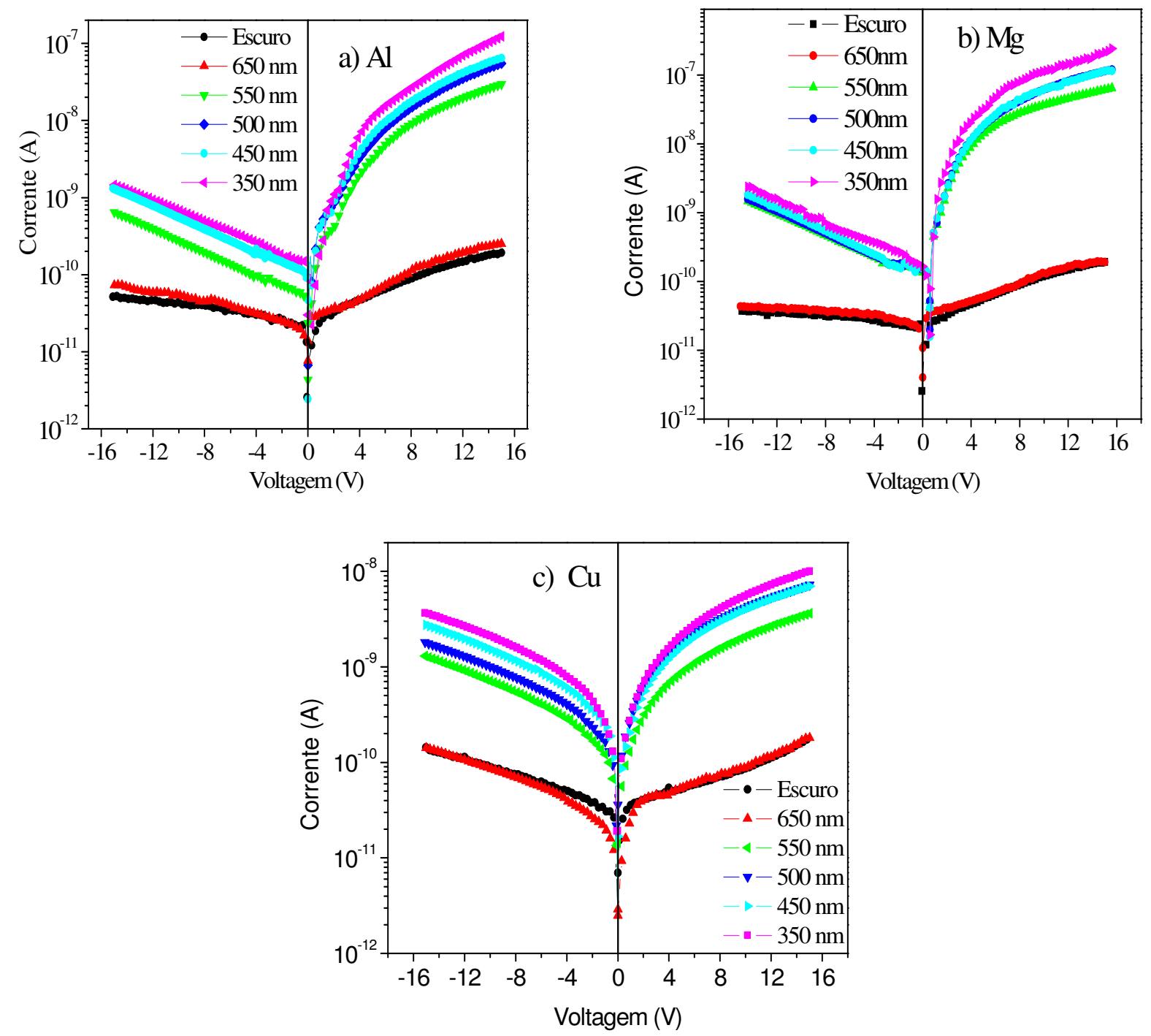

Figura 4.2: Dependência das curvas I-V dos dispositivos de ITO/MEHPPV/eletrodos com diferentes comprimentos de onda de luz incidente através do ITO para: a) eletrodo de Al; b) eletrodo de $\mathrm{Mg} \mathrm{e} \mathrm{c}$ ) eletrodo de $\mathrm{Cu}$.

Com a incidência de luz em comprimentos de onda de maior absorção do polímero (550 a $450 \mathrm{~nm}$ ) e com altas energias (400 e $350 \mathrm{~nm}$ ), o aumento na corrente no modo direto é observado para todos os eletrodos, principalmente para os de baixa função trabalho (Al, $\mathrm{Mg}$ ), os quais tiveram um aumento de 3 ordens de grandeza em relação à corrente no escuro. Para esses eletrodos, os valores de corrente no modo reverso para comprimentos de onda incidentes entre $500 \mathrm{~nm}$ e $350 \mathrm{~nm}$ tiveram um aumento de uma ordem de grandeza na corrente em relação ao escuro. Conseqüentemente, o fator de retificação (razão entre a corrente no 
modo direto e no modo reverso) destes dispositivos chegou a 100 sob tensão de 15 V. No entanto, o eletrodo de maior função trabalho $(\mathrm{Cu})$ apresentou valores totais de corrente no modo direto cerca de 10 vezes inferiores aos observados nos eletrodos de $\mathrm{Al}$ e $\mathrm{Mg}$. Os valores das tensões de circuito aberto $\left(V_{o c}\right)$ para cada tipo eletrodo quando iluminados com diferentes comprimentos de onda foram semelhantes aos encontrados nas curvas da Figura 4.1-b, exceto em $650 \mathrm{~nm}$, onde não foi observada tensão de circuito aberto.

Pode-se, em primeira aproximação, usar o esquema mostrado na Figura 4.3 para uma real ilustração da deposição de portadores gerados pela absorção de luz, e os sentidos de deslocamento dos portadores gerados em conseqüência do campo elétrico aplicado entre o ITO e o eletrodo metálico. Nesse esquema, o campo elétrico aplicado é uniforme ao longo do dispositivo, e o campo oriundo de efeitos de cargas espaciais (no volume), ou de depleção de bandas nas interfaces são considerados desprezíveis. A densidade de portadores gerados depende do comprimento de onda da luz incidente. É sabido de antemão que para comprimentos de onda muito maior que o equivalente da energia do gap óptico (ou eletrônico) não há geração de portadores; resultado registrado na curva de absorção do polímero, região em que o material é transparente. Será visto também, que para energias próximas ao gap há uma forte contribuição da fotocondutividade extrínseca, nesse caso devido a espécies excitônicas cuja energia entre seus dois níveis é ligeiramente menor do que a transição HOMO-LUMO. Essa geração independe da natureza do eletrodo metálico.

Para comprimentos de onda mais fortemente absorvidos pelo polímero (550 a 450nm), a profundidade de penetração da luz diminui consideravelmente, o que resulta em uma maior densidade de portadores fotogerados na região próxima à superfície de incidência da luz, como ilustrado na Figura 4.3-a. Para comprimentos de onda entre 350 a 400 nm, região de baixa absorção, a geração de portadores é praticamente uniforme ao longo do dispositivo (Figura 4.3-b), devido à alta penetração da luz, e a geração de portadores é dominada pela 
fotocondutividade intrínseca, devido à transição HOMO-LUMO. Como será discutido mais adiante, a geração intrínseca tem eficiência muito superior à extrínseca, o que explica os maiores valores de corrente em relação aos demais comprimentos incidentes.
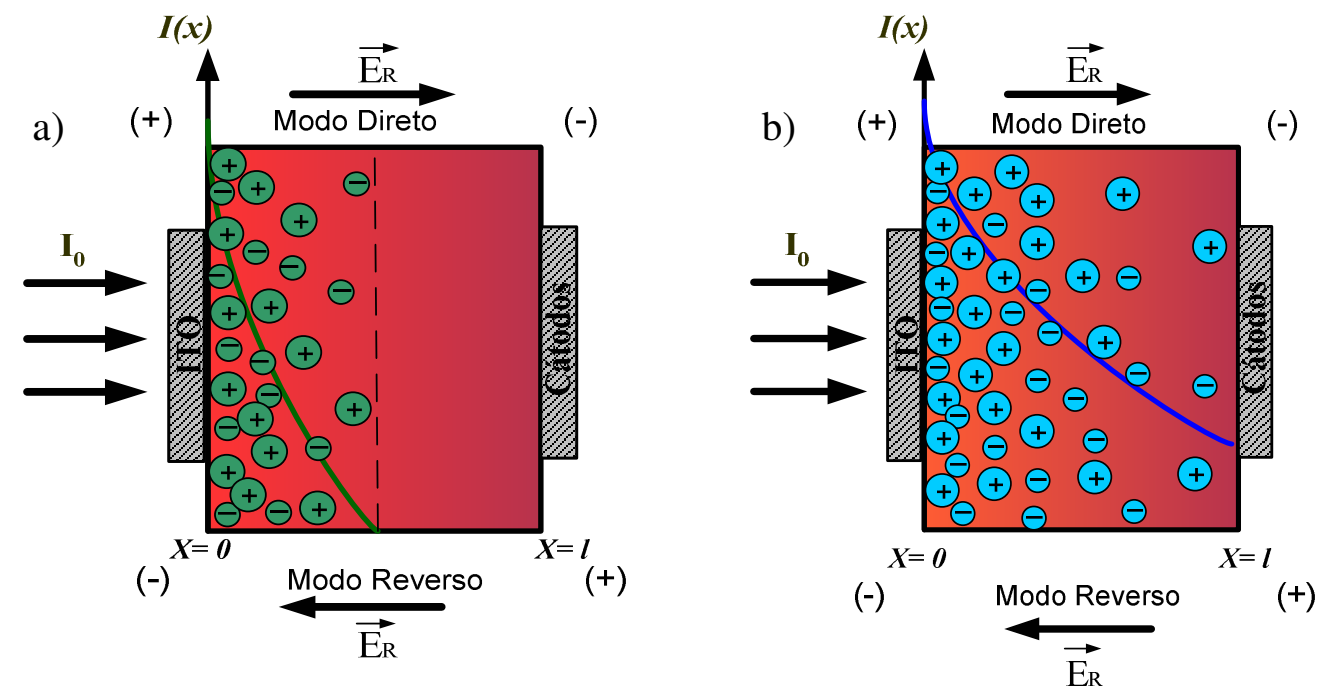

Figura 4.3: Ilustração do dispositivo sob incidência de luz através do ITO: a) em comprimentos de onda bem absorvidos pelo polímero (espessura $x=\emptyset$ ), e b) menos absorvidos e mais energéticos. Em detalhes são mostrados os sentidos do campo elétrico resultante $\left(E_{R}\right)$ no modo direto e reverso, e o perfil de absorção da luz e da foto-geração de portadores (buracos $\odot$ e elétrons $\Theta$ ) na região iluminada.

Quando o dispositivo com eletrodos de $\mathrm{Mg}$ e $\mathrm{Al}$ está polarizado no modo direto, os buracos fotogerados próximos ao ITO são conduzidos pelo campo elétrico resultante em direção ao eletrodo oposto. Este deslocamento de cargas, em princípio muito superior ao proveniente da corrente de injeção de elétrons pelos cátodos, dá origem ao grande acréscimo corrente observado no modo direto. No modo reverso, os elétrons fotogerados próximos ao ITO são conduzidos em direção ao eletrodo oposto (cátodo). Devido à sua baixa mobilidade, os elétrons contribuem muito pouco para a corrente total e por esse motivo a corrente no modo reverso é menor do que no modo direto, onde a contribuição dos buracos é dominante devido à sua superior mobilidade. Porém, apesar da maior mobilidade dos buracos fotogerados próximos ao eletrodo de polaridade negativa, pouca contribuição efetiva esses 
dão à corrente, devido ao seu curto deslocamento espacial que é bem menor do que a espessura da amostra. Portanto, as curvas de corrente elétrica observadas na Figura 4.2 devem ser compreendidas levando-se em consideração a competição entre a mobilidade dos portadores, a região onde eles são gerados e o comprimento do percurso até atingirem o eletrodo para onde são atraídos. Desse modo, pode-se entender as variações de correntes no escuro e sob iluminação nos modos direto e reverso para os dispositivos com $\mathrm{Al}, \mathrm{Mg}$ e $\mathrm{Cu}$.

\subsubsection{Incidência de luz através dos METAIS (curvas I-V).}

As hipóteses levantadas no item anterior também explicam, qualitativamente o comportamento dos dispositivos quando a iluminação é dada através dos eletrodos metálicos semitransparentes. A Figura 4.4 mostra as curvas $I$ - $V$ (mono-logarítmica) em função do comprimento de onda de excitação, para iluminação através dos eletrodos metálicos. 

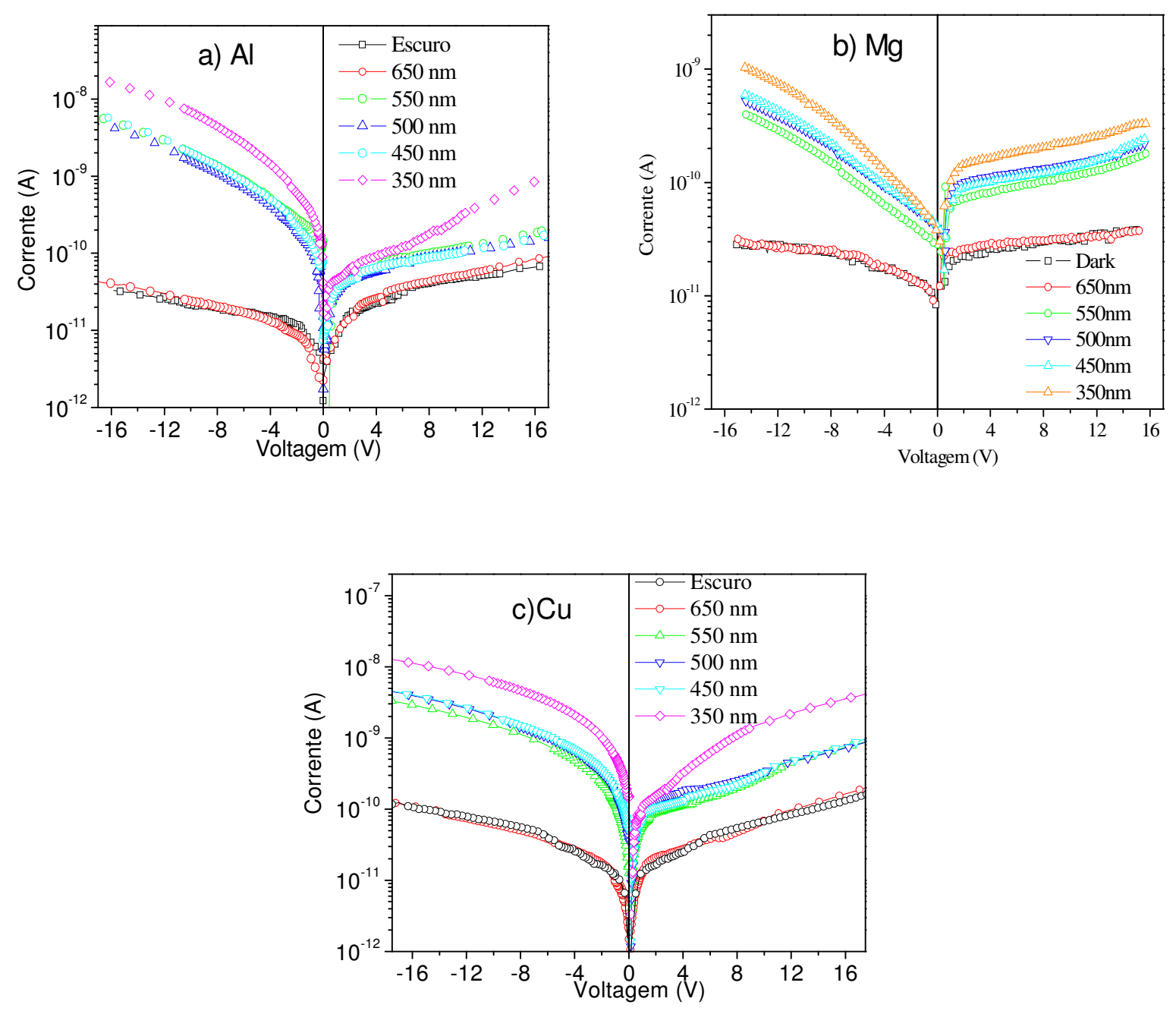

Figura 4.4: Dependência das curvas I-V dos dispositivos de ITO/MEHPPV/eletrodos com os diferentes comprimentos de onda da luz incidente através: a) do eletrodo de $\mathrm{Al}$; b) eletrodo de $\mathrm{Mg}$ e do c) eletrodo de $\mathrm{Cu}$.

Com incidência de luz em $650 \mathrm{~nm}$, os comportamentos das curvas $I$ - $V$ dos dispositivos foram semelhantes aos obtidos no escuro, assim como observado anteriormente. Entretanto, sob incidência de luz bem absorvida pelo polímero $(550,500$ e $450 \mathrm{~nm}$ ) e altamente energética (350 e $400 \mathrm{~nm}$ ) observou-se que as correntes no modo reverso foram superiores às do modo direto, ocorrendo inversão no fator de retificação, cujos valores foram inferiores aos obtidos para incidência de luz através do ITO. Para explicar estes comportamentos, é necessário levar em consideração o sentido do campo elétrico resultante e a região de maior densidade de portadores fotogerados, como ilustrado pela Figura 4.5. Nesta configuração, as 
maiores densidades de portadores fotogerados estão na interface dos eletrodos iluminados e a penetração da luz pelo material depende do seu comprimento de onda.

a)

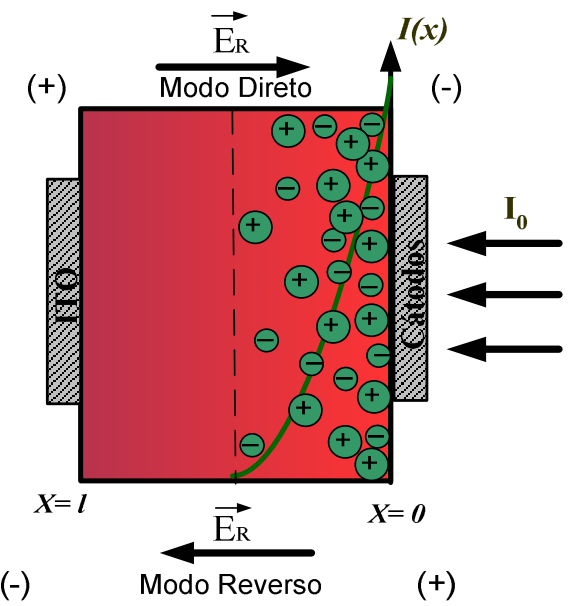

b)

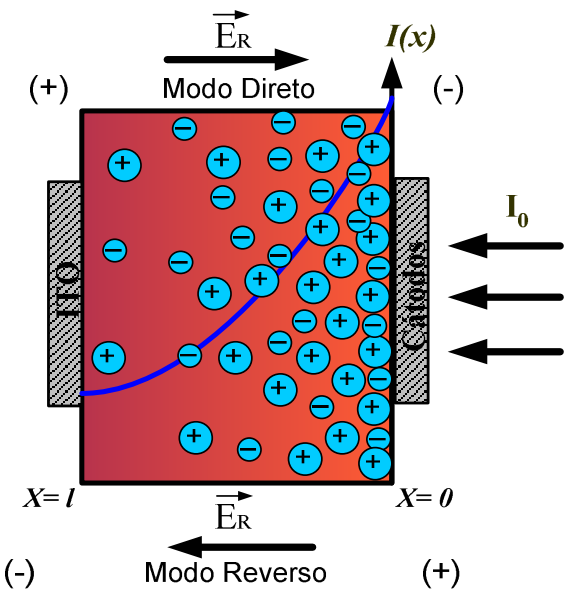

Figura 4.5: llustração do dispositivo sob incidência de luz através dos cátodos: a) em comprimento de onda bem absorvido pelo polímero (espessura $x=l$ ), e b) menos absorvido e mais energético. Em detalhes são mostrados os sentidos do campo elétrico resultante $\left(E_{R}\right)$ no modo direto e reverso, e o perfil de absorção da luz e da foto-geração de portadores (buracos $\odot$ e elétrons $\Theta$ ) na região iluminada.

Para o dispositivo no modo direto, os eletrodos de $\mathrm{Mg}$, $\mathrm{Al}$ e $\mathrm{Cu}$ são favorecidos a injetar elétrons e os buracos são injetados pelo ITO. Sob incidência de luz em comprimentos de onda bem absorvidos pelo MEH-PPV, a foto-geração de portadores ocorre principalmente na região próxima à interface polímero/eletrodo (Figura 4.5-a). Nesta polarização de campo elétrico, os buracos injetados pelo ITO e fotogerados próximos ao eletrodo oposto (cátodos) são conduzidos em direção aos cátodos onde são coletados. Os elétrons fotogerados na região do material próxima aos cátodos são conduzidos, junto aos elétrons injetados pelo cátodo (desprezível para o $\mathrm{Cu}$ ), em direção ao eletrodo oposto (ITO). Nesse caso, a principal contribuição para a fotocondutividade do dispositivo deve ser dada pelos portadores positivos (buracos) injetados pelo ITO, pois apesar de ser em número inferior aos fotogerados seu percurso sob o campo elétrico é muito superior, e mesmo que os elétrons fotogerados tenham um percurso semelhante, sua mobilidade é inferior. Invertendo-se a polarização, agora no 
modo reverso, os buracos fotogerados é que devem dominar amplamente o processo de condução sobre qualquer outro portador (buracos injetados e elétrons injetados ou fotogerados), isso porque, além da superior mobilidade dos buracos, seu percurso se faz através de todo o dispositivo. Como resultado, tem-se um expressivo aumento de corrente no modo reverso, invertendo-se a relação do fator de retificação.

Resultados semelhantes aos obtidos com o dispositivo feito com MEH-PPV foram obtidos com os outros dois polímeros: OC10-PPV e SY.

\subsection{ESPECTROS DE FOTOCORRENTE NO ESTADO ESTACIONÁRIO DOS DISPOSITIVOS:}

Nos estudos sobre o comportamento fotocondutivo dos dispositivos com estruturas ITO/polímero/metal (polímeros MEH-PPV, OC10-PPV e SY), mediram-se os espectros de fotocorrente no estado estacionário com incidência de luz ora pelo ITO, ora pelo metal semitransparente $(\mathrm{Al}, \mathrm{Mg}$ ou $\mathrm{Cu})$, para diferentes tensões aplicadas, positivas e negativas, e em curto-circuito. Todos os efeitos de absorção do vidro e dos eletrodos metálicos semitransparentes foram levados em consideração.

A fotocorrente é definida como a quantidade de cargas fotogeradas coletadas pelos eletrodos devido à incidência de radiação. Nesses dispositivos, os valores de fotocorrente obtidos foram da ordem de dezenas de nanoampéres, sob tensões de até $+5 \mathrm{~V}$. Para excluir a corrente atribuída aos portadores intrínsecos (não fotogerados) do polímero, descontou-se das fotocorrentes as correntes no escuro. Assim, a fotocorrente $\left(I_{p c}\right)$ apresentada nos espectros a seguir foi definida como $I_{p c}(\lambda)=I_{\lambda}-I_{e s c}$, onde $I_{\lambda}$ é a fotocorrente espectral medida sob iluminação e $I_{e s c}$ é a corrente medida no escuro. Além disso, os espectros de fotocorrente foram normalizados em relação ao fluxo radiante da lâmpada utilizada no experimento. 


\subsubsection{Dispositivo ITO/MEH-PPV/Al - Incidência através do ITO.}

A Figura 4.6 mostra o comportamento da fotocorrente normalizada de um dispositivo ITO/MEH-PPV/Al em função do comprimento de onda incidente através do eletrodo ITO para diferentes tensões aplicadas. Para o dispositivo em curto-circuito $(V=O V)$ foram observados valores negativos de fotocorrente em todo intervalo de comprimento de onda devido ao potencial intrínseco do dispositivo, denominado de potencial de built-in $\left(V_{B}\right)$ dado pela diferença entre as funções trabalho do ITO $\left(\phi_{\mathrm{ITO}}\right)$ e do metal $\left(\phi_{\mathrm{M}}\right)$. Para comprimentos de onda acima de $600 \mathrm{~nm}$ não há efeito de fotocondução, o qual se inicia em aproximadamente $600 \mathrm{~nm}$, atinge um máximo em $575 \mathrm{~nm}$, e permanece estacionário num valor muito baixo entre 425 e $525 \mathrm{~nm}$, voltando a crescer timidamente em $400 \mathrm{~nm}$. Observa-se que essa curva de fotocorrente não segue a de absorção do polímero, a qual apresenta um largo espectro no visível, com um máximo largo em aproximadamente $525 \mathrm{~nm}$ e com um decaimento assintótico acima de $600 \mathrm{~nm}$. Para todos os valores de tensões negativas (- 0,6 a - 3,0 V), o perfil do espectro de fotocorrente (Figura 4.6-b) foi o mesmo, com intensidade crescente quanto maior a tensão aplicada, definindo-se muito bem o pico em torno de $575 \mathrm{~nm}$. Como o comportamento da fotocorrente, para as tensões negativas, não segue a curva de absorção ele é dito antibático.

Ao aplicar $+0,6 \mathrm{~V}$, o espectro de fotocorrente tornou-se ligeiramente positivo, mantendo um pequeno pico semelhante aos observados nas tensões negativas. Entretanto, para valores de tensão acima de $+1 \mathrm{~V}$, o comportamento da resposta espectral da fotocorrente assemelha-se ao da absorção (o largo pico com máximo em torno de $525 \mathrm{~nm}$ ), exceto para os comprimentos de onda menores. Uma vez que acompanha bem o perfil da absorção óptica da amostra, esse comportamento é chamado simbático. A intensidade da corrente em cada ponto aumenta super-linearmente com o campo aplicado para o simbático e sub-linearmente para o antibático. No pico simbático $(525 \mathrm{~nm})$ e sob tensão aplicada de $+3 \mathrm{~V} \mathrm{e}+2 \mathrm{~V}$, as intensidades 
da fotocorrente do dispositivo foram de 55,0 e 22,0 nA, respectivamente. No pico antibático (575 nm) e sob tensão negativa de $-3 \mathrm{~V}$ e $-2 \mathrm{~V}$, as intensidades da fotocorrente foram de 10,0 e 8,0 nA, respectivamente. Desses resultados, pode-se, em primeira análise, inferir que o(s) mecanismo(s) envolvido(s) na geração da fotocorrente para polarizações positivas e negativas são distintos.

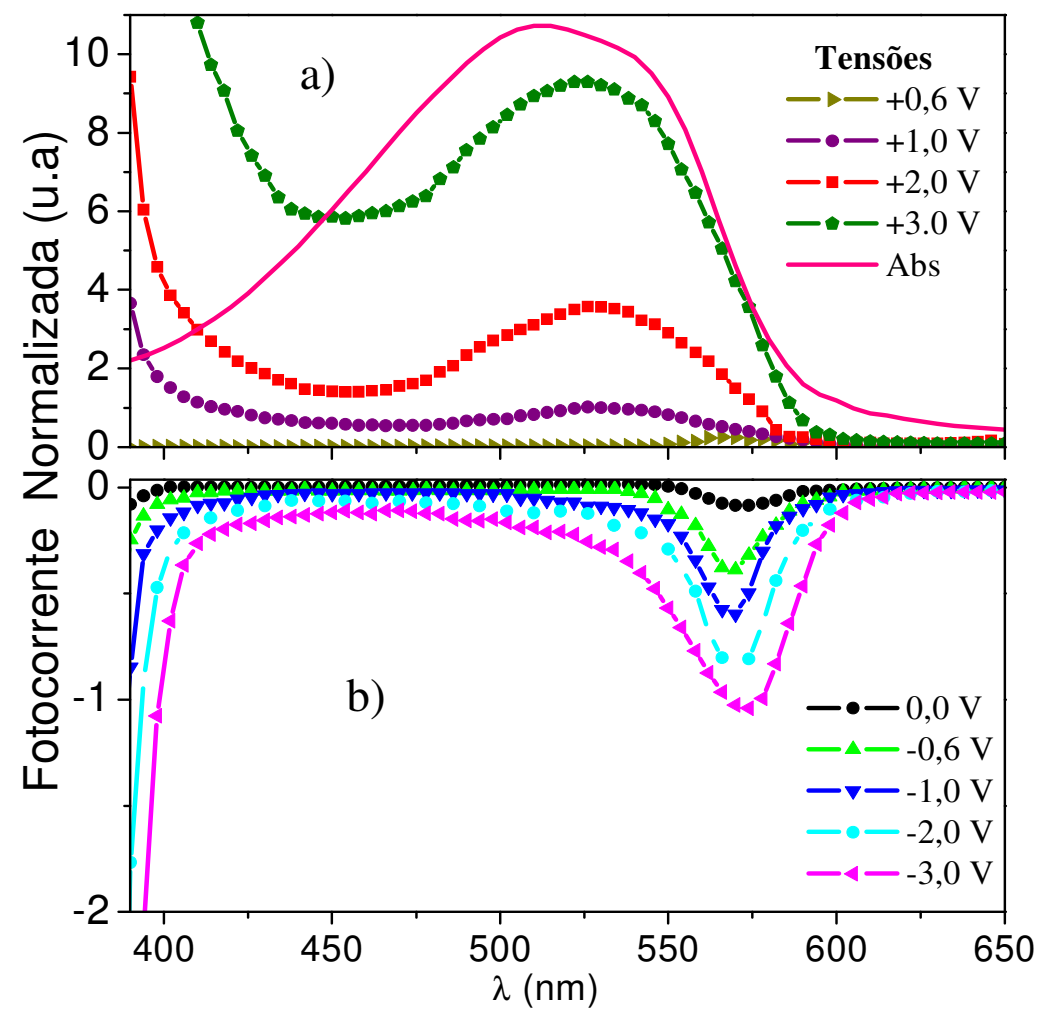

Figura 4.6: Espectro de fotocorrente normalizado no estado estacionário do dispositivo ITO/MEH-PPV/Al sob incidência no eletrodo ITO com diferentes tensões (a) positivas e (b) negativas aplicadas. Para comparação, o espectro de absorção normalizado do MEH-PPV é mostrado.

Dois efeitos são primordiais para explicar o comportamento do espectro de fotocorrente observado: a absorção óptica do material, representado pelo coeficiente de absorção $\alpha$, e o rendimento quântico $(\eta)$, os quais variam com do comprimento de onda. $\mathrm{O}$ primeiro efeito determina o perfil de penetração da luz no material. Para comprimentos de onda nos quais o coeficiente de absorção é alto, a profundidade de penetração da luz é 
pequena, e a luz é absorvida próximo ao contato. Do contrário, a profundidade de penetração da luz é alta, e a luz é absorvida em quase todo o volume do polímero. A literatura tem discutido o porquê da curva de fotocorrente ter início para energias inferiores ao gap HOMOLUMO do polímero $(\approx 2,3 \mathrm{eV}=540 \mathrm{~nm})$. A resposta está no fato de que, para comprimentos de onda mais elevados, a partir de aproximadamente $575 \mathrm{~nm}$, a absorção se dá por defeitos excitônicos que são muito populosos junto às interfaces devido à oxidação entre o eletrodo e o polímero, ou pela presença de segmentos da molécula com alto grau de conjugação (gaps de menores energias). Apesar da concentração relativamente elevada das espécies excitônicas, que ao se dissociarrem geram pares elétrons-buracos, o rendimento quântico de geração nessa região é muito baixo, da ordem de $10^{-3}$. A essa contribuição à resposta fotocondutiva do material é dado o nome de fotocondutividade extrínseca, que tem seu valor máximo atingido quando a luz tem comprimento de onda bem próximo ao gap óptico do polímero. Nessa condição, uma estreita faixa bem próxima à interface eletrodo/polímero fica iluminada e o alto valor de campo elétrico na região da interface devido ao contato Schottky contribui ainda mais para a dissociação dos éxcitons em cargas livres. A contribuição intrínseca se dá para comprimentos de onda acima do gap eletrônico, cujo rendimento quântico é muito superior, sendo próximo de $1^{66}$.

A Figura 4.7 compara o espectro de absorção do filme de MEH-PPV com os espectros de fotocorrente normalizados, para tensões com diferentes polaridades. Neste gráfico é possível observar mais claramente que o espectro de fotocorrente do dispositivo sob tensão positiva de $+3 \mathrm{~V}$ em relação ao ITO assemelha-se ao espectro de absorção do polímero, ou seja, o máximo de fotocorrente é obtido na região de máxima absorção do polímero. Este comportamento de fotocorrente em relação ao espectro absorção, como mencionado anteriormente, é chamado de simbático. Sob tensão negativa de $-3 \mathrm{~V}$, o pico do espectro 
fotocorrente do dispositivo em relação ao ITO não foi obtido na região de máxima absorção do polímero. A este comportamento do espectro de fotocorrente é dito antibático.

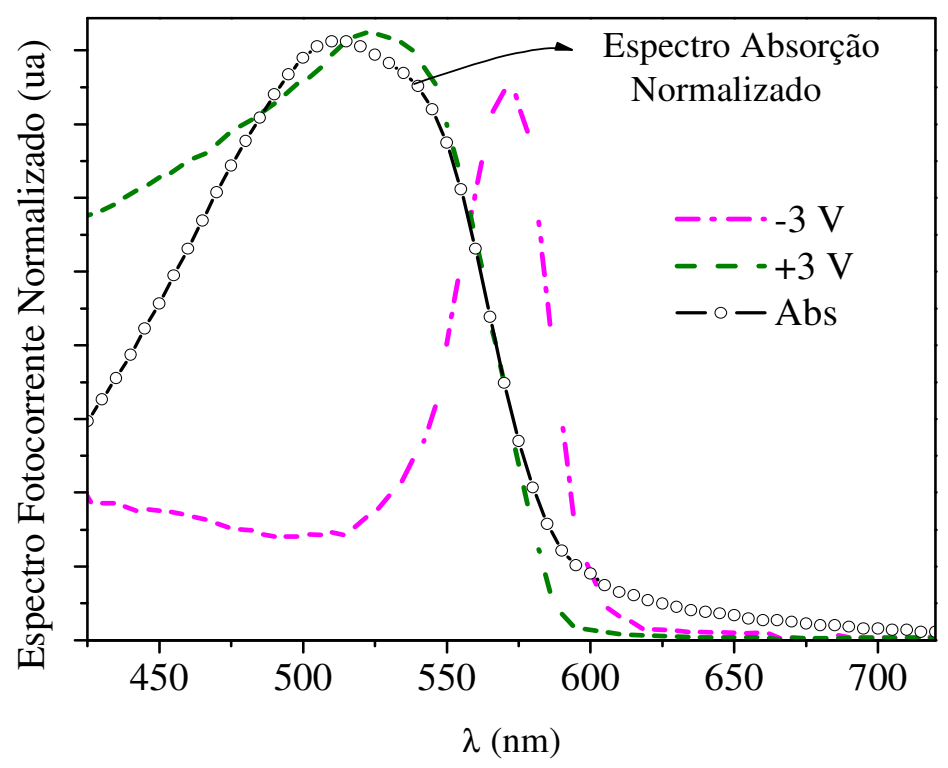

Figura 4.7: Comparação entre os espectros de fotocorrente normalizados para luz incidente no ITO, para tensões aplicadas positiva e negativamente no dispositivo ITO/MEH-PPV/Al, e o espectro de absorção do polímero.

\subsubsection{Dispositivo ITO/MEH-PPV/Cu e ITO/MEH-PPV/Mg - Incidência através do ITO.}

Comportamentos similares dos espectros de fotocorrente foram observados para dispositivos com eletrodos semitransparentes de $\mathrm{Cu}$ e $\mathrm{Mg}$, quando iluminados através do eletrodo ITO (Figura 4.8). A Figura 4.8-a mostra os espectros de fotocorrente para a estrutura ITO/MEH-PPV/Cu e de absorção (Abs) normalizados do MEH-PPV, para comparação. Para valores de tensões aplicadas acima de $+0,2 \mathrm{~V}$, o espectro apresentou valores positivos de corrente e comportamento simbático (mais evidente acima de +2 V). Em curto-circuito e sob tensões aplicadas entre -1 e $-3 \mathrm{~V}$, o espectro de fotocorrente apresentou valores negativos de 
corrente e comportamento antibático na região de maior absorção do polímero. Para a estrutura ITO/MEH-PPV/Mg (Figura 4.8-b), a fotocorrente assumiu valores positivos para tensões aplicadas acima de $+0,8 \mathrm{~V}$, e negativos em $0 \mathrm{~V}$ (curto-circuito) e para valores de tensões negativas. Para valores de tensão entre +2 e $+3 \mathrm{~V}$ o comportamento da fotocorrente assemelha-se ao espectro de absorção do polímero, caracterizando o comportamento simbático. Os valores máximos de fotocorrente se localizaram na região de maior energia dos fótons incidentes $(\lambda<435 \mathrm{~nm})$, evidenciando que o rendimento quântico de geração de portadores é maior para baixos comprimentos de onda (altas energias). Para o dispositivo com eletrodo de $\mathrm{Cu}$, a inversão do espectro de fotocorrente ocorre para tensão de $+0,2 \mathrm{eV}$, e no caso do $\mathrm{Mg}$, quando a tensão é de $+0,8 \mathrm{~V}$. Isso se explica pelo fato de a função trabalho do $\mathrm{Cu}$ ser próxima à do ITO, enquanto que a do $\mathrm{Mg}$ é menor que a do $\mathrm{Al}$. Nessas estruturas, $V_{B}$ é maior para o $\mathrm{Mg}$ (entre 0,7 e $0,9 \mathrm{eV}$ ) e menor para o $\mathrm{Cu}$ (entre $0,1 \mathrm{e} 0,3 \mathrm{eV}$ ).
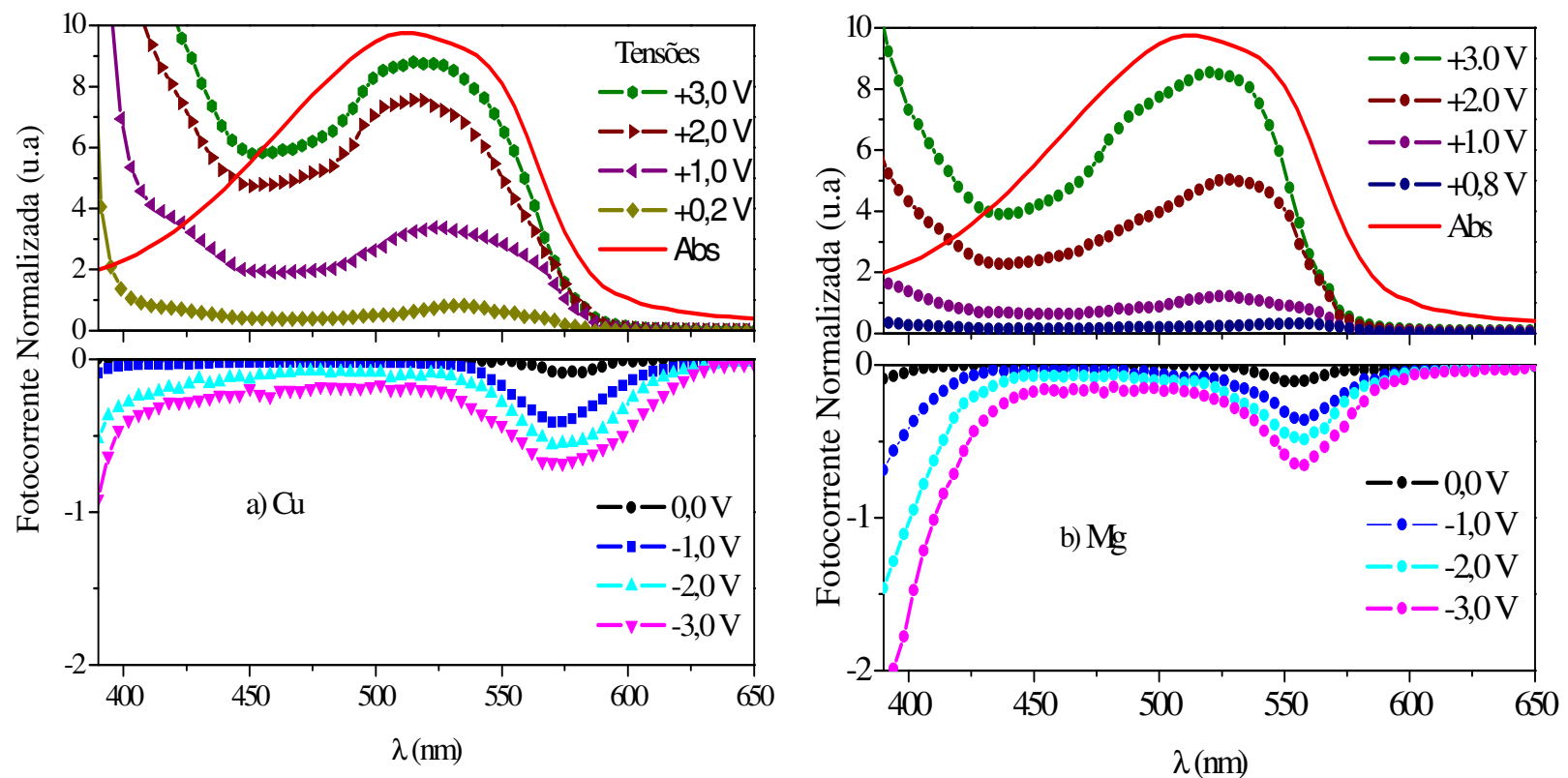

Figura 4.8: Espectros de fotocorrente do dispositivo ITO/MEH-PPV/eletrodo a) de $\mathrm{Cu}$ e b) de $\mathrm{Mg}$ sob incidência de luz através do ITO e o espectro de absorção normalizado do MEH-PPV para análise comparativa. 


\subsubsection{Dispositivo ITO/MEH-PPV/Metais - Incidência através dos metais.}

A Figura 4.9 mostra o comportamento do espectro de fotocorrente no dispositivo ITO/MEH-PPV/Al sob diferentes valores de tensão aplicada quando a incidência se dá através do eletrodos metálicos semitransparentes, no caso o de alumínio. Para tensões negativas, os espectros de fotocorrente da estrutura ITO/MEH-PPV/Al com incidência pelo $\mathrm{Al}$, apresentaram pico largo de fotocorrente na região de maior absorção do polímero $(\approx 520 \mathrm{~nm})$, caracterizando o comportamento simbático, e altos valores de corrente na região de comprimentos de onda menores que $450 \mathrm{~nm}$. A intensidade do espectro de fotocorrente aumenta à medida que a tensão aplicada também aumenta. Para tensões acima de $+0,6 \mathrm{~V}$, os espectros apresentaram valores positivos de fotocorrente com pico em torno de $580 \mathrm{~nm}$. Na região de altas energias foram observados aumentos consideráveis nas fotocorrentes, porém na região espectral de maior absorção do polímero foram registrados baixos valores de fotocorrente em relação às intensidades dos picos (antibático). A intensidade da corrente no pico simbático $(520 \mathrm{~nm})$ e sob tensão aplicada de $-3 \mathrm{~V}$ e $-2 \mathrm{~V}$, a intensidade da fotocorrente do dispositivo foi de 60,0 e 25,0 nA, respectivamente. No pico antibático (575 nm) e sob tensão positiva de $+3 \mathrm{~V}$ e $+2 \mathrm{~V}$, a intensidade da fotocorrente foi de 10,0 e 5,0 nA, respectivamente. 


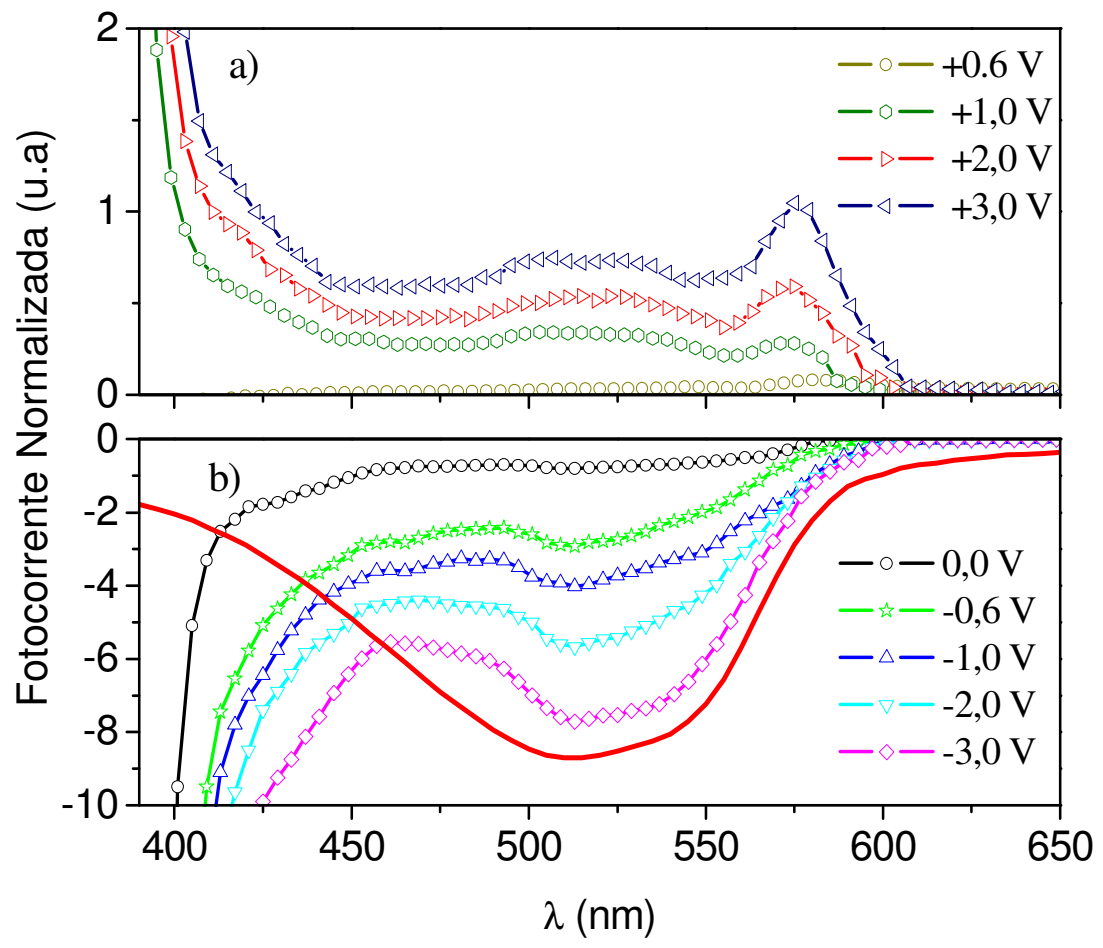

Figura 4.9: Espectros de fotocorrente em estado estacionário do dispositivo ITO/MEH-PPV/Al com incidência no eletrodo Al para diferentes valores de tensões aplicadas.

O gráfico da Figura 4.10 mostra com mais detalhes a comparação entre os espectros de fotocorrente normalizado, com a incidência da iluminação através do eletrodo de Al, para tensões aplicadas positiva de $+3 \mathrm{~V}$ e negativa de $-3 \mathrm{~V}$, com o espectro de absorção do polímero. Observa-se que o comportamento do espectro de fotocorrente em relação ao espectro de absorção é antibático ou simbático, respectivamente para tensões positivas ou negativas. 


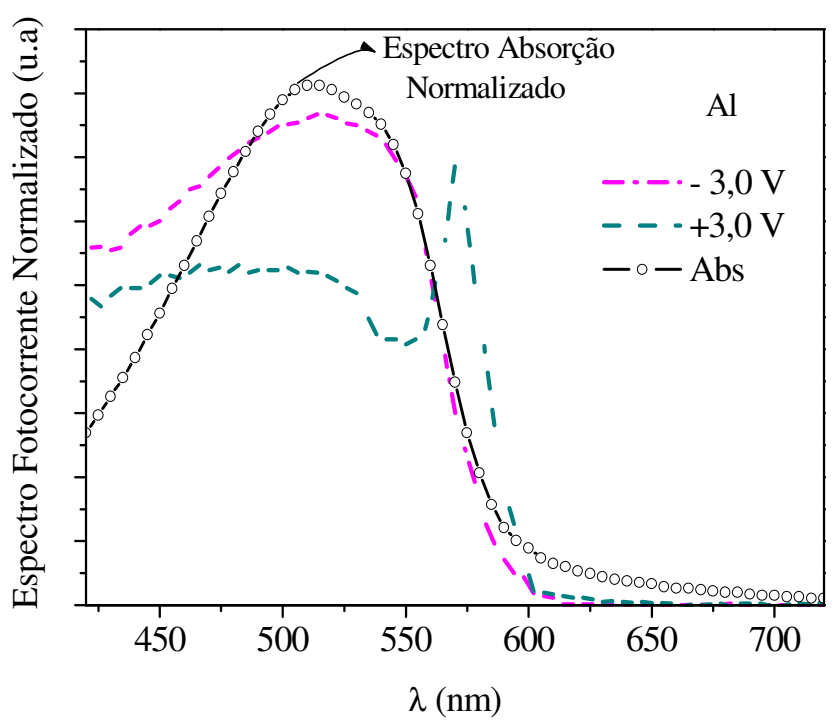

Figura 4.10: Comparação entre os espectros de fotocorrente normalizados para luz incidente através do Al semitransparente, para tensões aplicadas positiva e negativamente no dispositivo ITO/MEH-PPV/AI e o espectro de absorção do polímero.

A Figura 4.11 mostra os espectros de fotocorrente obtidos para o dispositivo com iluminação através dos eletrodos semitransparentes de Cu (Figura 4.11-a) e de Mg (Figura 4.11-b) para diferentes valores de tensões aplicadas e o espectro de absorção (Abs) normalizado do MEH-PPV, para análise comparativa. Para valores de tensões aplicadas acima $\mathrm{de}+0,2 \mathrm{~V}$ no dispositivo com eletrodo de $\mathrm{Cu}$, a fotocorrente apresentou valores positivos e os espectros apresentaram um comportamento simbático com relação à região de maior absorção do filme. Em curto-circuito e sob tensões negativas aplicadas $(-1$ e $-3 \mathrm{~V})$, os espectros de fotocorrentes apresentaram valores negativos de corrente e um comportamento antibático. Para medidas feitas com estrutura de eletrodo de Mg os resultados foram semelhantes. Nesse caso, a fotocorrente assumiu valores positivos para tensões aplicadas acima de $+0,8 \mathrm{~V}$, e negativos em curto-circuito e para valores de tensões negativas. Para tensões entre $-1 \mathrm{~V}$ e -3 $\mathrm{V}$, nota-se que à curva simbática se superpõe um pico, formando um ombro visível entre 575 
e $600 \mathrm{~nm}$. Esse efeito foi verificado nessa estrutura e somente nessas condições experimentais.
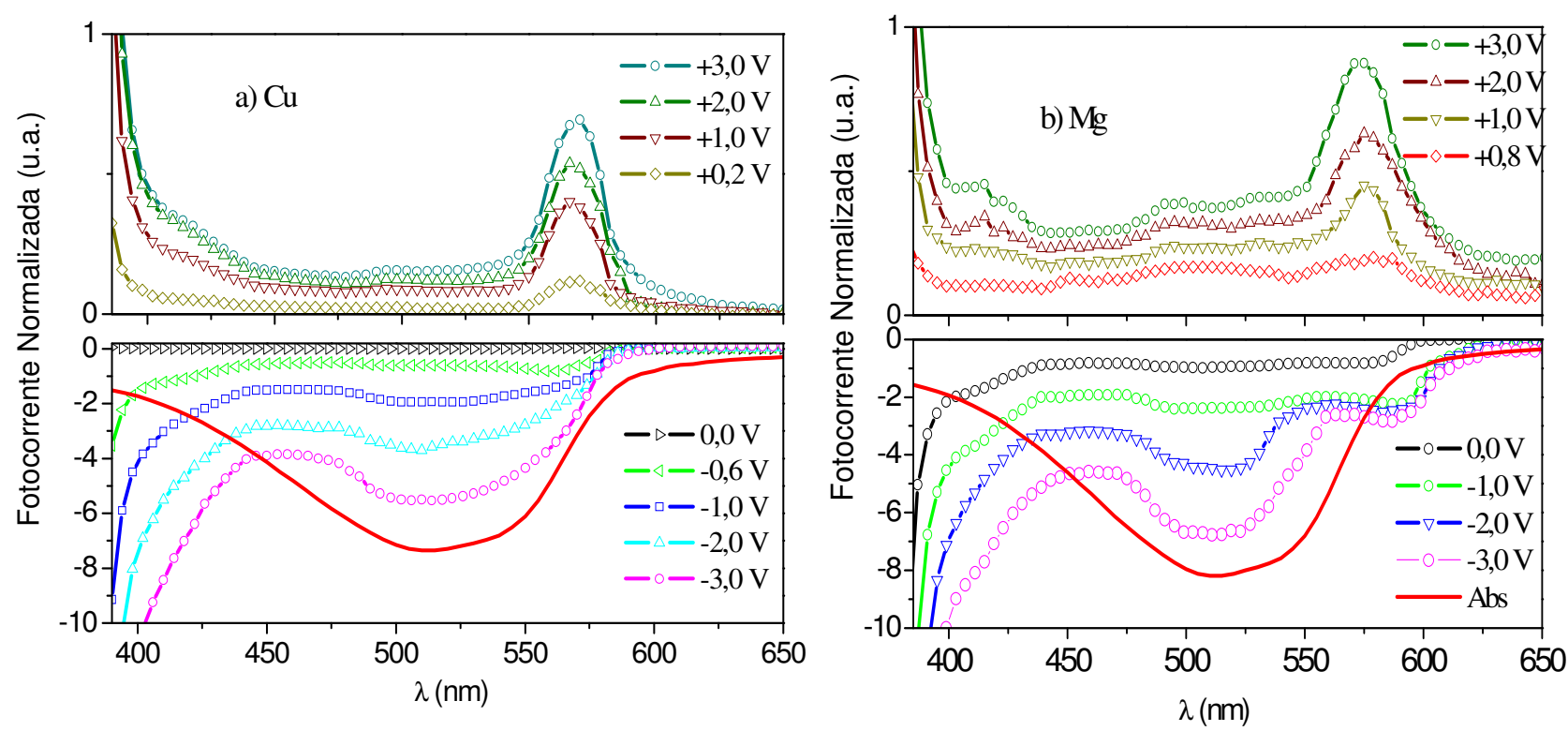

Figura 4.11: Espectros de fotocorrente do dispositivo ITO/MEH-PPV/eletrodo sob diferentes tensões aplicadas e com incidência de luz através do eletrodo a) de $\mathrm{Cu}$ e b) de Mg e o espectro de absorção normalizado do MEH-PPV.

Em relação às medidas obtidas quando a incidência se dá através do ITO, podemos dizer que há uma inversão nos comportamentos simbáticos e antibáticos. Ou seja, incidência através do ITO e tensão positiva no ITO, resulta curva simbática; incidência através do Al e tensão positiva no Al, resulta curva antibática. Já a incidência através do ITO e tensão negativa no ITO, resulta resposta antibática, enquanto incidência através do $\mathrm{Al}$ e tensão negativa no Al resulta curva simbática. O mesmo fenômeno ocorreu, como mostrado mais abaixo, para os eletrodos metálicos de magnésio e de cobre.

\subsubsection{Dispositivo ITO/OC10-PPV/Metais - Incidência através do ITO.}

Para a estrutura ITO/OC10-PPV/Metais os resultados obtidos foram similares aos dos dispositivos com MEH-PPV. A Figura 4.12, mostra resultados com eletrodo de Al com 
iluminação pelo ITO. Foram observados valores negativos de fotocorrente em curto-circuito $(V=O V)$ em todo intervalo de comprimento de onda, com um pico no espectro localizado em $550 \mathrm{~nm}$. O efeito de fotocondução se inicia em aproximadamente $570 \mathrm{~nm}$, atinge um máximo em $550 \mathrm{~nm}$, e permanece estacionário num valor muito baixo entre 375 e $525 \mathrm{~nm}$, voltando a crescer timidamente após $375 \mathrm{~nm}$. O espectro de fotocorrente não segue o espectro de absorção do polímero, o qual apresenta um largo espectro no visível, com máximo em aproximadamente $500 \mathrm{~nm}$. Para todos os valores de tensões negativas $(-0,6 \mathrm{a}-3,0 \mathrm{~V})$, o perfil do espectro de fotocorrente com pico em $575 \mathrm{~nm}$ (Figura 4.12-b) foi o mesmo, com intensidade crescente em função da tensão aplicada. O comportamento da fotocorrente, para as tensões negativas, não seguiu a curva de absorção caracterizando o comportamento antibático. $\mathrm{O}$ espectro de fotocorrente tornou-se positivo a partir de tensões maiores que $+0,6$ $\mathrm{V}$, mantendo um pequeno pico em 550nm, semelhante aos observados nas tensões negativas. Entretanto, para valores de tensão acima de $+1 \mathrm{~V}$, o comportamento da resposta espectral da fotocorrente (o largo pico com máximo em torno de $500 \mathrm{~nm}$ ) assemelha-se ao da absorção, caracterizando o comportamento simbático. No pico simbático $(500 \mathrm{~nm})$ e sob tensão aplicada de $+3 \mathrm{~V}$ e $+2 \mathrm{~V}$, a intensidade da fotocorrente do dispositivo foi de 70,0 e 48,0 nA, respectivamente. No pico antibático $(550 \mathrm{~nm})$ e sob tensão negativa de $-3 \mathrm{~V}$ e $-2 \mathrm{~V}$, a intensidade da fotocorrente foi de 20,0 e 16,0 nA, respectivamente. 


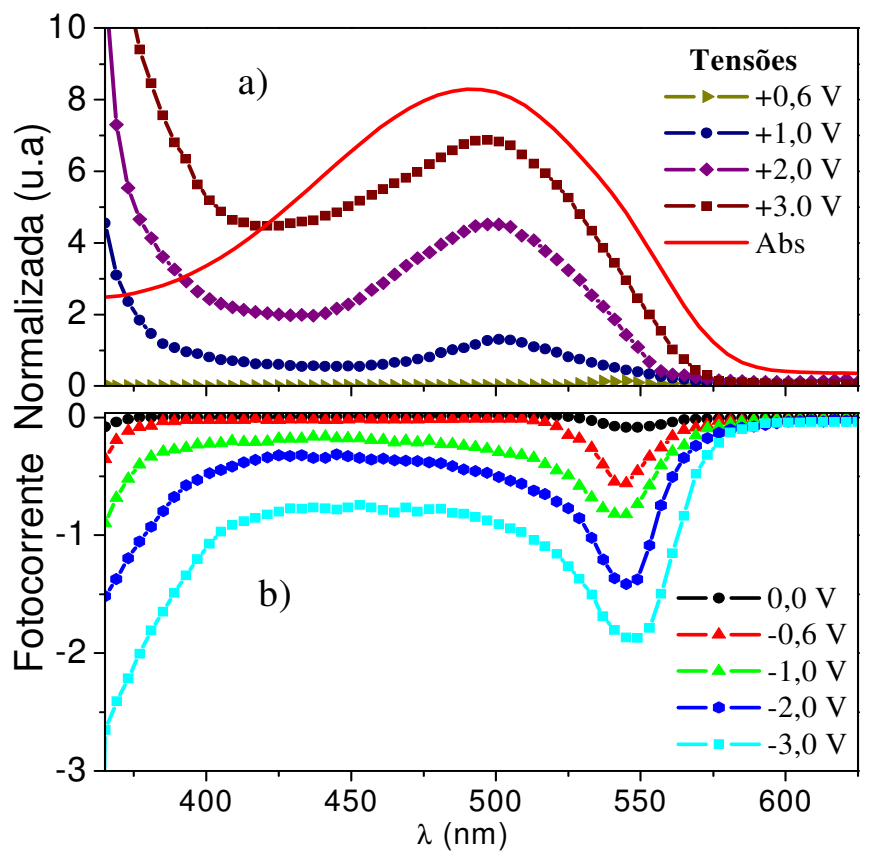

Figura 4.12: Espectro de fotocorrente normalizado no estado estacionário do dispositivo ITO/OC10-PPV/AI sob incidência no eletrodo ITO com diferentes tensões (a) positivas e (b) negativas aplicadas. O espectro de absorção normalizado do OC10-PPV é mostrado para comparação.

A Figura 4.13 mostra os comportamentos dos espectros de fotocorrente para a estrutura ITO/OC10-PPV/Cu e ITO/OC10-PPV/Mg, quando iluminados através do eletrodo ITO e sob diferentes tensões aplicadas. Os espectros de fotocorrente para a estrutura ITO/OC10-PPV/Cu e de absorção (Abs) normalizados do OC10-PPV são mostrados pela Figura 4.13-a. Para valores de tensões aplicadas superiores a $+0,2 \mathrm{~V}$, o espectro apresentou valores positivos de corrente e comportamento simbático. Em curto-circuito e sob tensões aplicadas entre -1 e $-3 \mathrm{~V}$, o espectro de fotocorrente apresentou valores negativos de corrente e comportamento antibático. Para a estrutura ITO/OC10-PPV/Mg (Figura 4.13-b), a fotocorrente assumiu valores positivos para tensões aplicadas acima de $+0,8 \mathrm{~V}$, e negativos para valores abaixo desta tensão, incluindo $0 V$ (curto-circuito) e valores de tensões negativas. Para valores de tensão entre +1 e $+3 \mathrm{~V}$ o comportamento da fotocorrente foi simbático. 

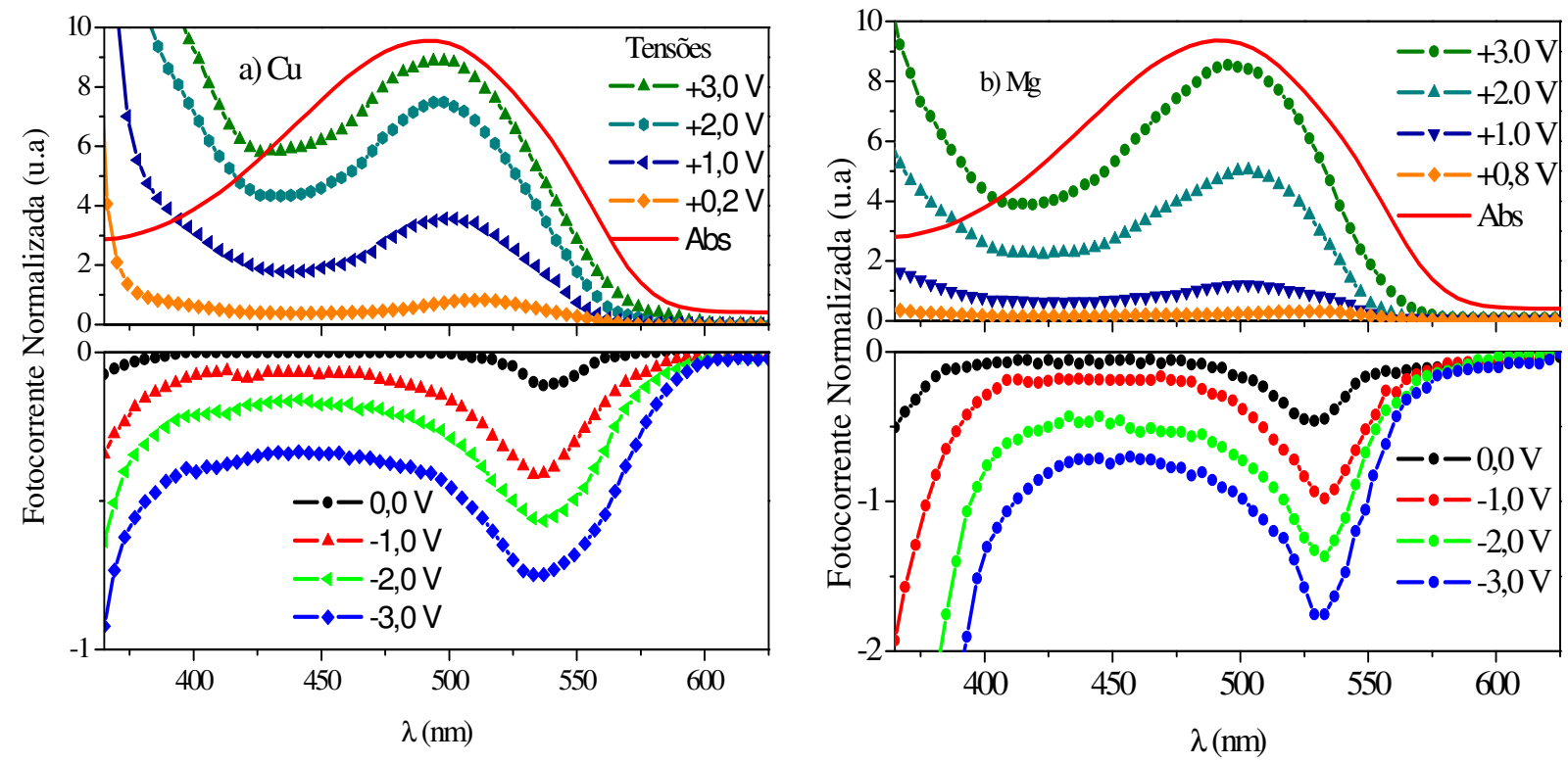

Figura 4.13: Espectros de fotocorrente do dispositivo ITO/OC10-PPV/eletrodo a) de $\mathrm{Cu}$ e b) de Mg sob incidência de luz através do ITO e o espectro de absorção normalizado do OC10-PPV para análise comparativa.

\subsubsection{Dispositivo ITO/OC10-PPV/Metais - Incidência através dos Metais.}

Os comportamentos dos espectros de fotocorrentes do dispositivo ITO/MEHPPV/Metais (Al, $\mathrm{Cu}$ e Mg) sob diferentes valores de tensão aplicada para incidência de luz através dos eletrodos metálicos semitransparentes, são mostrados a seguir. Para o eletrodo semitransparente de $\mathrm{Al}$, os espectros de absorção para diferentes valores de tensões aplicadas são apresentados pela Figura 4.14. Para tensões negativas, os espectros de fotocorrente apresentaram pico largo de fotocorrente na região de maior absorção do OC10-PPV $(\approx 500$ nm) (simbático) e elevados valores de corrente na região de comprimentos de onda menores que $425 \mathrm{~nm}$. A intensidade do espectro de fotocorrente aumentou proporcionalmente com a tensão aplicada. Para tensões acima de $+0,6 \mathrm{~V}$, os espectros apresentaram valores positivos de fotocorrente com pico em torno de $550 \mathrm{~nm}$. Na região espectral de maior absorção do polímero foram registrados baixos valores de fotocorrente (antibático). A intensidade da fotocorrente no pico simbático $(500 \mathrm{~nm})$ e sob tensão $-3 \mathrm{~V}$ e $-2 \mathrm{~V}$ foi de 80,0 e 60,0 nA, 
respectivamente. No pico antibático $(550 \mathrm{~nm})$ e sob tensão positiva de $+3 \mathrm{~V}$ e $+2 \mathrm{~V}$, a intensidade da fotocorrente foi de 15,0 e 8,0 nA, respectivamente. Observa-se novamente que houve inversão nos comportamentos simbáticos e antibáticos em relação às medidas obtidas quando a incidência se dá através do ITO.

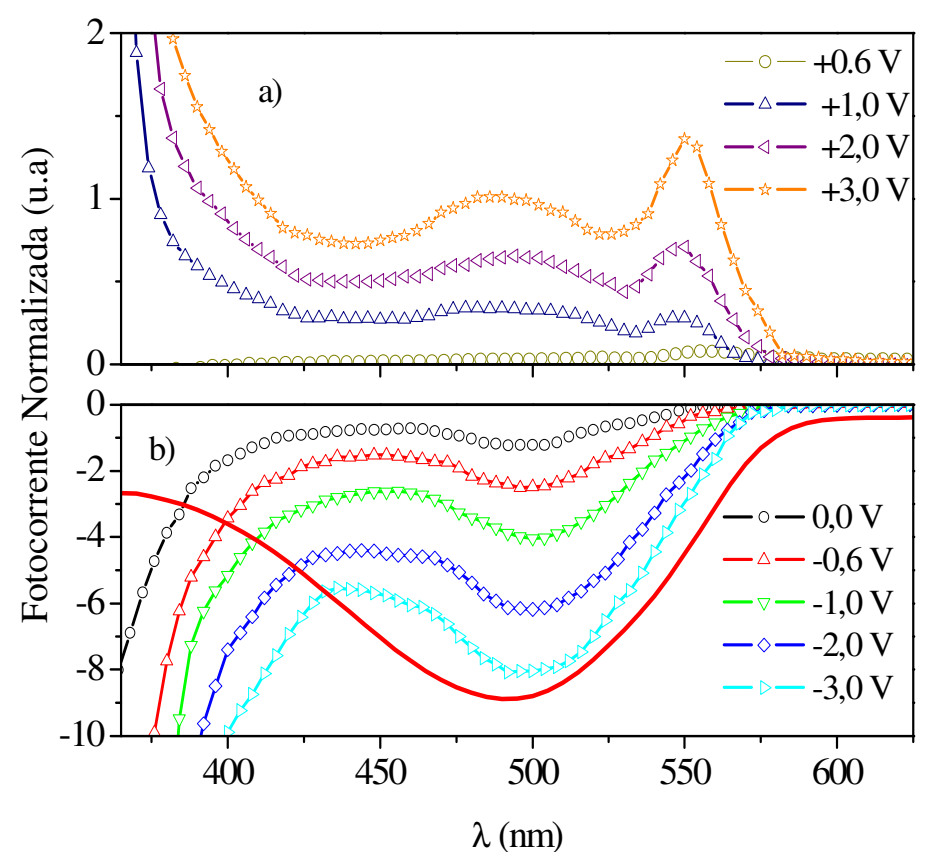

Figura 4.14: Espectros de fotocorrente normalizados do dispositivo ITO/OC10PPV/Al com incidência através do eletrodo semitransparente de Al para diferentes valores de tensões aplicadas.

Os espectros de fotocorrente obtidos para o dispositivo com iluminação através dos eletrodos semitransparentes de $\mathrm{Cu}$ e de $\mathrm{Mg}$ para diferentes valores de tensões aplicadas são mostrados na Figura 4.15, assim como o espectro de absorção (Abs) normalizado do OC10PPV, para análise comparativa. Para valores de tensões aplicadas acima de $+0,2 \mathrm{~V}$ no dispositivo com eletrodo de $\mathrm{Cu}$ (Figura 4.15-a), os espectros de fotocorrentes apresentaram valores positivos e um comportamento simbático. Para valores de tensões negativas aplicadas $(-1$ e $-3 \mathrm{~V})$ e em curto-circuito $(V=0)$, os espectros de fotocorrentes apresentaram valores negativos de corrente e um comportamento antibático. Para medidas feitas com estrutura de eletrodo de Mg (Figura 4.15-b) as fotocorrentes assumiram valores positivos para tensões 
aplicadas acima de $+0,8 \mathrm{~V}$ e os espectros apresentaram um comportamento antibático com relação ao espectro de absorção. Para valores negativos de tensões e em curto-circuito, as fotocorrentes assumiram valores negativos e comportamento simbático com relação ao espectro de absorção do OC10-PPV.
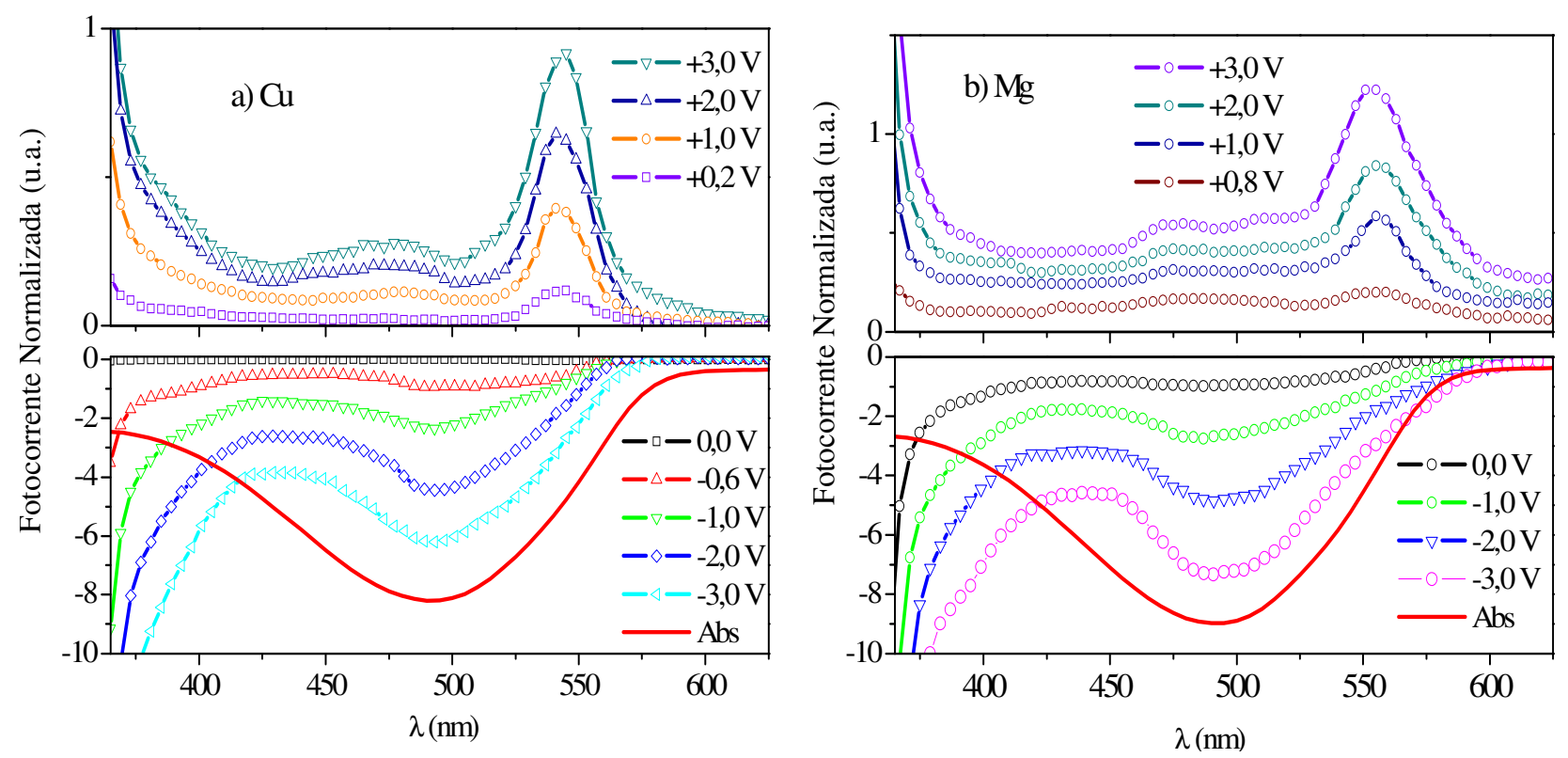

Figura 4.15: Espectros de fotocorrente do dispositivo ITO/OC10-PPV/eletrodo sob diferentes tensões aplicadas e com incidência de luz através do eletrodo a) de $\mathrm{Cu}$ e b) de Mg e o espectro de absorção normalizado do OC10-PPV.

\subsubsection{Dispositivo ITO/SY/AL.}

A Figura 4.16 mostra o espectro de fotocorrente do dispositivo de SY com estrutura ITO/SY/Al com incidência de luz através do eletrodo ITO (a) e através do eletrodo de $\mathrm{Al}$ (b), sob diferentes tensões aplicadas. No espectro obtido com incidência através do ITO (Figura 4.16-a) com o dispositivo em curto-circuito (tensão nula) observou-se a presença de um pico em torno de $500 \mathrm{~nm}$ que ficou mais evidente à medida que se aumentaram as tensões negativas $(-1 \mathrm{~V},-3 \mathrm{~V}$ e $-5 \mathrm{~V})$. Para essas tensões, a corrente assumiu valores nulos para comprimentos de onda acima de $550 \mathrm{~nm}$ e um vale no espectro de fotocorrente foi observado entre 400 e $475 \mathrm{~nm}$, cujo intervalo coincide com a região de maior absorção do polímero SY. 
Para comprimentos menores que $375 \mathrm{~nm}$, a corrente volta a aumentar. Ao aplicar tensão positiva de $0,7 \mathrm{~V}$, os valores de corrente foram extremamente pequenos em todos os comprimentos de onda da luz incidente, devido à extinção do campo elétrico interno pelo campo externo. Para tensões positivas superiores a $+0,7 \mathrm{~V}$ notou-se o surgimento de um pico no espectro de fotocorrente em torno de $450 \mathrm{~nm}$ e de vales entre 450 a $375 \mathrm{~nm}$. Para comprimentos de onda menores que $375 \mathrm{~nm}$ a fotocorrente apresenta um aumento significativo, muito provavelmente, devido ao aumento da eficiência de geração nessa região do espectro.
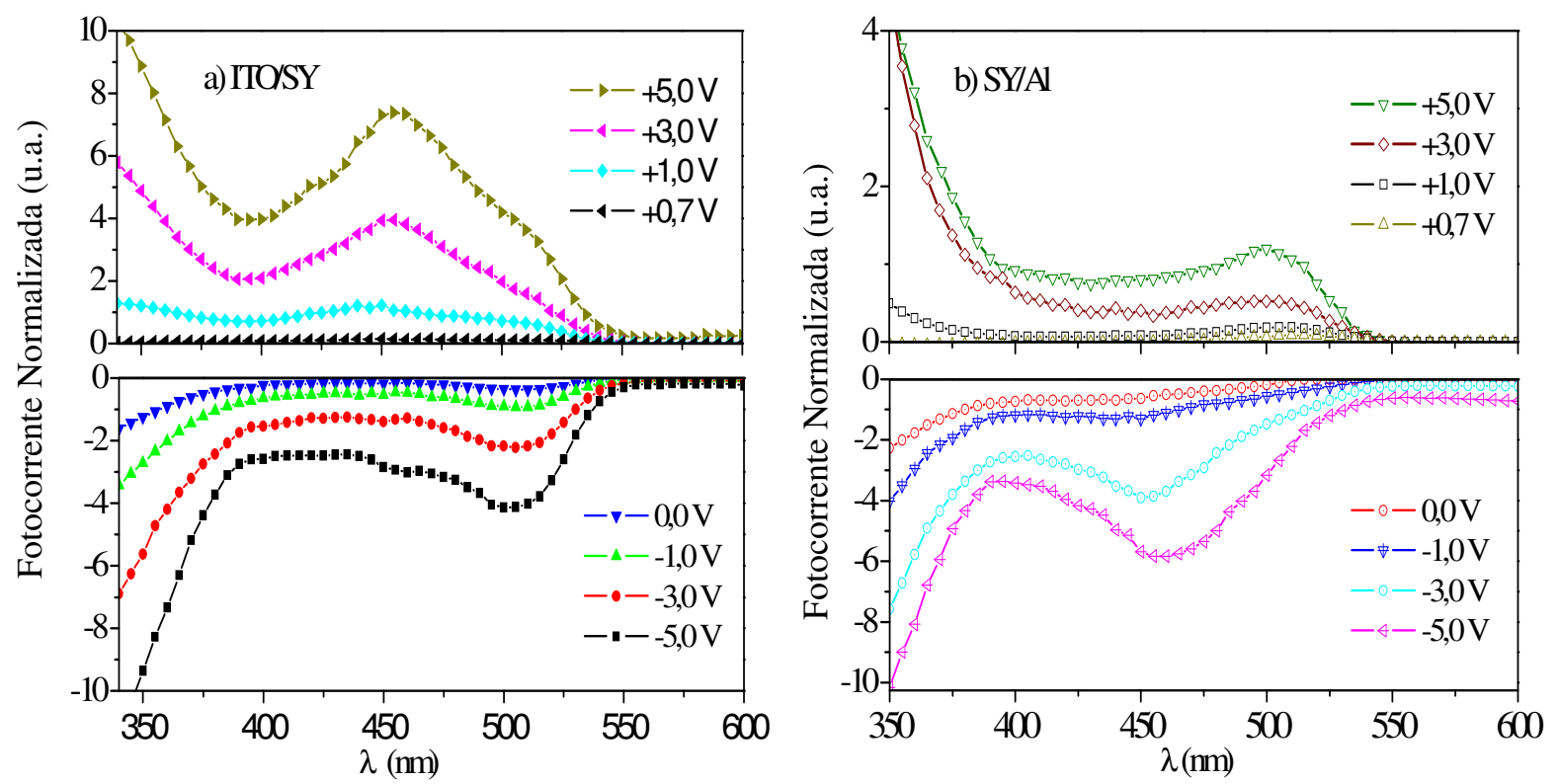

Figura 4.16: Espectro de fotocorrente do dispositivo ITO/SY/AI sob diferentes valores de tensões aplicadas com incidência de luz através: a) do eletrodo ITO e b) através do eletrodo Al.

Com incidência de luz através do eletrodo semitransparente de Al (Figura 4.16-b) para tensões positivas os espectros de fotocorrentes comportam-se de modo antibático, e para negativas, de modo simbático. Para tensões negativas, observou-se o surgimento de um pico (450 nm) na região de maior absorção do filme polimérico (SY) e mínimos de corrente entre 375 e $450 \mathrm{~nm}$. Para $+0,7 \mathrm{~V}$ aplicado, os valores de fotocorrente tornam-se positivos, porém 
extremamente pequenos em virtude da extinção do campo elétrico interno pelo campo externo. Para tensões positivas maiores os espectros de fotocorrente apresentaram picos com máximos próximos de $500 \mathrm{~nm}$, seguidos de um patamar de corrente entre 450 e $400 \mathrm{~nm}$ e de um aumento abrupto na fotocorrente a partir de comprimentos de onda de $400 \mathrm{~nm}$, ou seja, para energias mais altas do espectro. Uma análise mais detalhada da relação entre a absorção do polímero e o espectro de fotocorrente foi feita na Figura 4.17, que mostra as curvas simbáticas e antibáticas associada a tensão aplicada para os diferentes lados da incidência de luz. O comportamento do espectro de fotocorrente com iluminação através do ITO (Figura 4.17-a), foi antibático sob tensão de $-3 \mathrm{~V}$ e simbático sob tensão de $+3 \mathrm{~V}$. Entretanto, ao incidir luz através do eletrodo de Al (Figura 4.17-b) o espectro obtido sob tensão de $-3 \mathrm{~V}$ apresentou comportamento simbático, antibático sob tensão de $+3 \mathrm{~V}$.
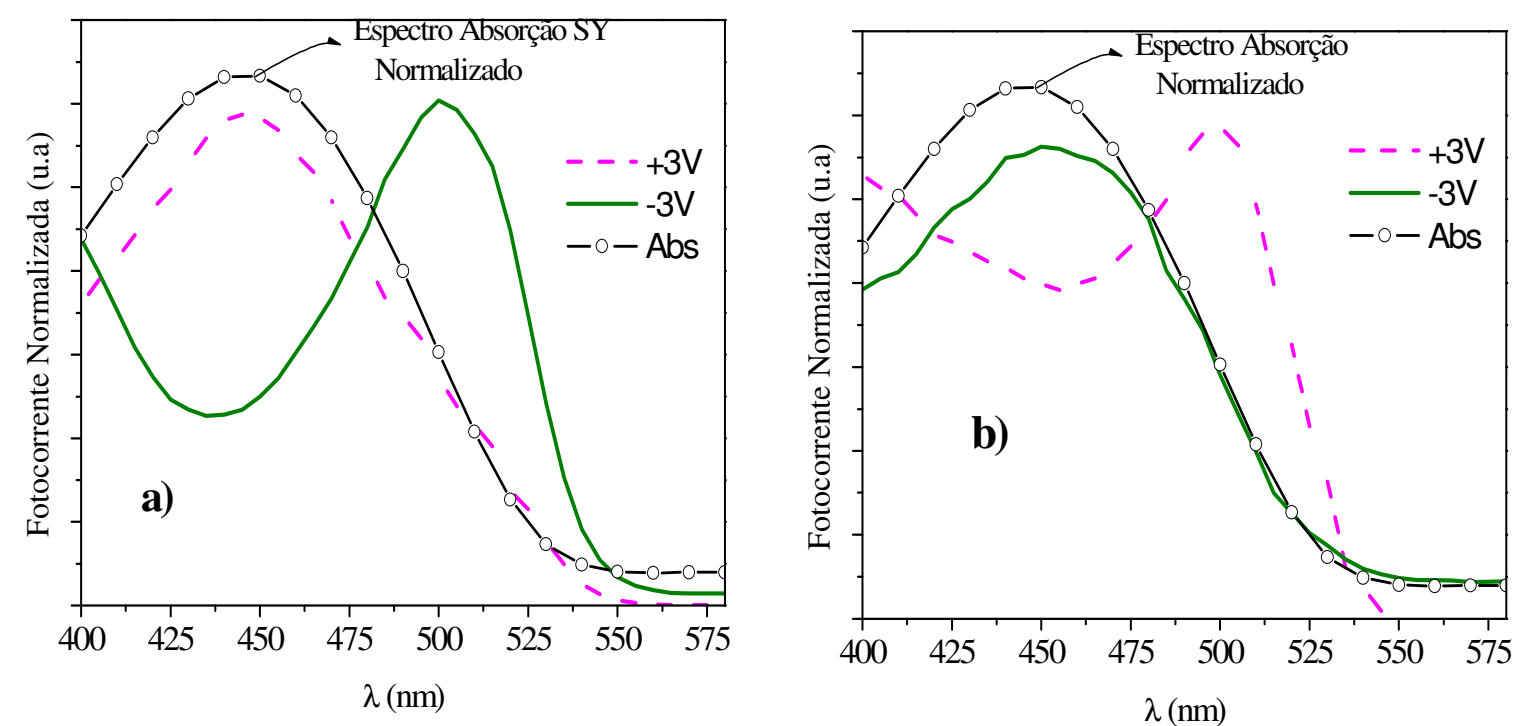

Figura 4.17: Espectro de absorção do SY normalizado em relação aos espectros de fotocorrente para duas polaridades de tensão aplicada (+3 $\vee$ e -3 V) com iluminação através a) do ITO e através do b) eletrodo de Al. 


\subsubsection{Dependência do Sinal da Fotocorrente dos Dispositivos com a Tensão} Aplicada:

O sinal da fotocorrente e sua dependência com a polaridade da tensão aplicada podem ser explicados qualitativamente através do esquema de diagrama de bandas de energia do polímero e das funções trabalho dos eletrodos. Considere o esquema ilustrativo para um dispositivo com estrutura ITO/Polímero/Al como mostrado na Figura 4.18.

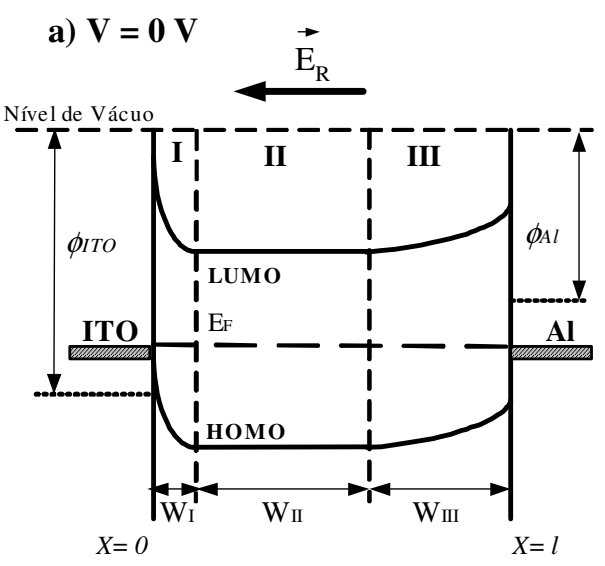

b) $\mathbf{V}<\mathbf{0}$

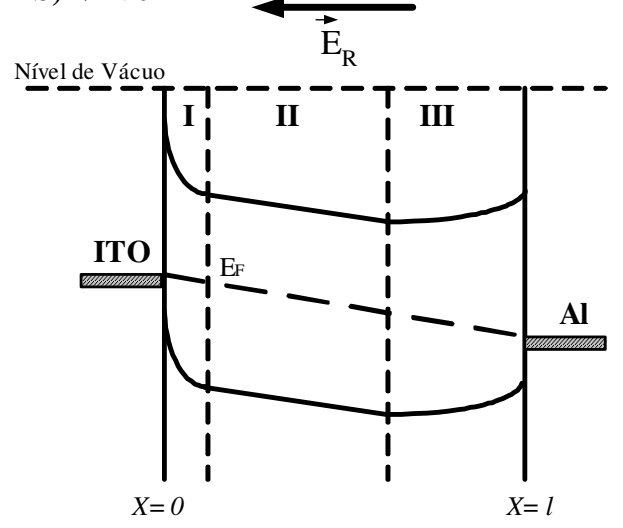

c) $\mathbf{V}=\left|\mathrm{V}_{\mathrm{B}}\right|>\mathbf{0}$

d) $\mathbf{V}>\left|\mathbf{V}_{\mathbf{B}}\right|>\mathbf{0}$
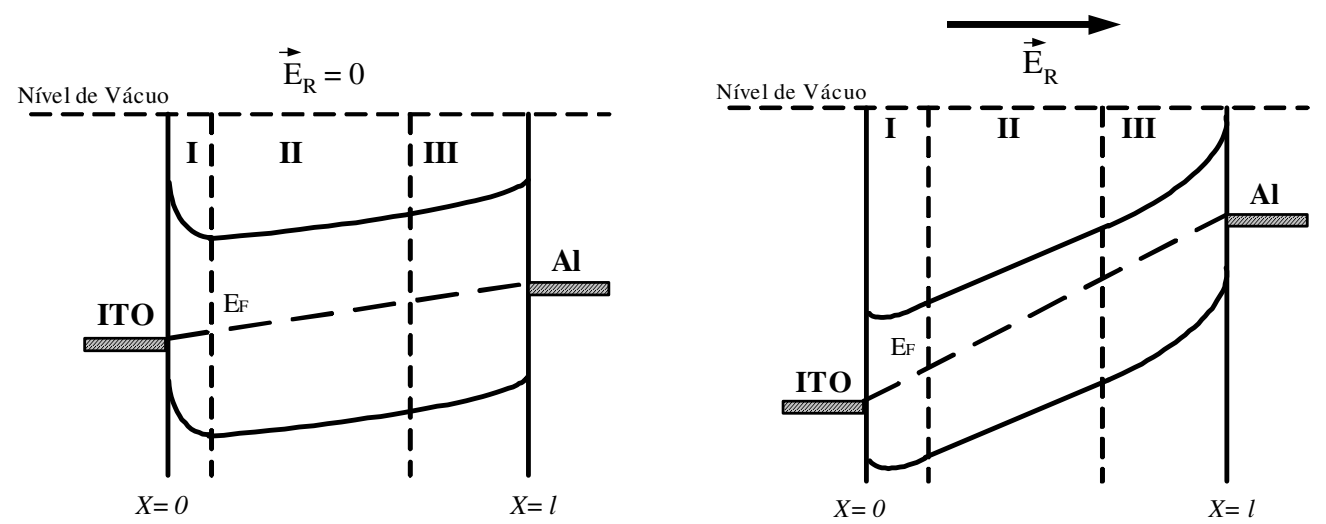

Figura 4.18: Ilustração do diagrama de bandas do dispositivo ITO/polímero/AI, para cada região do dispositivo utilizado para explicar qualitativamente 0 comportamento da fotocorrente com a tensão aplicada. Nesta figura, as regiões I e III estão exageradamente aumentadas por se tratar de uma ilustração. A polaridade das tensões aplicadas é relativa ao eletrodo de ITO. 
O entortamento das bandas próximo às interfaces se dá devido à injeção de portadores oriundo do efeito do equilíbrio do nível de Fermi, formando assim as regiões de depleção. Neste caso, considera-se esse entortamento como desprezível em relação ao efeito do campo elétrico externo. Com a incidência de luz através do eletrodo de ITO, há um aumento significativo de portadores positivos e negativos no semicondutor, em igual número, e que não altera a estrutura eletrônica do sistema. Com a incidência de luz através do eletrodo de ITO, há um aumento na densidade de portadores de carga fotogerados principalmente nas regiões próximas ao ITO (regiões I e II). Em curto-circuito, o campo elétrico resultante $\left(E_{R}\right)$ no interior do dispositivo devido ao potencial de built-in $\left(V_{B}\right)$ tem sentido do eletrodo de $\mathrm{Al}$ para o eletrodo de ITO, como indicado na Figura 4.18-a. Os portadores de carga positivos (buracos) fotogerados nas regiões iluminadas são conduzidos em direção ao eletrodo de ITO e os portadores negativos (elétrons) para o eletrodo oposto (Al). Neste sentido, a fotocorrente gerada pelos portadores livres tem sinal negativo. Sob tensões negativas, o campo elétrico gerado pela tensão aplicada tem o mesmo sentido do caso anterior (Al-ITO), e somado ao campo intrínseco, gera um campo resultante mais intenso (Figura 4.18-b). Com a maior intensidade do campo elétrico dois efeitos podem ocorrer: i) as velocidades de condução das cargas através da amostra tornam-se maiores e, ii) o campo elétrico pode contribuir na dissociação de éxcitons (efeito Onsager ${ }^{67}$, por exemplo) e no desarmadilhamento de cargas pelo efeito Poole-Frenkel ${ }^{68}$, aumentando a quantidade de cargas livres a serem conduzidas por ele. Conseqüentemente, os valores da fotocorrente se tornam maiores em módulo, como observado experimentalmente. Quando a tensão aplicada $(V)$ é igual em módulo ao potencial de built-in $\left(V_{B}\right)$, o campo elétrico externo aplicado iguala-se aos campos internos e a resultante do campo elétrico é praticamente nula (Figura 4.18-c). Nesta situação, o transporte de cargas pelo processo de difusão torna-se o principal meio de condução dos portadores, porém, como o comprimento de difusão dos portadores de cargas em derivados do PPV é da 
ordem de 8-12 $\mathrm{nm}$ (equivalente $2,5 \%$ da espessura da amostra), apenas as cargas geradas próximas a estas distâncias do eletrodo são aptas a serem coletadas. Portanto, os valores de fotocorrente na ausência de campo elétrico são extremamente baixos. Nos dispositivos medidos, a fotocorrente foi mínima para tensão aplicada igual em modulo aos valores do $V_{B}$. Para tensões acima do $V_{B}$ (Figura 4.18-d), o campo elétrico resultante no dispositivo tem o sentido do eletrodo ITO para o eletrodo Al, oposto aos casos anteriores (tensões negativas). Nesse caso, os portadores positivos são conduzidos em direção ao eletrodo de $\mathrm{Al}$ e os negativos em direção ao ITO e em quantidades e velocidades cada vez maiores à medida que este campo aumenta de intensidade, $\log$ a intensidade da fotocorrente aumenta proporcionalmente com o campo elétrico. Nesse sentido de condução dos portadores, a fotocorrente assume valores positivos.

\subsubsection{Explicação para o comportamento antibático e simbático da Fotocorrente:}

Para explicar qualitativamente o comportamento antibático e simbático da fotocorrente, considera-se novamente o esquema ilustrativo da Figura 4.18. Como a mobilidade dos buracos é bem superior à dos elétrons, apenas o movimento dos portadores positivos sob a ação do campo elétrico será levado em consideração. Quando a luz de comprimento de onda altamente absorvida pelo polímero incide através do ITO com tensão positiva aplicada ao ITO, a corrente é relativamente elevada, pois nesse caso os portadores positivos fotogerados têm que atravessar todo o dispositivo até alcançar o eletrodo oposto, o que faz aumentar a corrente. O resultado é o efeito simbático da fotocorrente. Mantendo-se o mesmo comprimento de onda, porém aplicando-se polaridade negativa no ITO, a corrente é muito pequena em virtude do pequeno deslocamento dos portadores positivos (buracos), resultando no efeito antibático da fotocorrente. Ao incidir a luz de comprimento de onda 
altamente absorvida pelo polímero através do eletrodo oposto, inverte-se o lado de fotogeração dos buracos, conseqüentemente inverte-se o comportamento da fotocorrente em relação à tensão aplicada. Entretanto essa explicação não é valida para altas energias do espectro visível, pois a luz é fracamente a absorvida e o aumento da fotocorrente é então explicado pelo aumento do rendimento de geração nessa região.

\subsubsection{Rendimento quântico na fotocondutividade intrínseca e extrínseca:}

$\mathrm{O}$ aumento da fotocorrente na região de comprimentos de onda menores que o gap óptico dos polímeros está relacionado com a fotocondutividade intrínseca, na qual o rendimento quântico de geração de portadores $(\eta)$ é maior que o rendimento quântico na fotocondutividade extrínseca (região de comprimentos de onda maiores que o gap óptico dos polímeros). Entretanto, os motivos que favorecem o aumento do rendimento da foto-geração de portadores nesta região ainda não estão totalmente esclarecidos na literatura. Esse efeito pode estar relacionado com a geração de pares elétron-buracos descorrelacionados (fracamente ligados), que são facilmente separados em cargas livres, através da foto-excitação com energias maiores que $3,1 \mathrm{eV}(\lambda<400 \mathrm{~nm})^{\mathbf{3 6}}$. Esse efeito é também relacionado com a dissociação de éxcitons fortemente ligados (tipo Frenkel) como sugerido pelo modelo de dissociação de éxcitons “quentes" ${ }^{\mathbf{6 9}, 70}$. Nesse modelo, o excesso de energia dos fótons incidentes (em relação ao gap óptico) poderia facilitar a dissociação dos éxcitons "quentes" antes que essa energia fosse dissipada através da geração de fônons. O excesso de energia seria suficiente para diminuir a interação coulombiana entre os pares elétron-buracos contribuindo para a completa separação. Para tanto, é assumido que o tempo de dissipação da energia na forma de fônons é muito mais curto que o tempo característico da interação elétron-fônon (entre $10^{-14}$ a $10^{-12} \mathrm{~s}$ ). 
Diferentes hipóteses também são empregadas para elucidar a fotocondutividade extrínseca que ocorre na região de comprimentos de onda maiores que o gap óptico do material, a qual é utilizada para explicar a origem do estreito pico de fotocorrente de comportamento antibático, que ocorre numa região de baixa energia do espectro de absorção. Segundo Gailberger et $a^{\mathbf{7 1}}$ e Harrison et al ${ }^{\mathbf{2 6}}$, o estreito pico antibático de fotocorrente, gerado pela fotocondutividade extrínseca, está localizado na região de mais baixa energia dos estados excitados vibracionais da transição $S_{0}-S_{l}$ dos PPVs de segmentos conjugados mais estendidos, ou seja, segmentos com gaps ópticos menores. Uma vez que os éxcitons residem nos segmentos mais longos, são muito poucos os locais favoráveis energeticamente para que se difundam e migrem, ou seja, nos segmentos mais estendidos da molécula o coeficiente de difusão do éxciton é reduzido. Além disso, éxcitons em segmentos mais estendidos podem ter tempos de vida aumentados por até três ordens de magnitude, comparados com éxcitons em segmentos menores (energia mais elevada), como determinado por medidas resolvidas no tempo do decaimento da fotoluminescência ${ }^{72,73}$. Entretanto, o prolongamento do tempo de vida poderia esclarecer o aumento da resposta de fotocorrente em baixas energias sob duas circunstâncias: (1) A dissociação dos éxcitons que geram a fotocorrente pode somente ocorrer para uma fração pequena dos éxcitons localizados nos segmentos mais longos, localizados próximo a um local de dissociação, tal como um elétrodo metálico ou um defeito (molécula do oxigênio, por exemplo). (2) Os éxcitons nos segmentos mais longos seriam gerados diretamente pela foto-excitação com fótons de baixa energia, e não populados através da difusão dos éxcitons provenientes de segmentos mais curtos. Embora a difusão possa ocorrer, a separação média entre os segmentos longos excede o raio médio de difusão dos éxcitons mais energéticos, de tempo de vida mais curto, gerados em segmentos curtos. Assumindo tais suposições, a desordem estrutural das moléculas do polímero tem um papel importante no mecanismo gerador da fotocorrente em baixas energias. Num filme polimérico, pequenos 
grãos cristalinos (altamente ordenados) com dimensões da ordem da difusão do éxciton (5-12 nm) estão imersos em regiões amorfas. Após a foto-excitação, os portadores da carga podem separar-se e contribuir para a fotocorrente se uma das cargas for transferida para um segmento conjugado próximo. É importante observar que os comprimentos de conjugação maiores são mais propícios ao transporte intra-molecular de cargas. Como mencionado acima, os segmentos conjugados mais longos correspondem ao lado de energia mais baixa do espectro de absorção. Considera-se, dessa forma, a possibilidade de um ou outro éxciton ser transferido e transportado pelos segmentos mais longos, contribuindo para o aumento da fotocorrente em baixas energias.

Uma outra hipótese utilizada para explicar a fotocondutividade extrínseca, relaciona a existência do pico antibático e o aumento do rendimento de geração de cargas com a presença de defeitos, os quais atuam como centros dissociadores de éxcitons. De acordo com Antoniadis et al ${ }^{40}$ e Chawdhury et al. $^{41}$ a presença de defeitos na cadeia polimérica proveniente da oxidação (exposição ao oxigênio e água) e da foto-oxidação (degradação por luz) podem causar um aumento na eficiência de foto-geração extrínseca de portadores. Os defeitos atuariam como armadilhas para umas das cargas do par elétron-buraco possibilitando o aumento da dissociação dos éxcitons e conseqüentemente gerando mais portadores livres. Análogo ao que é observado com o $C_{60}$ incorporado aos polímeros conjugados, onde a fotocorrente é aumentada drasticamente devido à captura de elétrons pelo dopante ${ }^{\mathbf{7 4}}$.

Os resultados obtidos dos espectros de fotocorrente do dispositivo ITO/OC10PPV/Mg exposto à luz (UV) por 7 dias durante as medidas de fotocorrente são condizentes com a segunda hipótese. Os espectros de fotocorrente em função da tensão aplicada no dispositivo de ITO/OC10-PPV/Mg quando fresca e após um período de 7 dias são mostrados pela Figura 4.19. De acordo com os resultados, o pico antibático de fotocorrente localizado em $530 \mathrm{~nm}$ teve um aumento $40 \%$ para tensões aplicadas de $-0,6 \mathrm{~V}$ e $-1,0 \mathrm{~V}$ e $45 \%$ para $+2,0$ 
V aplicado ao dispositivo após o período de 7 dias. Neste caso, o aumento da fotocorrente nas demais regiões do espectro não foi significante.

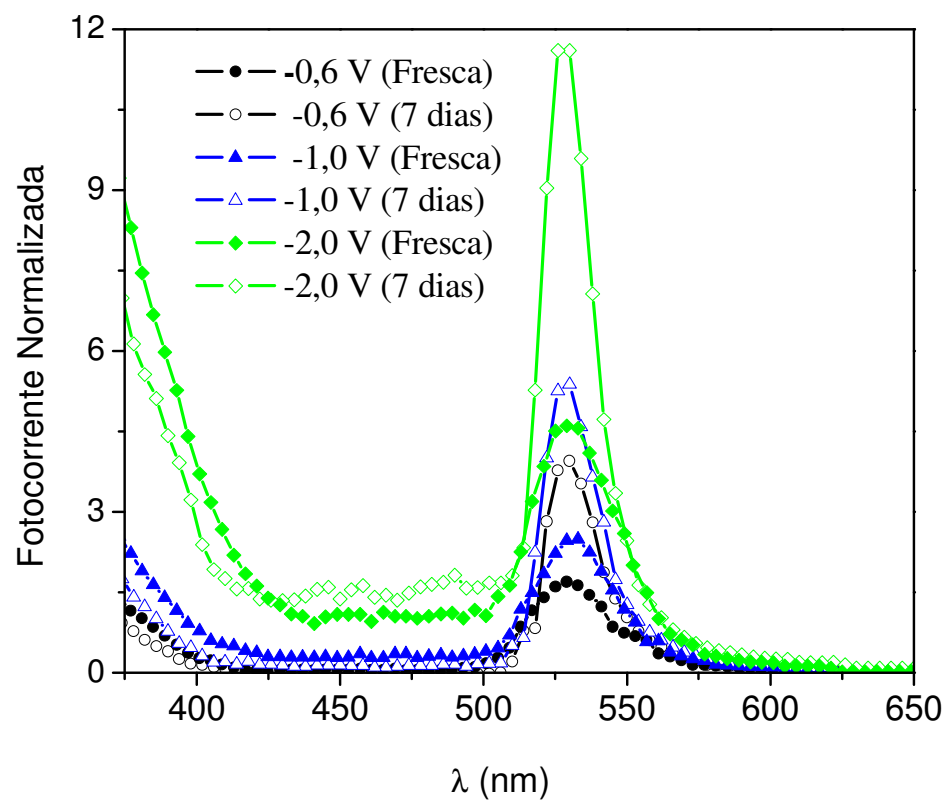

Figura 4.19: Espectros de fotocorrente em função da tensão aplicada no dispositivo de ITO/OC10-PPV/Mg, com incidência de luz através do ITO, quando fresca e após o período de 7 dias de exposição à luz.

A foto-oxidação de polímeros pela exposição à luz, principalmente com comprimentos de ondas altamente energéticos, resulta na quebra das cadeias poliméricas e conseqüentemente na diminuição do número de segmentos longos. Com a quebra das cadeias, em particular nos PPVs, são criadas moléculas com terminações em grupos carbonila ${ }^{\mathbf{7 5}}$, os quais geram defeitos na cadeia do polímero. Esses defeitos por sua vez, melhoram a eficiência de geração de portadores livres aumentando o valor da fotocorrente. 


\section{Análise dos Resultados}

Este capítulo apresenta os cálculos realizados sobre a eficiência dos dispositivos e principalmente, os ajustes teóricos dos espectros de fotocorrente dos dispositivos estudados.

\subsection{CÁLCULO DA EFICIÊNCIA INTERNA DOS DISPOSITIVOS:}

Um parâmetro importante a ser avaliado no processo de fotocondução de um dispositivo é a sua eficiência interna $\left(g_{p c}\right)$, dada pela razão entre o número de portadores coletados pelos eletrodos e o número de portadores fotogerados. Esse valor é dado pela equação:

$$
g_{p c}(\%)=\left(\frac{I_{P C} / q}{\varphi_{a b s} \cdot A}\right) x 100
$$

Onde a $I_{P C}$ é a fotocorrente medida, $A$ é a área ativa do dispositivo, $\varphi_{a b s}$ fluxo de fótons absorvido e $q$ é a carga elementar $(C)$. O fluxo de fótons absorvido é dado por $\varphi_{a b s}=\left(I_{0} / h v\right) \cdot \alpha$, onde $I_{0}$ é a intensidade da luz, $(h v)$ a energia dos fótons e $\alpha$ o coeficiente de absorção do polímero. O fluxo de fótons absorvidos, calculado nas condições experimentais, ficou entre as escalas de $10^{13}$ e $10^{14}$ fótons/s. O valor máximo de $g_{p c}$ é obtido quando todas as cargas fotogeradas pelos fótons incidentes são coletadas pelos eletrodos, ou seja, quando $g_{p c}=$ $\eta$. Calculando-se o $g_{p c}$ para cada comprimento de onda a partir do espectro de fotocorrente dos dispositivos para diferentes tensões aplicadas, foi possível verificar diferentes regiões do espectro, de maior ou menor eficiência. 


\subsubsection{Cálculo da eficiência interna do dispositivo ITO/SY/Al:}

Os gráficos da Figura 5.1 mostram o fluxo de fótons absorvido e as eficiências interna do dispositivo em função do comprimento de onda incidente no ITO/SY/Al através do ITO (Figura 5.1-a) e através do eletrodo semitransparente de Al (Figura 5.1-b), para diferentes tensões aplicadas. Como se pode observar na Figura 5.1-a, a eficiência do dispositivo em curto-circuito $(V=O V)$ foi extremamente baixa na região onde $\lambda>575 \mathrm{~nm}\left(10^{-6} \%\right)$. A partir de $\lambda<575 \mathrm{~nm}$ a eficiência aumenta atingindo um patamar em $550 \mathrm{~nm}$ que se estende até $350 \mathrm{~nm}$, com um valor de $g_{p c}$ em torno de $10^{-3} \%$. Entre 400 e $300 \mathrm{~nm}$ a eficiência interna do dispositivo aumentou cerca de 3 ordens de grandeza até atingir o valor máximo de eficiência em $300 \mathrm{~nm}$. Para as tensões positivas e negativas, as curvas são semelhantes, mas o patamar, que sempre se inicia em torno de $550 \mathrm{~nm}$, é mais curto quanto maior for a tensão aplicada. Para $\mathrm{V}=+3 \mathrm{~V}$, o valor inicial da eficiência é $10^{-5} \%$, enquanto que para $-3 \mathrm{~V}$ é de $10^{-3} \%$; a partir de $550 \mathrm{~nm}$ as curvas ficam semelhantes. Para $\mathrm{V}=+0,7 \mathrm{~V}$, o campo no interior da amostra é praticamente nulo, isso explica a aparente discrepância da curva sob tensão $0,7 \mathrm{~V}$. As eficiências no patamar ficam entre $10^{-2} \%$ e $10^{-1} \%$. 

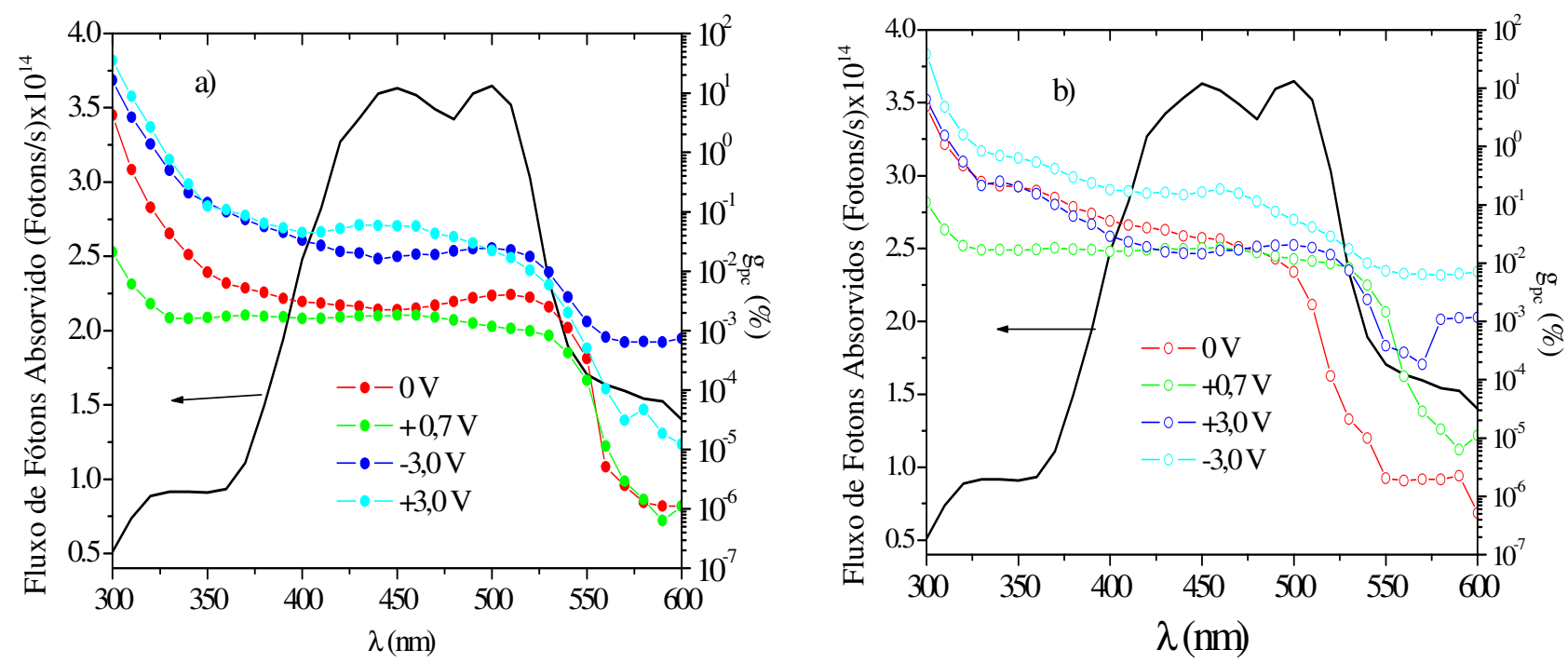

Figura 5.1: Fluxo de fótons absorvidos (linha continua) e as eficiências internas para o espectro da luz incidente no dispositivo ITO/SY/AI, a) através do ITO e b) através do eletrodo semitransparente de Al, sob diferentes tensões aplicadas.

As curvas de eficiência obtidas quando a incidência se dá pelo eletrodo metálico (Figura 5.1-b) são semelhantes às anteriores, e uma análise mais detalhada mostra a coerência com a análise feita no Capítulo 4 sobre as curvas simbáticas e antibáticas. Isso quer dizer que, os portadores positivos, de maior mobilidade, quanto mais distantes do eletrodo coletor são gerados, maior é a fotocorrente. As pequenas diferenças entre as duas curvas vêm do fato de que há uma pequena contribuição à corrente, oriunda da injeção de portadores, que são diferentes para as diferentes polaridades.

\subsubsection{Cálculo da eficiência interna do dispositivo ITO/MEH-PPV/Metais:}

As mesmas considerações gerais feitas para a estrutura ITO/SY/Metal são válidas para o ITO/MEH-PPV/Metal. Os gráficos da Figura 5.2-a mostram as eficiências do dispositivo ITO/MEH-PPV/Al com incidência de luz através do ITO sob tensão de -3 e +3 V e em curtocircuito $(V=0)$. Sob tensão positiva $(+3 \mathrm{~V})$, o máximo de eficiência do dispositivo foi de $34 \%$ em $370 \mathrm{~nm}$. Para $\lambda>370 \mathrm{~nm}$, os valores diminuíram até atingir um patamar de eficiência 
em torno de $0,04 \%$ entre 450 e $550 \mathrm{~nm}$, que compreende a região de maior absorção do MEHPPV. Para $\lambda>550 \mathrm{~nm}$, as eficiências diminuíram rapidamente para valor em torno de 0,001\%. Sob polaridade contrária $(-3 \mathrm{~V})$, os valores foram em média menores que na polaridade positiva. Houve duas regiões de $g_{p c}$ consideráveis, uma em torno de $570 \mathrm{~nm}$ $(0,02 \%)$ e outra em $370 \mathrm{~nm}(4,5 \%)$. Para incidência através do eletrodo de Al (Figura 5.2-b), entretanto, as eficiências do dispositivo sob tensão negativa foram em média maiores que nas tensões positivas. O máximo valor de $g_{p c}$ obtido foi de $32 \%$ em $370 \mathrm{~nm}$ para $-3 \mathrm{~V}$. Sob tensão positiva, a eficiência nesta região foi de $16 \%$. Estando o dispositivo em curto-circuito e com luz incidente em 350nm através do ITO, o máximo de eficiência foi de 0,009\%, enquanto para incidência através do eletrodo a eficiência foi de $0,005 \%$. Isso é devido à diferença de função trabalho entre os eletrodos.
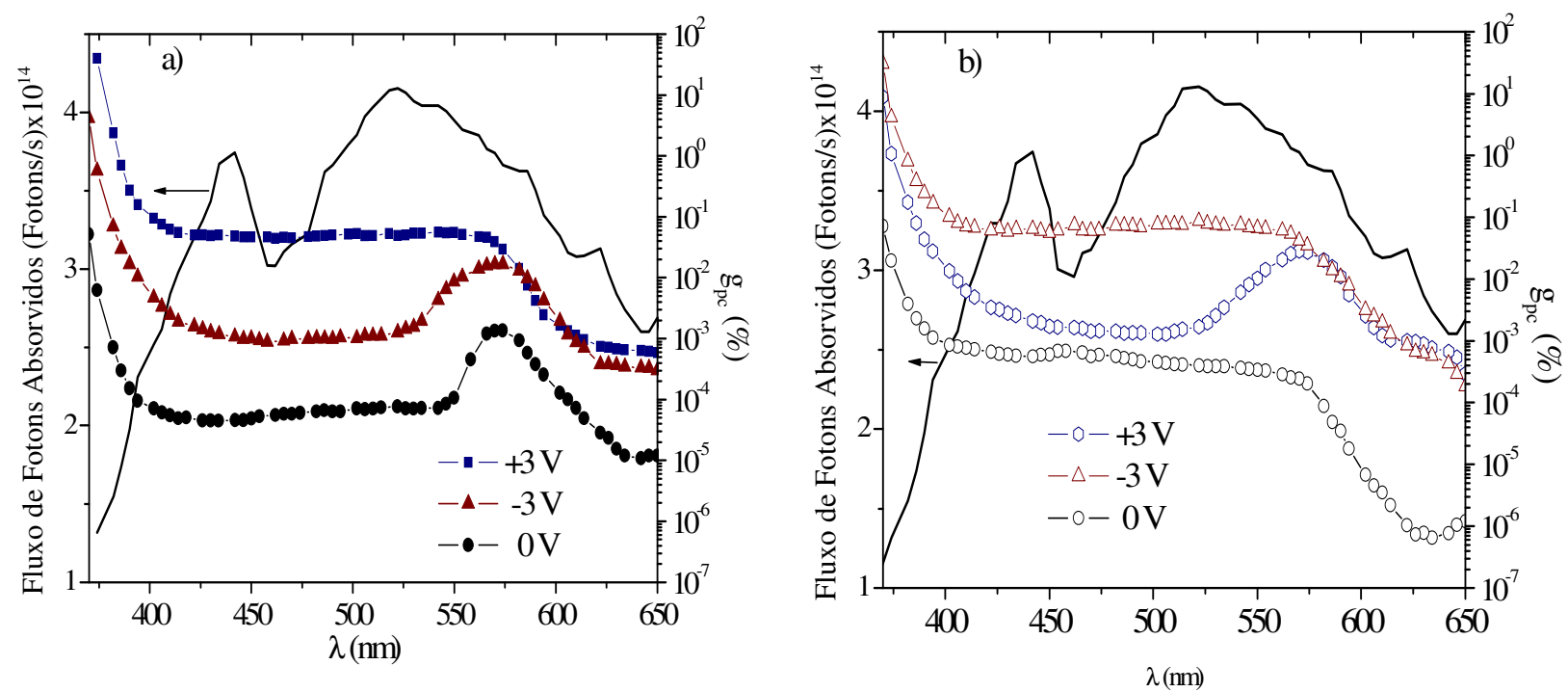

Figura 5.2: Fluxo de Fótons absorvidos (linha continua) e a eficiência interna para todo o espectro da luz incidente no dispositivo ITO/MEH-PPV/AI, a) através do ITO e b) através do eletrodo semitransparente de Al, em curto circuito $(V=0 \mathrm{~V})$ e sob tensões plicadas de $-3 \mathrm{~V}$ e $+3 \mathrm{~V}$.

Como observado nos gráficos da Figura 5.2-a e Figura 5.2-b, a maior diferença entre as eficiências internas ocorreram na região de maior absorção do polímero MEH-PPV, entre 
450 e $550 \mathrm{~nm}$. No gráfico da Figura 5.2-a, a diferença de valores de $g_{p c}$ nesta região para tensão aplicada $+3 \mathrm{~V}$ e $-3 \mathrm{~V}$ foi de aproximadamente duas ordens de grandezas, para incidência através do ITO e do Al. A diferença entre as $g_{p c}$ do dispositivo sob tensões com polaridades opostas está relacionada com a diferença de mobilidade dos portadores fotogerados, como discutido anteriormente. De maneira análoga é explicada a diferença entre as eficiências nesta mesma região para o dispositivo em curto-circuito. As Tabela 5.1 e Tabela 5.2 apresentam as eficiências $\left(g_{p c}\right)$ para dispositivos de MEH-PPV com eletrodos de $\mathrm{Cu}$ e $\mathrm{Mg}$ para diferentes tensões aplicadas e diferentes comprimentos de onda incidente através do ITO e dos eletrodos, respectivamente.

Tabela 5.1: Eficiência interna para dispositivos de MEH-PPV com diferentes eletrodos metálicos, sob diferentes tensões e comprimentos de onda incidentes no ITO.

\begin{tabular}{|r|c|c|c|}
\hline & $\mathbf{- 3 , 0} \mathbf{~ V}$ & $\mathbf{0 , 0} \mathbf{~ V}$ & $\mathbf{+ 3 , 0 ~ V}$ \\
\hline & $370 \mathrm{~nm}-500 \mathrm{~nm}$ & $370 \mathrm{~nm}-500 \mathrm{~nm}$ & $370 \mathrm{~nm}-500 \mathrm{~nm}$ \\
\hline $\mathbf{A l}$ & $4,5 \%-0,02 \%$ & $0,05 \%-0,00007 \%$ & $34 \%-0,04 \%$ \\
\hline $\mathbf{C u}$ & $3 \%-0,01 \%$ & $0,09 \%-0,00001 \%$ & $28 \%-0,02 \%$ \\
\hline $\mathbf{M g}$ & $5 \%-0,02 \%$ & $0,05 \%-0,00008 \%$ & $36 \%-0,04 \%$ \\
\hline
\end{tabular}

Tabela 5.2: Eficiência interna para dispositivos de MEH-PPV com diferentes eletrodos metálicos, sob diferentes tensões e comprimentos de onda incidentes nos eletrodos metálicos.

\begin{tabular}{|r|c|c|c|}
\hline & $\mathbf{- 3 , 0} \mathbf{~ V}$ & $\mathbf{0 , 0} \mathbf{~}$ & $\mathbf{+ 3 , 0 ~ V}$ \\
\hline $\mathbf{A l}$ & $370 \mathrm{~nm}-500 \mathrm{~nm}$ & $370 \mathrm{~nm}-500 \mathrm{~nm}$ & $370 \mathrm{~nm}-500 \mathrm{~nm}$ \\
\hline $\mathbf{C u}$ & $32 \%-0,07$ & $0,07 \%-0,0004$ & $16 \%-0,05 \%$ \\
\hline $\mathbf{M g}$ & $37 \%-0,02 \%$ & $0,01 \%-0,00001 \%$ & $8 \%-0,01 \%$ \\
\hline & & $0,04 \%-0,00002 \%$ & $22 \%-0,03 \%$ \\
\hline
\end{tabular}


De acordo com as tabelas de eficiência interna, o dispositivo com maior eficiência foi o de eletrodo de $\mathrm{Mg}$ sob iluminação de $370 \mathrm{~nm}$ sob tensão de $-3,0 \mathrm{~V}$ e incidência através do ITO. Em curto circuito e sob iluminação de $500 \mathrm{~nm}$ através dos eletrodos, os maiores valores de eficiências foram obtidos para o dispositivo com eletrodo de $\mathrm{Mg}$, o qual apresenta com maior tensão de built-in, e conseqüentemente, possui maior campo elétrico interno.

\subsubsection{Cálculo da eficiência interna do dispositivo ITO/OC10-PPV/Metais:}

As eficiências internas do dispositivo ITO/OC10-PPV/Al para diferentes comprimentos de onda e sob tensão aplicada de $-3 \mathrm{~V}$ e $+3 \mathrm{~V}$ e em curto-circuito, são mostradas pela Figura 5.3. Para incidência de luz através do eletrodo de ITO (Figura 5.3-a) as eficiências foram em média maiores para a tensão aplicada de $+3 \mathrm{~V}$ com relação às eficiências obtidas sob tensão de $-3 \mathrm{~V}$, incluindo a região de máxima absorção do OC10-PPV (450 a 550 $\mathrm{nm})$. Sob tensão de $+3 \mathrm{~V}$, a eficiência máxima obtida foi de $27 \%$ em $350 \mathrm{~nm}$. Para $\lambda>350$ nm, os valores diminuíram até atingir um patamar entre 400 e $500 \mathrm{~nm}$ onde as eficiências ficaram em torno de $0,06 \%$. Para $\lambda>500 \mathrm{~nm}$, as eficiências diminuíram até atingir um segundo patamar (entre 600 e $650 \mathrm{~nm}$ ) com eficiências de 0,0005\%. Sob tensão de $-3 \mathrm{~V}$, a eficiência máxima obtida foi de 5,6\% em $350 \mathrm{~nm}$. Para $\lambda>350 \mathrm{~nm}$, os valores diminuíram e atingiram um patamar de eficiências de $0,01 \%$ (entre 400 e $500 \mathrm{~nm}$ ) antes de diminuir para $\lambda$ $>550 \mathrm{~nm}$ até atingir um segundo patamar (entre 600 e $650 \mathrm{~nm}$ ) com eficiências de $0,004 \%$. Em curto-circuito, o máximo de eficiência ocorreu em $350 \mathrm{~nm}$ com valor de $0,1 \%$. Para comprimentos de onda entre 400 e $510 \mathrm{~nm}$ as eficiências permaneceram constantes com valores em torno de $0,02 \%$. Com incidência pelo eletrodo semitransparente de Al (Figura 5.3b), entretanto, as eficiências do dispositivo sob tensão negativa foram em média maiores que nas tensões positivas. O máximo valor de $g_{p c}$ obtido foi de $34 \%$ em $370 \mathrm{~nm}$ para $-3 \mathrm{~V}$. Sob 
tensão positiva, a eficiência nesta região foi de $11 \%$. Em curto circuito o máximo de eficiência foi de $0,1 \%$ e ocorreu em 350nm.
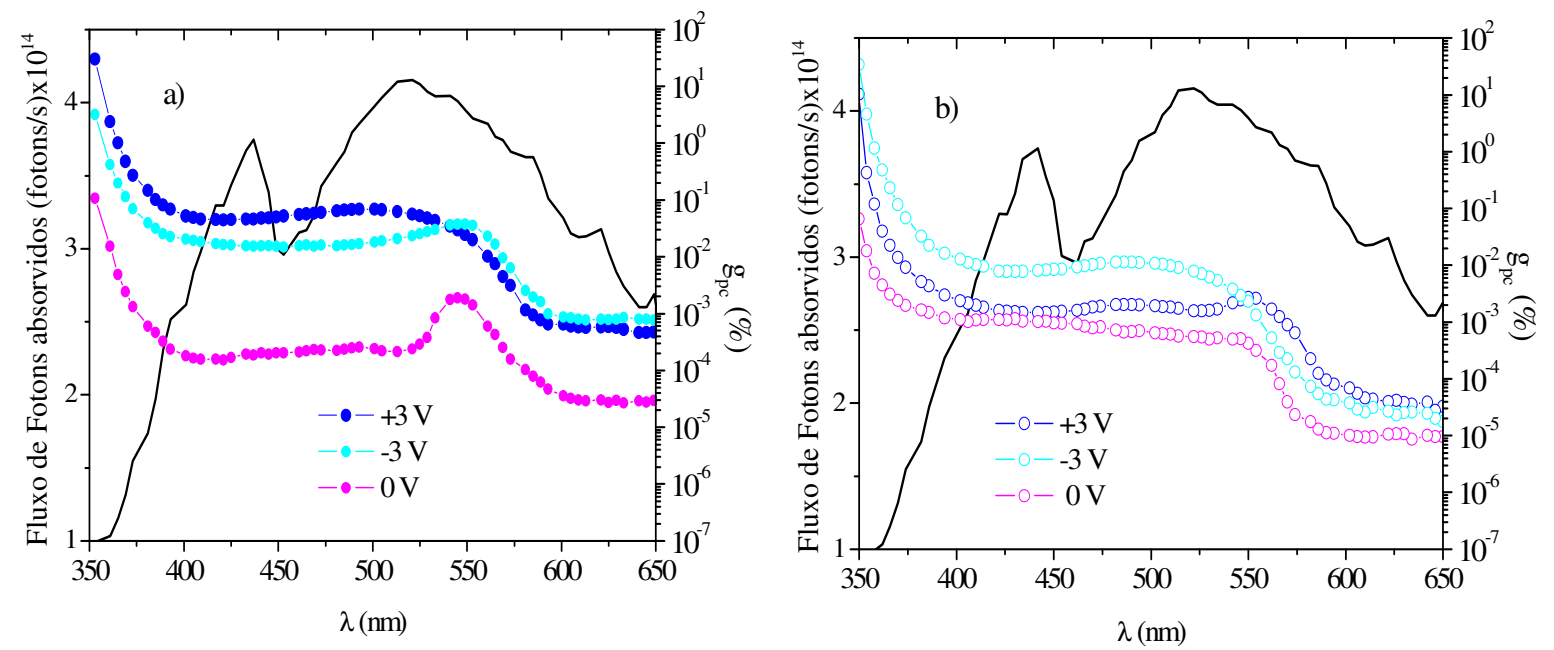

Figura 5.3: Fluxo de Fótons absorvidos (linha continua) e a eficiência interna para todo o espectro da luz incidente no dispositivo ITO/OC10-PPV/AI, a) através do ITO e b) através do eletrodo semitransparente de $\mathrm{Al}$, em curto circuito $(\mathrm{V}=0 \mathrm{~V})$ e sob tensões plicadas de $-3 \mathrm{~V}$ e $+3 \mathrm{~V}$.

Os valores das eficiências internas do dispositivo com estrutura ITO/OC10-PPV/Cu e ITO/OC10-PPV/Mg com incidência através do ITO, em curto-circuito e para tensões aplicadas de $+3 \mathrm{~V}$ e $-3 \mathrm{~V}$ são apresentados na Tabela 5.3. Os valores das eficiências do dispositivo para as mesmas tensões, com incidência através dos eletrodos semitransparente de $\mathrm{Cu}$ e $\mathrm{Mg}$, estão apresentados na Tabela 5.4.

Tabela 5.3: Eficiência interna para dispositivos de OC10-PPV com diferentes eletrodos metálicos, sob diferentes tensões e comprimentos de onda incidentes no ITO.

\begin{tabular}{|c|c|c|c|}
\hline & $\mathbf{- 3 , 0} \mathbf{~ V}$ & $\mathbf{0 , 0} \mathbf{~ V}$ & $\mathbf{+ 3 , 0} \mathbf{~}$ \\
\hline & $370 \mathrm{~nm}-500 \mathrm{~nm}$ & $370 \mathrm{~nm}-500 \mathrm{~nm}$ & $370 \mathrm{~nm}-500 \mathrm{~nm}$ \\
\hline $\mathbf{A l}$ & $5,6 \%-0,01 \%$ & $0,1 \%-0,02 \%$ & $27 \%-0,06 \%$ \\
\hline $\mathbf{C u}$ & $1,2 \%-0,01 \%$ & $0,1 \%-0,0002 \%$ & $30 \%-0,04 \%$ \\
\hline $\mathbf{M g}$ & $6 \%-0,02 \%$ & $0,4 \%-0,0003 \%$ & $45 \%-0,03 \%$ \\
\hline
\end{tabular}


Tabela 5.4: Eficiência interna para dispositivos de OC10-PPV com diferentes eletrodos metálicos, sob diferentes tensões e comprimentos de onda incidentes nos eletrodos metálicos.

\begin{tabular}{|c|c|c|c|}
\hline & $\mathbf{- 3 , 0} \mathbf{~ V}$ & $\mathbf{0 , 0} \mathbf{~ V}$ & $\mathbf{+ 3 , 0 ~ V}$ \\
\hline & $370 \mathrm{~nm}-500 \mathrm{~nm}$ & $370 \mathrm{~nm}-500 \mathrm{~nm}$ & $370 \mathrm{~nm}-500 \mathrm{~nm}$ \\
\hline $\mathbf{A l}$ & $34 \%-0,01 \%$ & $0,09 \%-0,0003 \%$ & $11 \%-0,002 \%$ \\
\hline $\mathbf{C u}$ & $30 \%-0,01 \%$ & $0,1 \%-0,0004 \%$ & $6 \%-0,02 \%$ \\
\hline $\mathbf{M g}$ & $33 \%-0,04 \%$ & $0,3 \%-0,0005 \%$ & $8 \%-0,005 \%$ \\
\hline
\end{tabular}

De acordo com as tabelas de eficiências internas do dispositivo com estrutura ITO/OC10-PPV/Al, a maior eficiência registrada foi $45 \%$ obtido para o eletrodo de $\mathrm{Mg}$ sob tensão de -3,0 V, com iluminação através do ITO.

\subsection{DEPENDÊNCIA FOTOCORRENTE DOS DISPOSITIVOS COM A INTENSIDADE INCIDENTE ( $\mathbf{I}_{\mathrm{PC}}$ VS $\left.\mathrm{I}_{0}\right)$ :}

Através da dependência da fotocorrente $\left(I_{p c}\right)$ gerada no dispositivo com a intensidade da luz monocromática incidente $\left(I_{0}\right)$, pode-se determinar o tipo de recombinação que ocorre entre as cargas fotogeradas nos polímeros usando a equação $I_{p c}=\left(I_{0}\right)^{m}$ (1.12). Para variar a intensidade da luz incidente, utilizaram-se combinações de filtros neutros de diferente transmitância. Os gráficos de $\log \left(I_{p c}\right)$ vs $\log \left(I_{0}\right)$ para as estruturas de SY, MEH e OC10, mostram que a dependência da fotocorrente com a intensidade de luz incidente é praticamente linear, ou seja, $m \approx 1$. Isso implica em que os mecanismos de recombinação se resumem ao denominado monomolecular, consistindo num mecanismo não de recombinação germinativa, mas preferencialmente num aprisionamento em armadilhas profundas de portadores (elétrons ou buracos) sob potencial de cargas opostas. 


\section{Dispositivo ITO/SY/Al:}

O gráfico da Figura 5.4 mostra a dependência linear da fotocorrente do dispositivo ITO/SY/Al em função de intensidade da luz em $470 \mathrm{~nm}$. A inclinação da curva obtida foi $m=$ 0,92, caracterizando a recombinação monomolecular entre as cargas fotogeradas no dispositivo ITO/SY/Al para este comprimento de onda.

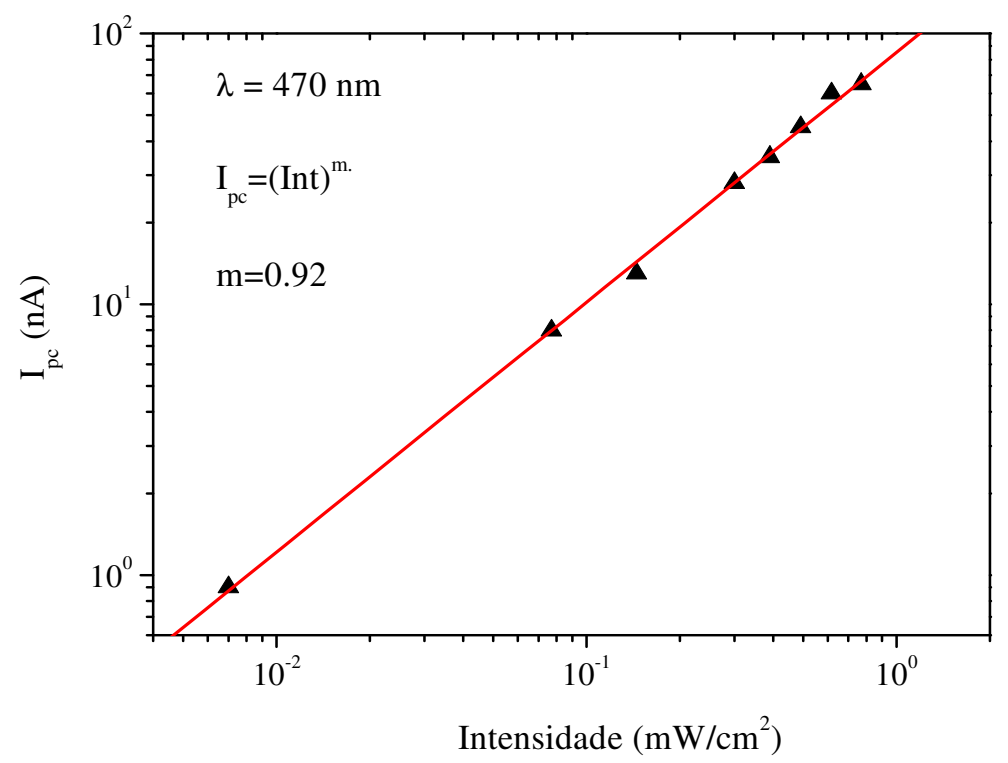

Figura 5.4: Dependência fotocorrente do dispositivo ITO/SY/AI em função das intensidades da luz monocromática de $470 \mathrm{~nm}$. 


\section{Dispositivo ITO/MEH-PPV/AI:}

O gráfico da Figura 5.5 mostra a dependência linear da fotocorrente do dispositivo ITO/MEH-PPV/Al em função de intensidade da luz em $550 \mathrm{~nm}$.

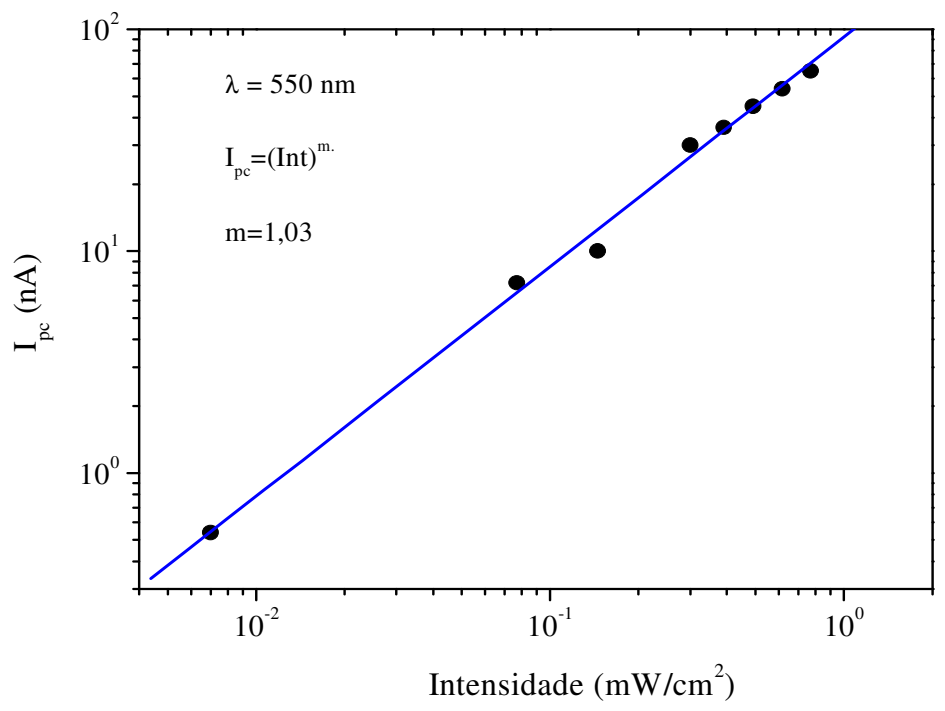

Figura 5.5: Dependência fotocorrente do dispositivo ITO/MEH-PPV/Al em função das intensidades da luz monocromática de $550 \mathrm{~nm}$.

A inclinação da curva da Fotocorrente em função da intensidade incidente de $m=1,03$ sugere que a recombinação entre os portadores fotogerados no MEH-PPV para este comprimento de onda é do tipo monomolecular. Este resultado está de acordo com os valores encontrados por Park et al $^{\mathbf{7 6}}$, que foi de 1,05 .

\section{Dispositivo ITO/OC10-PPV/AI:}

O gráfico da Figura 5.6 mostra a dependência linear da fotocorrente do dispositivo ITO/OC10-PPV/Al em função de intensidade da luz em $550 \mathrm{~nm}$. A inclinação da curva da fotocorrente em função da intensidade incidente de $m=0,96$ sugere que a recombinação entre os portadores fotogerados no OC10-PPV para este comprimento de onda é do tipo monomolecular. 


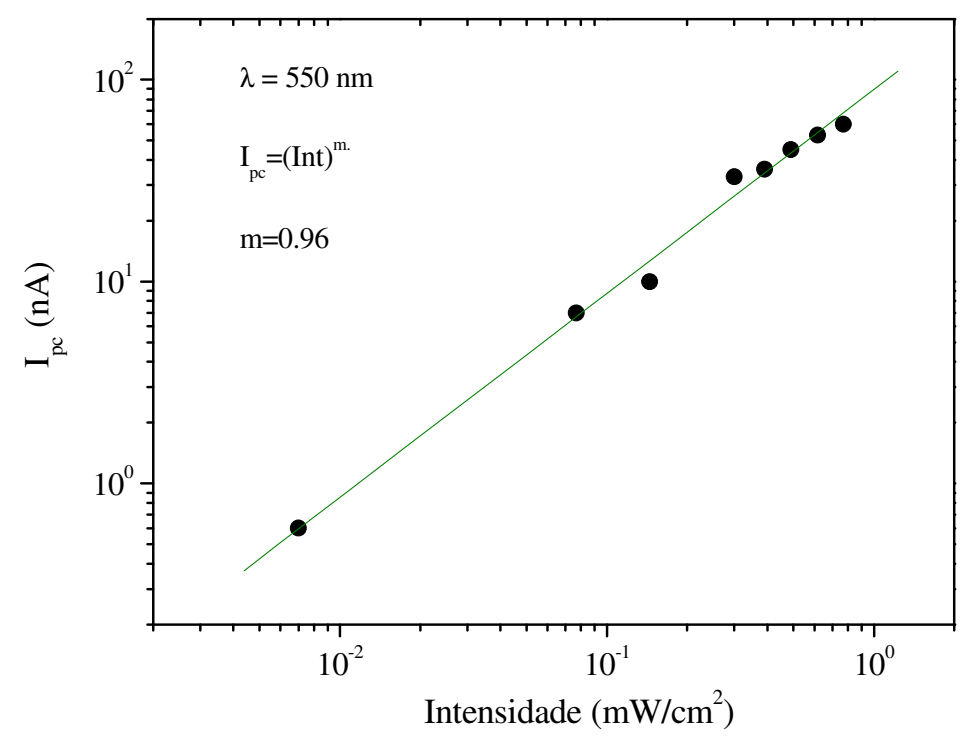

Figura 5.6: Dependência fotocorrente do dispositivo ITO/OC10-PPV/AI em função das intensidades da luz monocromática de $550 \mathrm{~nm}$.

\subsection{AJUSTE DOS ESPECTROS DE FOTOCORRENTE:}

As curvas de fotocorrente são importantes porque sua dependência com o comprimento de onda envolve vários fenômenos, desde o perfil de absorção da luz pelo polímero até os fenômenos de geração e recombinação. Nessas estruturas, é extremamente difícil definir equações que descrevam completamente os efeitos envolvidos. Mesmo assim, os resultados dos ajustes mostrados abaixo fornecem significativa contribuição quantitativa ao estudo do fenômeno de fotocondução em dispositivos orgânicos. Para realizar os ajustes teóricos através das Equações 2.37 e 2.38, assumiu-se que $x=l$ onde $l$ é a espessura do filme e o campo elétrico é uniforme ao longo da amostra. Foi necessário gerar funções que descrevessem o espectro de absorção dos polímeros, a Figura 5.7 mostra a comparação dos espectros de absorção experimental e da função teórica para os filmes (a) de SY, (b) de MEHPPV e (c) de OC10-PPV. 

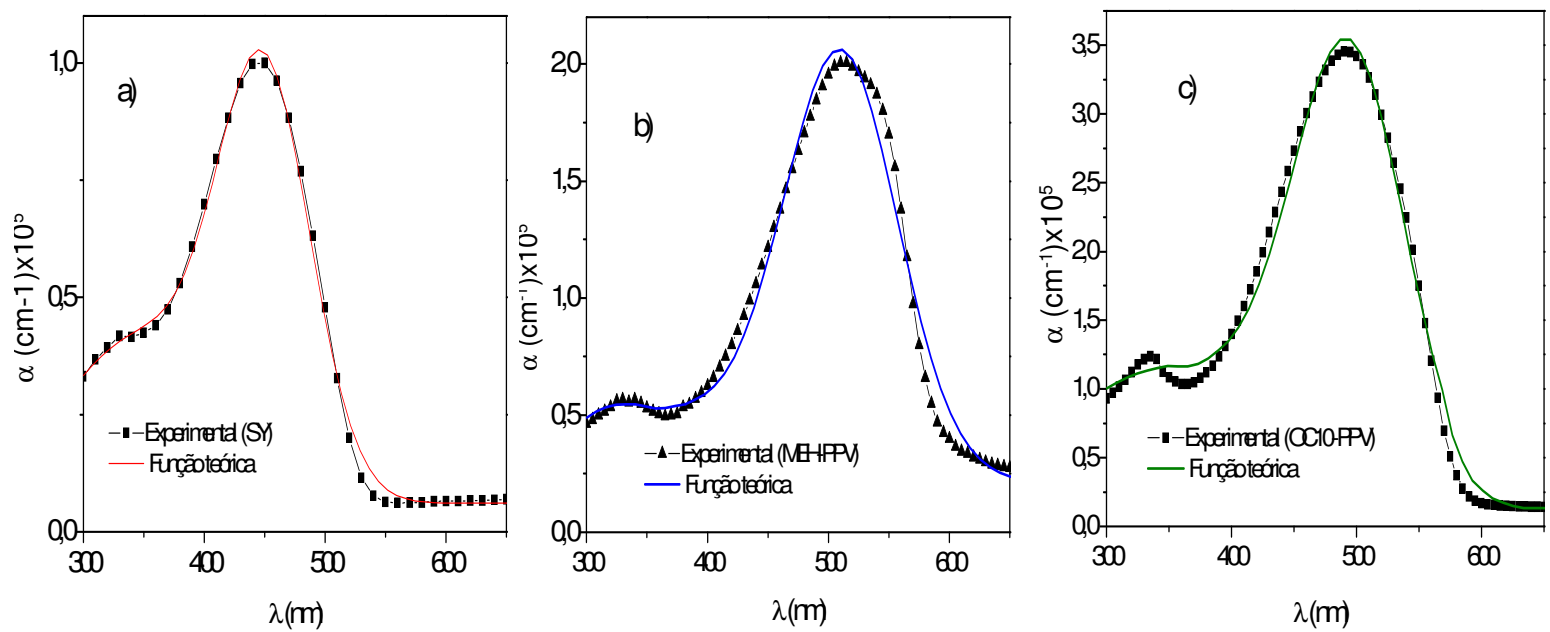

Figura 5.7: Espectros de absorção dos filmes a) SY, b) MEH-PPV e c) OC10PPV em comparação com as curvas geradas pelas funções teóricas (linha continua) do espectro de absorção utilizados posteriormente no ajustes teóricos dos espectros de fotocorrente.

Em seguida, os ajustes dos espectros simbáticos de fotocorrente dos dispositivos de SY, MEHPPV e OC10-PPV sob diferentes tensões aplicadas foram ajustados com êxito principalmente para comprimentos de onda maiores. Para esses comprimentos de onda a contribuição extrínseca é dominante. Na região de baixos comprimentos de onda, a curva experimental apresentou um aumento muito mais acentuado que a curva teórica, devido às altas eficiências de geração da fotocondução intrínseca nesta região. Foi necessário deconvoluir os espectros experimentais de fotocorrente para obter duas curvas, a primeira em baixos comprimentos de onda referentes à fotocondutividade intrínseca e a segunda, em comprimentos de onda maiores que o gap HOMO-LUMO dos polímeros, referente à fotocondutividade extrínseca. As curvas foram ajustadas separadamente, utilizando a mesma equação. Porém, para ajustar a curva deconvoluída referentes à fotocondutividade intrínseca, utilizou-se na equação teórica uma expressão dado por $\left(1 / \lambda-1 / \lambda_{0}\right)^{2}$ para produzir uma alta fotocorrente na região de baixos comprimentos de onda ${ }^{77,78}$, onde $\lambda_{0}$ representa o gap óptico do polímero. Esse parâmetro $\lambda_{0}$ traduz uma dependência do rendimento quântico com o comprimento de onda, visto que próximos aos eletrodos há uma maior densidade de espécies excitônicas. 


\section{Dispositivo ITO/SY/Al:}

A Figura 5.8 mostra os ajustes realizados nas curvas deconvoluídas do dispositivo ITO/SY/Al, quando iluminado pelo ITO, sob diferentes tensões aplicadas. A Figura 5.9 mostra os ajustes do mesmo dispositivo (ITO/SY/Al), quando iluminado através do eletrodo semitransparente de Al, sob diferentes tensões aplicadas. As curvas A e B são a deconvolução do espectro de fotocorrente. Os valores para o rendimento quântico $(\eta)$ dos ajustes (A e B), são apresentados na Tabela 5.5 assim como em detalhes nos gráficos
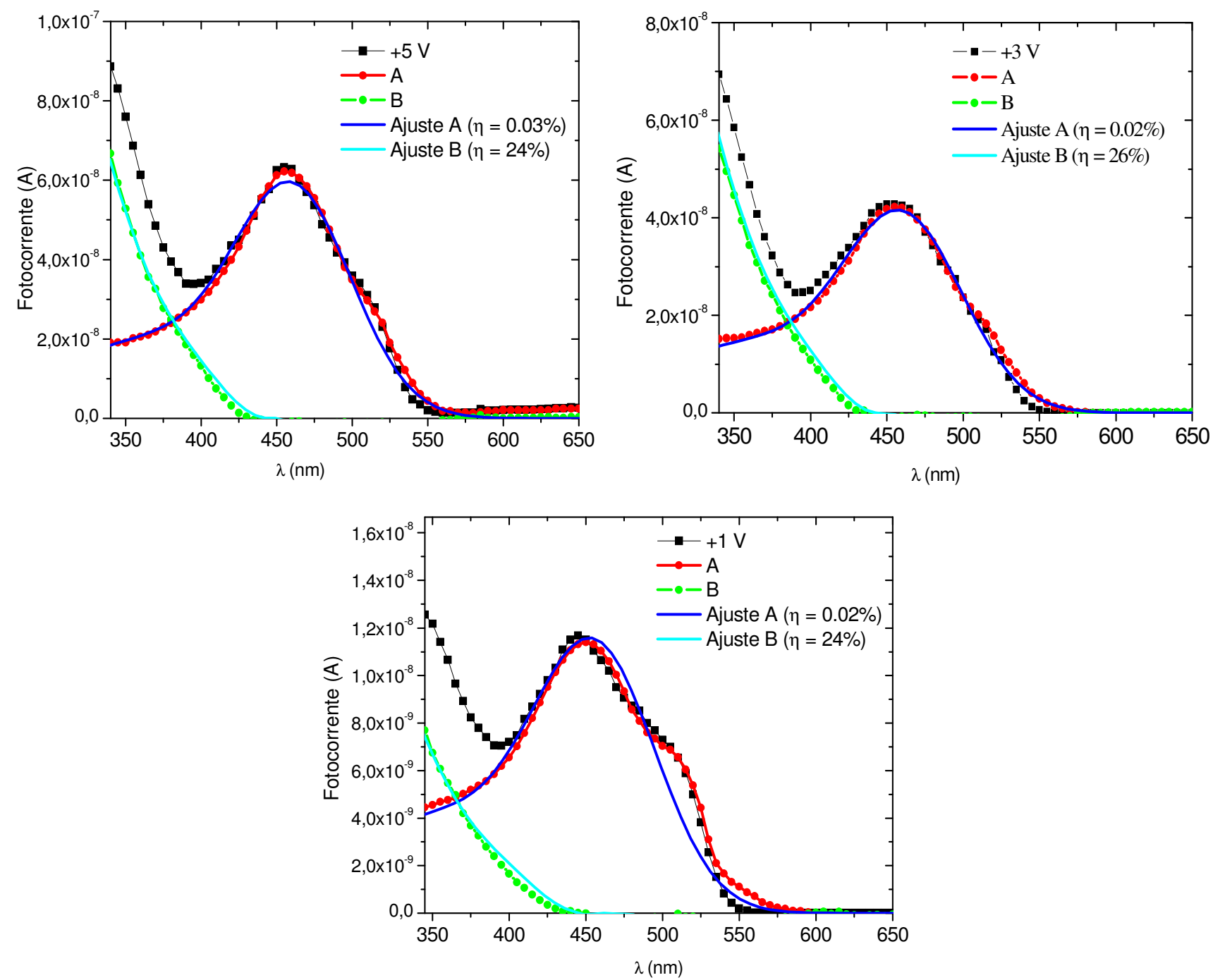

Figura 5.8: Ajustes das curvas deconvoluídas do espectro de fotocorrente com diferentes tensões aplicadas positivas no dispositivo ITO/SY/AI iluminado pelo ITO. 

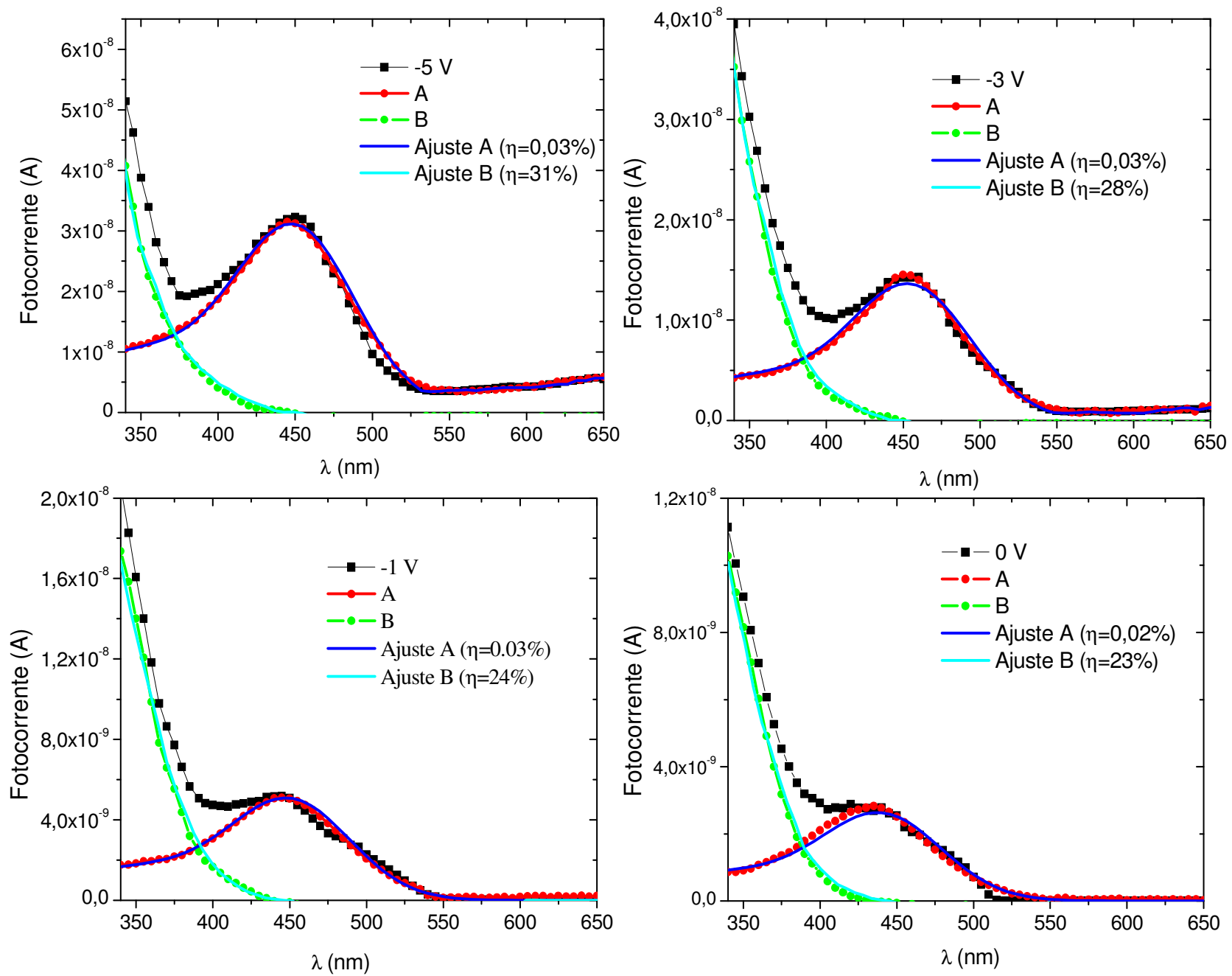

Figura 5.9: Ajustes das curvas deconvoluídas do espectro de fotocorrente com diferentes tensões aplicadas negativas no dispositivo ITO/SY/AI iluminado pelo Al.

Tabela 5.5: Valores do rendimento quântico obtidos dos ajustes das curvas A e B deconvoluídas do espectro de fotocorrente do dispositivo ITO/SY/Metal iluminado ora pelo ora pelos eletrodos metálicos (Al,Cu e Mg), sob diferentes tensões aplicadas.

\begin{tabular}{|c|c|c|c|c||c|c|c|c|}
\hline \multicolumn{2}{|c|}{ ITO/SY/Metal } & \multicolumn{3}{c||}{ Incidência pelo ITO } & \multicolumn{4}{c|}{ Incidência pelo metal } \\
\hline Metal & Ajuste & $\mathbf{+ 5 , 0} \mathbf{~ V}$ & $\mathbf{+ 3 , 0} \mathbf{~}$ & $\mathbf{+ 1 , 0}$ V & $\mathbf{- 5 , 0 ~ V}$ & $\mathbf{- 3 , 0}$ V & $\mathbf{- 1 , 0 ~ V}$ & $\mathbf{0 , 0}$ V \\
\hline \hline \multirow{2}{*}{ Al } & A $(\eta)$ & $0,03 \%$ & $0,02 \%$ & $0,02 \%$ & $0,03 \%$ & $0,03 \%$ & $0,03 \%$ & $0,02 \%$ \\
\cline { 2 - 9 } & B $(\eta)$ & $24 \%$ & $26 \%$ & $24 \%$ & $31 \%$ & $28 \%$ & $24 \%$ & $23 \%$ \\
\hline \hline
\end{tabular}




\section{Dispositivo ITO/MEH-PPV/Metais.}

A Figura 5.10 mostra os ajustes realizados nas curvas deconvoluídas dos espectros de fotocorrente do dispositivo ITO/MEH-PPV/Al $(l=480 \mathrm{~nm})$, quando iluminado pelo ITO, sob diferentes tensões aplicadas.
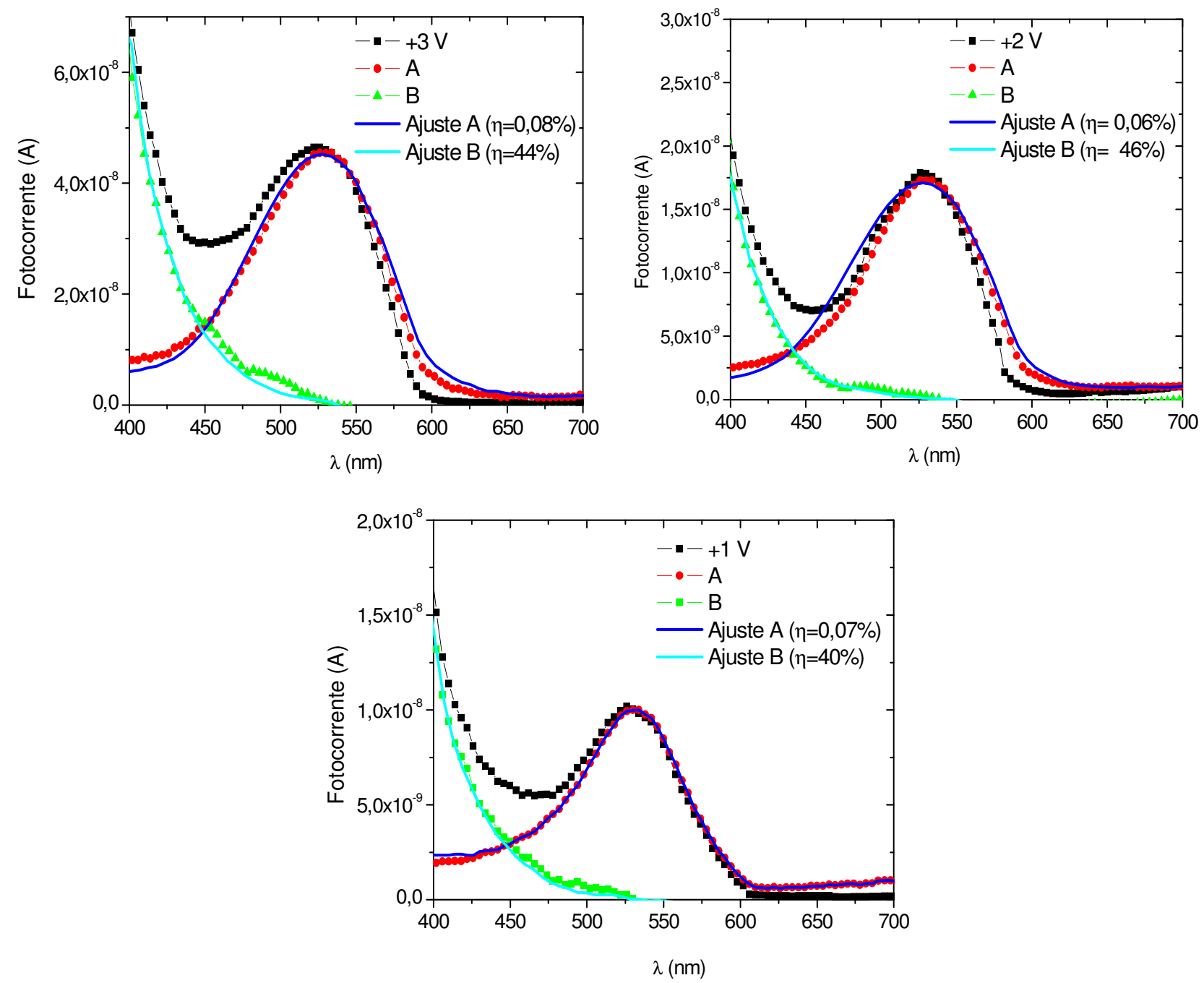

Figura 5.10: Ajustes das curvas deconvoluídas do espectro de fotocorrente com diferentes tensões aplicadas positivas no dispositivo ITO/MEH-PPV/AI iluminado pelo ITO. 
A Tabela 5.6 mostra os valores obtidos para o rendimento quântico $(\eta)$ dos ajustes realizados nos espectros obtidos do dispositivo ITO/MEH-PPV/Metal, quando iluminado ora através do ITO ora através do eletrodo metálico semitransparente sob diferentes tensões aplicadas.

Tabela 5.6: Valores do rendimento quântico obtidos dos ajustes das curvas A e B deconvoluídas do espectro de fotocorrente do dispositivo ITO/MEH-PPV/Metal iluminado ora pelo ora pelos eletrodos metálicos (Al,Cu e Mg), sob diferentes tensões aplicadas.

\begin{tabular}{|c|c|c|c|c||c|c|c|c|}
\hline \multicolumn{2}{|c|}{$\begin{array}{c}\text { ITO/MEH- } \\
\text { PPV/Metal }\end{array}$} & \multicolumn{3}{c||}{ Incidência pelo ITO } & \multicolumn{4}{c|}{ Incidência pelo metal } \\
\hline Metal & Ajuste & $\mathbf{+ 3 , 0}$ V & $\mathbf{+ 2 , 0}$ V & $\mathbf{+ 1 , 0}$ V & $\mathbf{- 3 , 0}$ V & $\mathbf{- 2 , 0}$ V & $\mathbf{- 1 , 0}$ V & $\mathbf{0 , 0}$ V \\
\hline \multirow{2}{*}{$\mathrm{Al}$} & $\mathrm{A}(\eta)$ & $0,08 \%$ & $0,06 \%$ & $0,07 \%$ & $0,07 \%$ & $0,08 \%$ & $0,06 \%$ & $0,07 \%$ \\
\cline { 2 - 9 } & $\mathrm{B}(\eta)$ & $44 \%$ & $46 \%$ & $40 \%$ & $42 \%$ & $40 \%$ & $39 \%$ & $40 \%$ \\
\hline \multirow{2}{*}{$\mathrm{Cu}$} & $\mathrm{A}(\eta)$ & $0,05 \%$ & $0,05 \%$ & $0,06 \%$ & $0,06 \%$ & $0,06 \%$ & $0,04 \%$ & $0,07 \%$ \\
\cline { 2 - 9 } & $\mathrm{B}(\eta)$ & $40 \%$ & $40 \%$ & $42 \%$ & $44 \%$ & $41 \%$ & $47 \%$ & $40 \%$ \\
\hline \hline \multirow{2}{*}{$\mathrm{Mg}$} & $\mathrm{A}(\eta)$ & $0,08 \%$ & $0,09 \%$ & $0,08 \%$ & $0,06 \%$ & $0,08 \%$ & $0,07 \%$ & $0,06 \%$ \\
\cline { 2 - 9 } & $\mathrm{B}(\eta)$ & $53 \%$ & $55 \%$ & $51 \%$ & $49 \%$ & $51 \%$ & $55 \%$ & $47 \%$ \\
\hline
\end{tabular}

\section{Dispositivo ITO/OC10-PPV/Metais.}

Os espectros de fotocorrente obtidos do dispositivo ITO/OC10-PPV/Metais foram deconvoluídos e ajustados separadamente. A Tabela 5.7 mostra os valores obtidos para o rendimento quântico $(\eta)$ para cada um dos ajustes (A e B) realizados nos espectros obtidos do dispositivo quando iluminado através do ITO e dos eletrodos Metalicos, sob diferentes tensões aplicadas. 
Tabela 5.7: Rendimentos quânticos obtidos dos ajustes das curvas deconvoluídas do espectro de fotocorrente do dispositivo ITO/OC10-PPV/AI iluminado ora pelo ora pelos eletrodos metálicos (Al,Cu e Mg), sob diferentes tensões aplicadas.

\begin{tabular}{|c|c|c|c|c|c|c|c|c|}
\hline \multicolumn{2}{|c|}{$\begin{array}{c}\text { ITO/OC10- } \\
\text { PPV/AI }\end{array}$} & \multicolumn{3}{|c|}{ Incidência pelo ITO } & \multicolumn{4}{|c|}{ Incidência pelo metal } \\
\hline Metal & Ajuste & $+3,0 \mathrm{~V}$ & $+2,0 \mathrm{~V}$ & $+1,0 \mathrm{~V}$ & $-3,0 \mathrm{~V}$ & $-2,0 \mathrm{~V}$ & $-1,0 \mathrm{~V}$ & $\mathbf{0 , 0} \mathrm{V}$ \\
\hline \multirow{2}{*}{$\mathrm{Al}$} & $\mathrm{A}(\eta)$ & $0,08 \%$ & $0,07 \%$ & $0,08 \%$ & $0,06 \%$ & $0,07 \%$ & $0,05 \%$ & $0,06 \%$ \\
\hline & $\mathrm{B}(\eta)$ & $44 \%$ & $42 \%$ & $38 \%$ & $38 \%$ & $31 \%$ & $35 \%$ & $40 \%$ \\
\hline \multirow{2}{*}{$\mathrm{Cu}$} & $A(\eta)$ & $0,06 \%$ & $0,06 \%$ & $0,07 \%$ & $0,07 \%$ & $0,05 \%$ & $0,04 \%$ & $0,04 \%$ \\
\hline & $\mathrm{B}(\eta)$ & $36 \%$ & $38 \%$ & $36 \%$ & $41 \%$ & $40 \%$ & $40 \%$ & $39 \%$ \\
\hline \multirow{2}{*}{$\mathrm{Mg}$} & $\mathrm{A}(\eta)$ & $0,08 \%$ & $0,08 \%$ & $0,05 \%$ & $0,07 \%$ & $0,06 \%$ & $0,07 \%$ & $0,07 \%$ \\
\hline & $\mathrm{B}(\eta)$ & $51 \%$ & $55 \%$ & $50 \%$ & $48 \%$ & $46 \%$ & $51 \%$ & $48 \%$ \\
\hline
\end{tabular}

Os valores dos rendimentos quânticos obtidos das curvas A (fotocondutividade extrínseca) foram 3 ordens de magnitude menores que os valores obtidos das curvas B (fotocondutividade intrínseca). Os valores obtidos dos ajustes de rendimento quântico $(\eta)$ foram satisfatórios e estão coerentes com os valores de eficiência interna dos dispositivos já apresentados nesse capítulo. Esses valores estão em pleno acordo com o rendimento quântico de geração extrínseco e intrínseco para os polímeros da família do PPV. 


\section{Discussões e Perspectivas}

\subsection{DISCUSSÕES:}

\subsubsection{Medidas de corrente versus tensão (I-V) iluminada.}

Os resultados das medidas de corrente versus tensão $(I-V)$ permitiram analisar a fotocondutividade dos dispositivos com estrutura ITO/polímero/metais em função do comprimento de onda da luz incidente e concluir que os portadores são fotogerados com maior eficiência pelos comprimentos de onda mais energéticos e penetrantes, e pelos comprimentos de onda fortemente absorvidos. A disparidade entre as mobilidades dos portadores (elétrons e buracos), e a distância entre a região onde eles foram gerados e os eletrodos onde foram coletados, explicam o comportamento da curva $I$ - $V$ no modo reverso e direto para os diferentes lados de incidência da luz. Em vários casos, o lado de incidência da luz causou a inversão no fator de retificação do diodo. A utilização dos eletrodos metálicos com diferentes funções trabalho possibilitou a comparação entre o potencial de built-in $\left(V_{B}\right)$ e a tensão de circuito aberto $\left(V_{O C}\right)$ dos dispositivos, cujos valores foram bem próximos, demonstrando que as propriedades fundamentais dos dispositivos não foram alteradas.

Realizou-se, durante esta tese, medidas de condutividade alternada (ac) nos dispositivos com estrutura ITO/polímero/metais em diferentes condições de iluminação e valores de tensão dc aplicada, e observou-se que a condutividade em altas freqüências não varia com o comprimento de onda da luz incidente. Porém, em baixas freqüências observouse uma dependência considerável, como mostra os resultados da Figura 6.1. 


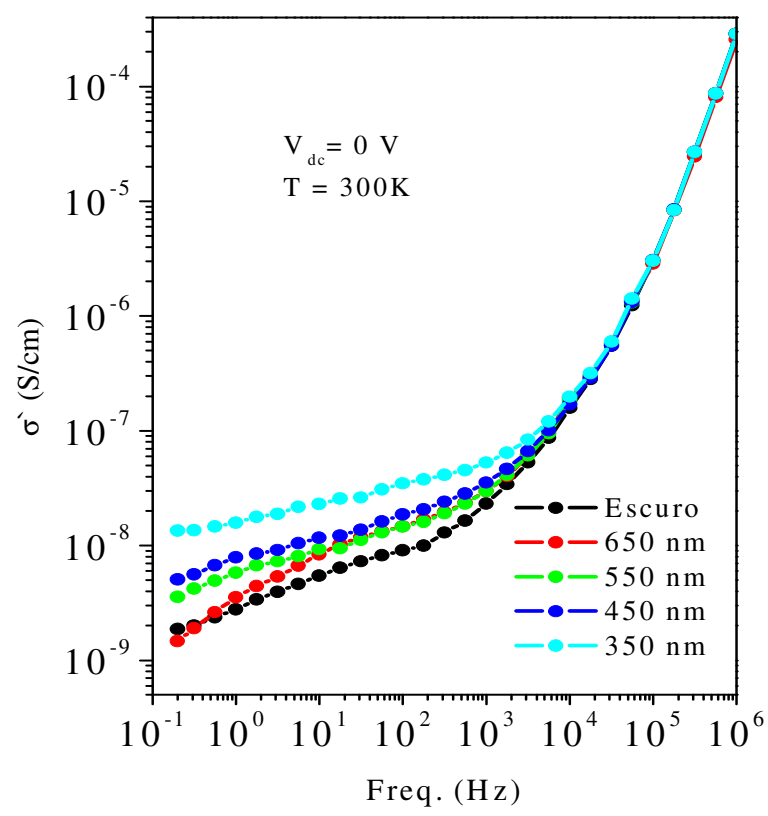

Figura 6.1: Componente real da condutividade complexa do dispositivo ITO/OC10-PPV/AI em curto-circuito $\left(V_{d c}=0 \mathrm{~V}\right)$, no escuro e sob iluminação em diferentes comprimentos de onda.

Pode-se, numa primeira análise, inferir que os portadores que se movem a distâncias comparáveis à espessura da amostra são responsáveis pela condutividade e pela fotocondutividade no domínio de baixas freqüências e, portanto, o escopo desse trabalho se limitou à fotocondução no regime dc. No domínio de altas freqüências, não se observou o fenômeno da fotocondutividade, pois o movimento dos portadores fica limitado a uma pequena região no interior do filme e sua densidade não deve variar sob iluminação.

\subsubsection{Medidas dos espectros de fotocorrente.}

Através dos espectros de fotocorrente obtidos nos dispositivos foi possível constatar que, independentemente do eletrodo utilizado, a fotocorrente foi sempre dominada pelos portadores de maior mobilidade (buracos) e que o comportamento simbático e antibático é, 
em primeira aproximação, determinado pela mobilidade dos portadores e pela distância entre a região de foto-geração e o eletrodo para onde são conduzidos. A intensidade da fotocorrente está relacionada com a intensidade do campo elétrico no interior do dispositivo. Utilizando-se eletrodos metálicos com diferentes funções trabalho, observou-se que a inversão de sinal do espectro de fotocorrente ocorreu para valores de tensão aplicada equivalentes a tensão de circuito aberto $\left(V_{O C}\right)$ e, portanto, semelhantes em modulo ao potencial built-in $\left(V_{B}\right)$ da estrutura. O comportamento da fotocorrente é regido pela combinação de vários parâmetros: i) o perfil de penetração da luz no polímero, determinado pelo coeficiente de absorção; ii) a variação da quantidade de cargas fotogeradas em função do comprimento de onda, determinado pelo rendimento quântico $(\eta)$ do polímero; iii) a competição entre as fotocondutividades intrínseca e extrínseca. Esse estudo levou a conclusão de que, a eficiência de geração de portadores, que está diretamente associada ao rendimento quântico do efeito intrínseco, é muito superior ao extrínseco, o que está de acordo com a literatura.

\subsubsection{Modelo utilizado no ajuste dos espectros de fotocorrente.}

Para se chegar a um modelo teórico que descrevesse a fotocorrente obtida dos dispositivos sob o efeito do campo elétrico, utilizou-se uma teoria de transporte de cargas em que o processo de difusão dos portadores foi negligenciado, levando-se em consideração que a condução das cargas livres fotogeradas pelo campo elétrico aplicado é o processo dominante. Os ajustes dos espectros de fotocorrente deconvoluídos pelo modelo teórico utilizado foram bastante satisfatórios, permitindo-se obter informações do rendimento quântico da fotocondutividade intrínseca e extrínseca, cujos valores corroboraram com os valores da literatura. É bom destacar que uma das aproximações usadas foi a uniformidade do campo elétrico ao longo da amostra. Além disso, foi constatado através dos cálculos de 
eficiências, que os dispositivos com eletrodo de $\mathrm{Mg}$ apresentaram maiores eficiência em relação aos demais eletrodos metálicos.

\subsection{PERSPECTIVAS:}

Como perspectiva para trabalhos futuros, sugere-se realizar o estudo da fotocondutividade em regime dc dos diodos poliméricos para diferentes temperaturas verificando questões de mobilidade, difusão e dissociação de éxcitons. Além disso, estudar o efeito da fotocondutividade em regime ac, realizadas através da espectroscopia de fotoimpedância ${ }^{79}$ limitada para freqüências até $10^{4} \mathrm{~Hz}$, visto que acima dessa freqüência a fotocondutividade não se faz presente. Através dessa técnica, é possível determinar o comportamento da fotocondutividade em função da freqüência do campo elétrico e os processos de relaxação, assim como analisar a distribuição de cargas nas interfaces metal/polímero dos dispositivos com incidência de diferentes comprimentos de onda ${ }^{\mathbf{8 0}}$ e para diferentes temperaturas.

A mobilidade dos portadores fotogerados é uma grandeza de fundamental importância para a melhor compreensão do comportamento dos espectros de fotocorrente. Através das medidas de fotocorrente no transiente (resolução temporal) é possível determinar não somente a mobilidade dos portadores fotogerados como também verificar o tempo de vida, a dinâmica dos portadores fotogerados e das recombinações ${ }^{\mathbf{8 1}}$.

Para melhorar o modelo teórico, propõe-se substituir o efeito "cut-off" do parâmetro $\lambda_{0}$ utilizados nos ajustes da fotocondução intrínseca, por uma função $\eta(\lambda)$ - rendimento em função do comprimento de onda - seguindo os valores experimentais da eficiência do dispositivo $\left(g_{p c}\right)$ apresentado no capítulo 5 . 


\section{REFERÊNCIAS}

${ }^{1}$ GREENHAM N. C.; FRIEND R. H., Quantum theory of solids. Solid State Physics, v. 49, p. $1,1995$.

2 HEEGER, A. J. et al, Solitons in conducting polymers. Reviews of Modern Physics, v. 60. n. 3, p. 781-850, 1988.

${ }^{3}$ POPE M.; SWENBERG C. E., Electronic process in organic crystals and polymers. 2.ed. Oxford: Clarendon Press, 1999.

${ }^{4}$ DAVYDOV A. S., Theory of molecular éxcitons. New York: Plenum, 1971.

${ }^{5}$ UETA M., Excitonic processes in solids. Berlin: Springer-Verlag, 1986.

${ }^{6}$ HARRIS, D. C.; BERTOLUCCI, M. D. Symmetry and spectroscopy an introduction to vibrational and electronic spectroscopy. New York, Dover Publications, 1989.

7 BURROUGHES J. H.; JONES C. A.; FRIEND R. H., Light-emitting diodes based on conjugated polymers. Nature, London, v. 335, n. 6186, p. 137, 1988.

${ }^{8}$ Marks R. et al, The photovoltaics response in poly (p-phenylene vinylene) thin film devices. Journal of Physics: Condensed Matter, v. 6, n. 7, p. 1379-1394, 1994.

${ }^{9}$ RHODERICK E. H., Metal-Semiconductor Contacts. 3.ed. Oxford: Clarendon Press, 1980.

10 SANTOS L. F., Estudos de processos de transporte em dispositivos poliméricos emissores de luz, 2003. 201p. Tese (Doutorado em Ciência: Física Aplicada), Instituto de Física IFSC, São Carlos, 2003.

11 PARKER, L. D., Carrier tunneling and device characteristics in polymer light-emitting diodes. Journal Applied Physics, v. 75, n. 3, p. 1656, 1994.

12 PETRITSCH K., Organic solar cells architectures, 159p. Tese (Doutorado), TechnishNaturwissenschaft Fakultat der Universitat Graz (Áustria), 2000.

13 BRABEC C. J. et al, Organic Photovoltaics. Berlim: Springer-Verlag, 2003.

14 INGANÄS O. et al, Recent progress in thin film organic photodiodes. Synthetic Metals. v. 121, n. 1-3, p. 1525-1528, 2001.

15 SPANGGAARD H.; KREBS F. C., A brief history of the development of organic and polymeric photovoltaics. Solar Energy Materials \& Solar Cells, v. 83, n. 2-3, p. 125, 2004.

16 HALlS J. J. M. et al, Exciton diffusion and dissociation in a poly (pphenylenevynilene)/C60 heterojunction photovoltaic cell. Applied Physics Letters, v. 68, n. 22, p. 3120, 1996. 
${ }^{17}$ MUNTERS, T. et al, A comparison between state-of-the-art gilch and sulphinyl synthesized MDMO-PPV/PCBM bulk hetero-junction solar cells. Thin Solid Films, v. 403-404, p. $247-$ $251,2002$.

${ }^{18}$ LIU, J.; SHI, Y. J.; YANG, Y., Solvation-induced morphology effects on the performance of polymer-based photovoltaic devices. Advanced Functional Materials, v.11, n.6, p.420424, 2001.

19 BUBE R. H., Photoconductivity of Solids. New York: Wiley,1960. p.461.

20 ROSE A., Concepts in photoconductivity and allied problems. New York, Interscience Publishers, 1963.

21 MORT J.; PAI D. M., Photoconductivity and related problems. Amsterdam: Elsevier Scientific, 1979.

${ }^{22}$ SMITH W., Effect of light on selenium during the passage of an electric current. Nature. v. 7, n. 314, p. 303, 1873.

23 PATSIS A. V.; SEANOR D. A., Photoconductivity in Polymer: a interdisciplinary approach. WestPort: Conn, Thecnomic Pub Co, 1976, 377.

${ }^{24}$ KATO K.; BRAUN C. L., The photoconduction threshold in anthracene single crystals. Journal Chemical Physics, v. 72, n. 1, p. 172, 1980.

25 SWORAKOWSKI J.; ULANSKI J., Electrical properties of organic materials. Annual Reports Chemistry, Section C. v. 99, DOI 10.1039/b208498h, p. 87-125, 2003.

${ }^{26}$ HARRISON M. G., GRÜNER J., SPENCER G. C. W. Analysis of the photocurrent action spectra of MEH-PPV polymer photodiodes. Physical Review B. v. 55, n. 12, p. 7831, 1997.

27 FARCHIONI R.; GROSSO G., Organic Electronic Materials. Berlim:Springer-Verlag, 2001. ISBN: 0933-033X.

28 HENDRY. E. et al, Efficiency of exciton and charge carrier photogeneration in a semiconducting polymer. Physical Review Letters, v. 92, n. 19, p. 196601-1, 2004.

${ }^{29}$ WEISER, G., Stark effect of one-dimensional Wannier excitons in polydiacetylene single crystals. Physical Review B, v. 45, n. 24, p. 14076, 1992.

30 GAILBERGER M.; THANH B. N.; BÄSSLER H., Photoconductivity in conjugated polymers. Molecular crystals and Liquid crystals, v. 216, p. 485-489, 1992.

31 SANTOS L. F. et al, Photogenerated carrier profile determination in polymeric lightemitting diodes by steady-state and transient photocurrent measurements. Material Science \& Engineering B, v. 135, n. 2, p. 103-107, 2006.

32 LEE C. H.; YU G.; HEEGER A. J., Persistent Photoconductivity in poly(pphenilenevinylene): Spectra response and slow relaxation. Physical Review B, v. 47, n. 23, p. 15 543, 1993. 
33 PAKBAZ K. et al, Nature of the primary photoexcitations in poly(arylene-vinylenes). Synthetic Metals, v. 64, n.2-3, p. 295, 1994.

${ }^{34}$ KAO K. C.; HWANG W., Electrical Transport in Solids. Oxford: Pergamon, 1979.

35 HARRISON M. G.; GRÜNER J., Further Evidence for the role of excitons in photogeneration of charges in poly (phenylene vinylenes)s. Synthetic Metals. v. 84, n. 1-3, p. 653-654, 1997.

${ }^{36}$ CHANDROSS M., et a.l Excitons in poly (para-phenylenevinylene). Physical Review B. v. 50, n. 19, p. 14702-14705, 1994.

${ }^{37}$ FRANKEVICH E. L., et al. Polaron-pair generation in poly(phenylene vinylenes). Physical Review B. v. 46, n. 15, p. 9320, 1992.

38 KHAN I. M.; BARZAN G. C.; POPOVIC Z. D., Evidence for electrical field-assisted dissociation of the excited singlet state into charge carriers in MEH-PPV. Chemical Physics Letter. v. 298, n. 4-6, p. 309-314, 1998.

${ }^{39}$ PERSSON B. N. J.; LANG N. D., Electron-hole-pair quenching of excited states near a metal. Physical Review B, v. 26, n. 10, p. 5409-5415, 1982.

40 ANTONIADIS H., ABKOWITZ M. A. Enhanced carrier photogeneration by defects in conjugated polymers and its mechanism. Physical Review B. v. 50, n. 20, p. 14 911, 1994.

41 CHAWDHURY N. et al, The effects of $\mathrm{H}_{2} \mathrm{O}$ and $\mathrm{O}_{2}$ on the photocurrent spectra of MEHPPV. Synthetic Metals. v. 102, n. 1-3, p. 871-872, 1999.

42 TANG C. W., Two-layer organic photovoltaic cell. Applied Physics Letters, v. 48, n. 15, p. 183-185, 1986.

43 CHEN L et al, Excitation Transfer in Polymer Photodiodes for Enhanced Quantum Efficiency. Advanced Materials, v. 12, n. 15, p. 1110-1114, 2000.

44 BIANCHI R. F. et al, Alternating electrical conductivity of polyaniline. Journal of Chemical Physics, v. 110, n. 9, p. 4602, 1999.

45 . ROTH S., One-Dimensional Metals. Weinheim: Wiley-VCH, 1995.

46 MOTT N. F.; DAVIS E. A., Electronic Process in Non-Crystalline Materials. Oxford: Clarendon, 1979.

47 BREDAS J. L. et al, Ab initio effective Hamiltonian study of the electronic properties of conjugated polymers. Journal Chemical Physics, v. 76, n. 7, p. 3673-3678, 1982.

48 TAKIGUCHI T. et al, Photoconductivity and carrier transport process in poly (p-phenylene vinylene) film. Synthetic Metals. v. 17, n. 1-3, p. 657-662, 1987.

49 OBRZUT J.; OBRZUT M. J.; KARASZ F. E., Photoconductivity of poly (p-phenylene vinylene). Synthetic Metals. v. 29, n. 1, p. 103-108, 1989. 
50 ANTONIADIS H.; ABKOWITZ M. A.; HSIEH B. R., Carrier Deep-Trapping MobilityLifetime Products in poly (p-phenylene vinylene). Applied Physics Letters. v. 65, n. 16, p. 2030-2032, 1994.

51 ASHCROFT N. W.; MERMIN N. D., Solid State Physics. New York; Holt, Rinehart and Winston, 1976, cap. 1.

52 RAKHMANOVA, S. V.; CONWELL, E. M., Mobility variation with field in conducting polymer films. Synthetic Metals, v.116, n.1-3, p.389-391, 2001.

53 MOSES D.; DOGARIU A.; HEEGER A. J., Ultrafast photoinduced charge generation in conjugated polymers. Chemical Physics Letter. v. 316, n. 5-6, p. 356, 2000.

${ }^{54} \mathrm{GHOSH}$ A. K. et al, Photovoltaic and rectification properties of $\mathrm{Al} / \mathrm{Mg}$ phtalocyanine/Ag Schottky-barrier cells. Journal Applied Physics. v. 45, n. 1, p. 230-236, 1974.

55 TANG C. W.; ALBRECHT A. C., Transient photovoltaic effects in metal-chlorophyll-ametal sandwich cells. Journal Chemical Physics, v. 62, n. 2, p. 2139, 1975.

${ }^{56}$ DEVORE H. B., Spectral distribution of Photoconductivity. Physical Review, v. 102, n. 1, p. $86,1956$.

${ }^{57}$ GHOSH A. K.; FENG T., Merocyanine organic solar cells. Journal of Applied Physics, v. 49, n. 12, p. 5982, 1978.

58 DÉSORMEAUX A.; MAX J. J.; LEBLANC R. M., Photovoltaic and Electrical Properties of Al/Langmuir-blodgett films/Ag sandwich cells incorporating either chlorophyll a, chlorophyll b, or zinc porphyrin derivative. Journal of Physical Chemistry, v. 97, n. 6, p. 6670, 1993.

59 PETTERSSON L. A. A.; ROMAN L.S.; INGANAS O., Modeling photocurrent action spectra of photovoltaic devices based on organic thin films. Journal of Applied Physics, v. 86, n. 1, p. 487, 1999.

60 STUBINGER T.; BRÜTTING W. Excitons diffusion and optical interference in organic donor-acceptor photovoltaics cells. Journal of Applied Physics, v. 90, n. 7, p. 3632, 2001.

${ }^{61}$ LOUSSAIEF N. et al, Theoretical and experimental study of photocurrent action spectrum of ITO/sexithiophene/Al structure. Synthetic Metals, v. 128, n. 1-3, p. 283-287, 2002.

62 JOSHI N. V., Photoconductivity, New York: Marcel Dekker, 1990.

${ }^{63}$ SURVEY A., Organic Light-Emitting Devices. New York: Springer, 2003.

64 GELINCK G. H.; WARMAN J. M.; STARING E. G. J., Polaron Pair Formation, Migration, and Decay on Photoexcited Poly(phenylenevinylene) Chains. Journal of Physical Chemistry, v. 100, n. 13, p. 5485, 1996.

65 SPREITZER H. et al, Soluble Phenyl-Substituted PPVs-New Materials for Highly Efficient Polymer LEDs. Advanced Materials, v. 10, n. 16, p. 1340, 1998. 
${ }^{66}$ BARTH, S., BÄSSLER, H., ROST, H. E HÖRHOLD, H. H. Extrinsic and Intrinsic dc Photoconductivity in a Conjugated Polymer. Physical Review B. v. 56, n. 7, p. 3844, 1997.

${ }^{67}$ ONSAGER L. Initial Recombination of Ions. Physical Review. v. 54, n. 8, p. 554, 1938.

${ }^{68}$ SIMMONS J. G. Poole-Frenkel effect and Schottky effect in metal-insulator-metal systems. Physical Review, v. 155, n. 3, 1967.

69 ARKHIPOV V. I., EMELIANOVA E. V., BÄSSLER H. Hot Exciton Dissociation in a Conjugated Polymer. Physical Review Letters. v. 82, n. 6, p. 1321, 1999.

70 ARKHIPOV V. I., EMELIANOVA E. V., BARTH S., BÄSSLER H. Ultrafast on-chain dissociation of hot éxcitons in conjugated polymers. Physical Review B. v. 61, n. 12, p. 8207, 2000 .

${ }^{71}$ GAILBERGER M. E BÄSSLER H. dc and transient photoconductivity of poly (2-phenyl1,4-phenylenevinylene). Physical Review B. v. 44, n. 16, p. 8643, 1991.

72 MOLLAY B. et al, Dynamics of singlet excitations in conjugated polymers: Poly(phenylenevinylene) and poly(phenylphenylenevinylene). Physical Review B. v. 50, n. $10769,1994$.

73 HAYES G. R., SAMUEL I. D. W., PHILliPS R. T. Exciton dynamics in electroluminescent polymers studied by femtosecond time-resolved photoluminescence spectroscopy. Physical Review ,. v. 52, n. 16, p 11 569, 1995.

74 KRAABEL B. et al, Ultrafast photoinduced electron transfer in conducting polymerbuckminsterfullerene composites. Physical Review Letters. v. 213, n. 2, p. 389, 1993.

75 BIANCHI, R. F. et al, Photo-oxidation phenomenon of MH-PPV films studied by ellipsometry and infrared spectroscopy. Molecular Crystals and Liquid Crystals Science and Technology. Section A, Molecular Crystals and Liquid Crystals. v. 374, n. 6, p. 457-462, 2002.

${ }^{76}$ PARK J. Y., LE H. M., KIM G. T., PARK H., KANG I. N., HWANG D. H. E SHIM H. K. Steady State Photoconductivity of a Polymer Blend. Synthetic Metals, v. 85, n. 1-3, p. 1239$1240,1997$.

${ }^{77}$ LEE S. B., YOSHINO K., PARK J. Y. E PARK Y. W. Extrinsic photoconductivity in poly (3-dodecylthiophene) sandwich cells. Physical Review B. v. 61, n. 3, p. 2151-2158, 2000.

78 STUBINGER T. E BRUTTING W. Exciton diffusion and optical interference in organic donor-acceptor photovoltaic cells. Journal of Applied Physics. v. 90, n. 7, p. 3632, 2001.

${ }^{79}$ HARRISON M. G., GRÜNER J., SPENCER G. C. W. Investigation of electroluminescent diodes by impedance spectroscopy, photo-impedance spectroscopy and modulated photovoltage spectroscopy. Synthetic Metals, v. 76, n. 1-3, p. 71-75, 1996.

${ }^{80}$ MEIER M., KARG S., RIESS W., Light-emitting diodes on poly-p-phenylene-vinylene: II.Impedance spectroscopy. Journal of Applied Physics. v. 82, n. 4, p. 1961, 1997. 
81. MOSES D et al, Mechanism of carrier generation in conducting polymer. Synthetic Metals. v. 84, n. 1-3, p. 539-544, 1997. 